\title{
A History of Collapse Factor Modeling and Empirical Data for Cryogenic Propellant Tanks
}

\author{
Laurence de Quay* \\ NASA Stennis Space Center, MS, 39529, USA \\ B. Keith Hodge ${ }^{\dagger}$ \\ Mississippi State University, MS, 39762, USA
}

\begin{abstract}
One of the major technical problems associated with cryogenic liquid propellant systems used to supply rocket engines and their subassemblies and components is the phenomenon of propellant tank pressurant and ullage gas collapse. This collapse is mainly caused by heat transfer from ullage gas to tank walls and interfacing propellant, which are both at temperatures well below those of this gas. Mass transfer between ullage gas and cryogenic propellant can also occur and have minor to significant secondary effects that can increase or decrease ullage gas collapse. Pressurant gas is supplied into cryogenic propellant tanks in order to initially pressurize these tanks and then maintain required pressures as propellant is expelled from these tanks. The net effect of pressurant and ullage gas collapse is increased total mass and mass flow rate requirements of pressurant gases. For flight vehicles this leads to significant and undesirable weight penalties. For rocket engine component and subassembly ground test facilities this results in significantly increased facility hardware, construction, and operational costs. "Collapse Factor" is a parameter used to quantify the pressurant and ullage gas collapse. Accurate prediction of collapse factors, through analytical methods and modeling tools, and collection and evaluation of collapse factor data has evolved over the years since the start of space exploration programs in the 1950's. Through the years, numerous documents have been published to preserve results of studies associated with the collapse factor phenomenon. This paper presents a summary and selected details of prior literature that document the aforementioned studies. Additionally other literature that present studies and results of heat and mass transfer processes, related to or providing important insights or analytical methods for the studies of collapse factor, are presented.
\end{abstract}

\section{INTRODUCTION}

Following initial developmental work in the 1920's and 1930's by Robert H. Goddard, liquid propellant rockets have been further developed and utilized extensively for military missile, earth-to-orbit launch system, and space propulsion-system applications. The vast majority of larger high thrust (greater than 44,000 N or 10,000 lb) liquid propellant rockets utilize one or more cryogenic liquid propellants because of the high combustion-energy-to-mass ratio or high combustion energy to volume ratio provided with these types of propellants.

The more than 80-year history of liquid propellant rockets has been a series of continuous improvements in propulsive efficiency, increased thrust levels, significant increases in thrust-to-weight ratios, and an expanding variety of engine cycles.

Initiatives starting in the late 1980's have placed the emphasis on reduction of costs with improved reliability and safety in the manufacture, ground testing, and operation of all rocket propulsion systems. Further development initiatives starting in the middle 1990's have included renewed interest in liquid-oxidizer-solid-fuel (hybrid) rocket motors and liquid propellant rocket engines with oxidizer-rich, staged-combustion power cycles or unchoked low differential pressure propellant injectors. These initiatives have necessitated the use of ground test facilities with cryogenic run systems operating at high subcritical and supercritical pressures.

\footnotetext{
*Aerospace Engineer, NASA/SSC Mail Stop EA33, SSC, MS, Associate Fellow

${ }^{\dagger}$ Professor of Mechanical Engineering, Mail Stop 9552, Mississippi State, MS, Associate Fellow
}

Page 1 of 29 


\section{A. Flight Vehicles}

All flight vehicles propelled by liquid propellant and hybrid rocket engines require one or more pressurized propellant tanks in which propellant is expelled from tanks to supply one or more rocket engines. A simplified schematic of a pump fed liquid propulsion system, which employs one of the simple basic power cycles, is shown in Figure 1. In this system, turbopumps boost the pressures of propellants supplied from the propellant tanks such that these propellants can be injected into the rocket engine's thrust (main combustion) chamber denoted in the Figure.

Figure 1 is obtained from Ref. 1 and a more detailed discussion about liquid propellant rockets is also presented in this reference.

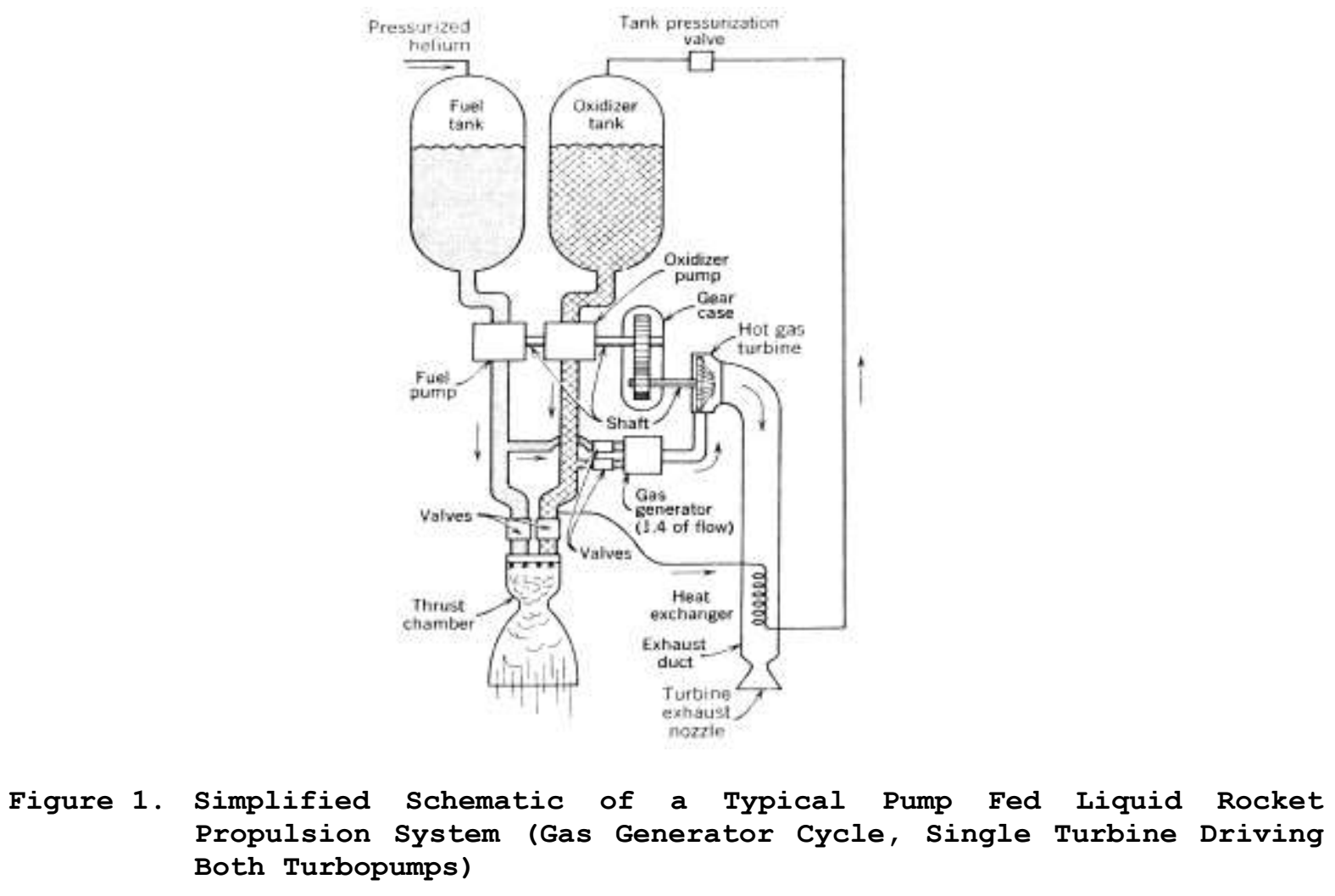

\section{B. Ground Test Facilities}

A key and critical component for design concept evaluation, development, flight certification, and subsequent use of rocket propulsion systems is the ground testing of rocket engine assemblies, subassemblies, and components as well as integrated rocket stages and major segments of the flight vehicle. The ground testing of individual rocket engine components and subassemblies during the early stages of development has been given increased attention and importance due to the aforementioned cost reduction and reliability and safety enhancement initiatives started in the late 1980's. Additionally, increased complexity and higher propulsion system pressures associated with a number of recent liquid propellant rockets to increase propulsive efficiency has emphasized the importance of rocket engine component and subassembly ground testing.

For the majority of high-thrust liquid propellant rocket engines and hybrid rocket motors, where one or more pressurized cryogenic propellants are used, a high fidelity and performance ground testing facility is essential. This facility normally operates one to three low- and high-pressure cryogenic propellant feed (run) systems that supply propellants to rocket engine assembly, subassembly, or component test articles at required interface pressures and

Page 2 of 29 
mass flow rates. For the cases where rocket engine subassemblies and components, such as turbopumps and combustion devices, are ground tested, at least one of the test facility cryogenic propellant run systems operates at high subcritical or supercritical pressures. (Critical pressures for oxygen, nitrogen, and hydrogen are 187.5-psia, 493.0-psia, and 731.2-psia respectively.) In all cases, the ground testing facility is required to simulate the remaining propulsion system or flight vehicle by providing required propellant pressures, mass flows, and temperatures at main fluid interfaces of the component being tested.

Figure 2 shows a simplified schematic of a ground test facility cryogenic propellant feed system, which supplies propellant to a typical interface on a test article.

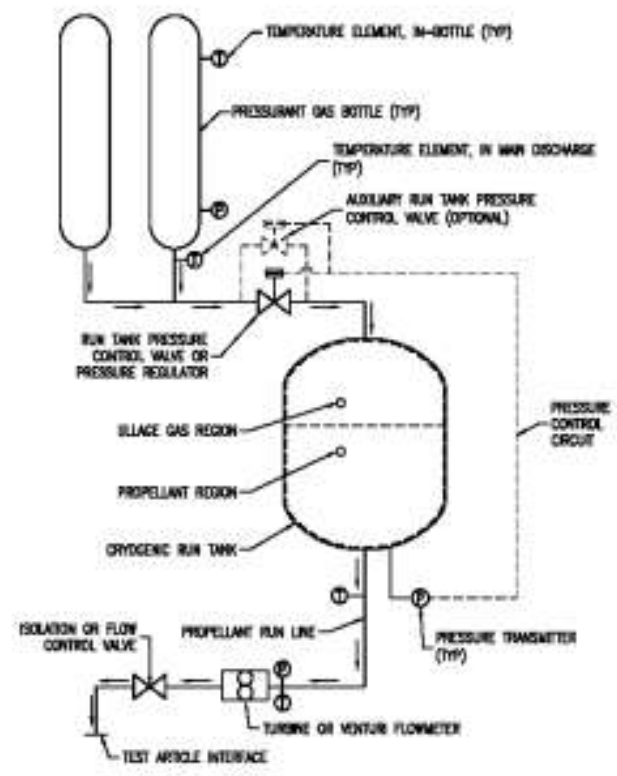

Figure 2. Simplified Schematic of a Cryogenic Propellant Feed System

\section{Cryogenic Run Tank}

The main component of the cryogenic propellant feed (or run) system is the cryogenic propellant run tank. This component serves as the system reservoir where liquid or cold supercritical cryogenic propellant; typically liquid oxygen, liquid hydrogen, or liquid methane; is expelled under pressure at the main discharge nozzle. This propellant is conveyed via a cryogenic propellant run system, comprised of series of pipelines that generally includes valves, filtration device, and flow meter(s), to one or more of the test article interfaces. The cryogenic run tank main discharge nozzle is located at or near the lowest point of the tank such that nearly all propellant can be expelled from the tank.

Referring to Figure 2, the internal volume of the cryogenic run tank is comprised of two regions, the propellant region and the ullage-gas region.

Pressurant gas needs to be supplied into the ullage gas region as the volume or internal pressure of this region increases. This pressurant gas is normally supplied by one of two methods. In one method, called the autogenous tank pressurant gas supply method, a portion of the liquid or supercritical cryogen exiting the main discharge of the run tank is vaporized or heated by a heat exchanger and is then routed into the tank ullage region at one or more entry points near the top of the tank. For the other method, called the external pressurant gas supply method, pressurant gas is supplied into the tank ullage externally from one or more gas bottles or other sources.

For cryogenic propellant run systems used on ground testing facilities, the external pressurant gas supply method is generally employed. Pressurized gas bottles, as shown in Figure 2, provide this gas via a series of pipelines and components to the cryogenic run tank ullage.

Page 3 of 29 


\section{Pressurant Gas Subsystem}

The pressurant gas subsystem supplies all or most of the additional gas needed in the run tank ullage for maintaining required cryogenic run tank pressures as propellant is expelled from the tank. The pressurant gas subsystem is depicted as the gas bottles and pipelines with associated components between these bottles and the cryogenic run tank ullage gas region in Figure 2.

\section{Heat and Mass Transfer Processes in the Cryogenic Run Tank}

Unique heat and mass transfer processes occur in cryogenic propellant tanks. These tanks (and flight vehicle propellant tanks) have propellant regions and tank walls that are generally tens to hundreds of degrees $\mathrm{R}$ colder than most of the ullage and the pressurant gases that enter the ullage gas regions. This results in significant rates of heat transfer from the ullage gas region to tank walls and the cryogenic propellant. Subsequently this heat transfer reduces the temperatures of the ullage gas region, thereby causing it's mean density to increase (as compared to the ideal condition where negligible heat transfer takes place). This increase in mean ullage gas density is known as ullage gas collapse and has the net effect of increasing the mass flow rate and total mass accumulation of pressurant gas entering the cryogenic run tank ullage.

\section{Collapse Factor}

An important parameter, "Collapse Factor," has been defined and used in much of the literature as a measure of performance for the process in which a pressurant gas is transferred into the ullage of a cryogenic propellant tank in order to maintain and control pressures in the tank.

"Collapse Factor" is defined as the ratio of actual-to-ideal pressurant gas requirements for both tank pressurization and pressurized propellant expulsion from a cryogenic propellant run tank. There are two types of collapse factor that are defined as performance metrics when designing, analyzing, or evaluating pressurant gas subsystems used for cryogenic run tanks. These are "Instantaneous Collapse Factor" and "Cumulative Collapse Factor." Instantaneous collapse factor is defined as the ratio of pressurant gas mass flow rate into a cryogenic propellant run tank under actual conditions to the mass flow rate under ideal conditions. Cumulative collapse factor is defined as the total mass of pressurant gas transferred into the cryogenic propellant tank under actual conditions divided by the total mass of this gas transferred under ideal conditions. For both types of collapse factors, the ideal conditions are based on and derived under the following assumptions:

1.) Negligible heat transfer at ullage gas and propellant region boundaries,

2.) Propellant and ullage gas occupy two distinct regions in the tank,

3.) Propellant region and ullage gas region are each at uniform temperatures,

4.) Pressurant gas that enters the ullage gas region is uniformly mixed with ullage gas in this region,

5.) Mass transfer across the interface between the propellant and the ullage gas is negligible,

6.) The ullage gas region has a uniform mixture ratio of gases if more than one species of gas is present in the region.

\section{Importance of Collapse Factor}

The collapse factor during each operation of a cryogenic propellant tank has a direct effect on the required sizing and design of the pressurant gas subsystem described in Section I.B.2. The proper sizing and design of this subsystem to provide the needed total mass transfer and flow rates of pressurant gas into the run tank ullage for all operating conditions is very critical for both flight vehicles and ground testing facilities. An undersized subsystem results in system or flight vehicle mission failure as the propellant mass flow rate out of the tank cannot be maintained for the required time durations. Conversely, an oversized pressurant gas subsystem results in significant construction and operational cost impacts with no beneficial returns. For flight vehicles, the severe penalty of added weight also exists with an oversized pressurant gas subsystem. 


\section{Empirical Collapse Factor Data}

Since the late 1950's, a wide variety of collapse factor data have been obtained. Table 1 presents a sampling of empirically-obtained collapse factors for tank pressurization and pressurized tank expulsion of liquid oxygen (LOX), liquid methane $\left(\mathrm{LCH}_{4}\right)$, and liquid nitrogen ( $\left.\mathrm{LN}\right)$. Table 2 reviews empirical collapse factor data from tank pressurization and pressurized tank expulsion of liquid hydrogen (LH) and slush hydrogen (SLH) propellants. In both Tables 1 and 2, other data are presented in addition to collapse factors to provide an indication of the variety and range of propellant tank and interfacing system conditions associated with the range of collapse factor values. Unless noted otherwise, all empirical collapse factors in Tables 1 and 2 are cumulative collapse factors at the end of tank expulsion where single values are listed. Where a range of collapse factor values is presented, this range defines the minimum and maximum cumulative collapse factors between the start of propellant expulsion from the tank and the end of this expulsion process, unless noted otherwise on the tables.

Perhaps the most important and significant observation from the empirical collapse factor data is the paucity of empirical data for supercritical and high subcritical tank pressure conditions. Only four tests, from References 3 and 8 in Tables 1 and 2, are conditions where tank pressures are above the critical pressures of the LOX propellant. The data from References 2, 14, and 15 have tests where high subcritical tank pressure conditions existed during tests. Another test from Reference 8 also had a high subcritical pressure tank pressure condition for an LN tank expulsion.

\section{Phenomena Affecting Collapse Factor}

There are various observed phenomena during the operation of cryogenic propellant tanks that appear to have significant influences on empirical collapse factors. These include properties distributions within the ullage gas, liquid or cold supercritical propellant, and tank walls. The predominant property where spatial distribution has significant effects is temperature. The spatial distribution of mass fraction of constituent fluids in the ullage gas and propellant regions can also have non-negligible effects on collapse factors under certain operating conditions.

\section{A. Ullage Gas Region Properties Distribution}

One of the most important and influential attributes of a cryogenic propellant tank system with respect to collapse factors during tank pressurization and pressurized propellant expulsion processes is the variation and distribution of fluid properties within the ullage gas region. The variation of ullage gas properties is mainly due to temperature gradients in the ullage gas region as pressures vary very little because of low ullage gas densities, short vertical tank (and maximum ullage gas region) heights, and ullage gas elevation head pressures being small in comparison to absolute tank pressures.

For selected cases where propellant and pressurant gas are different species and where significant levels of mass transfer of propellant species into and within the ullage gas region are occurring, the distribution of propellant species mass fraction within the ullage gas region can also have an effect on the distribution of fluid properties in the ullage gas region. The observed dominant effect of temperature on the distribution of ullage gas properties is primarily due to the relatively short time durations of typical tank pressurization and propellant expulsion processes as well as the natural stability of the fluid regions inside the tank where fluid temperatures decrease and fluid densities increase when traversing from the top to the bottom in the tank.

Regarding the literature, there are a number of empirical tests where temperatures are measured at many discrete locations in the ullage gas region of cryogenic propellant tanks. These measurements have been recorded at discrete times through tank pressurization and pressurized propellant expulsion processes. Unfortunately, there are no ullage gas region temperature distribution data for supercritical tank pressure conditions and no practicable methods exist to obtain these data at the high supercritical pressures. Previous attempts to utilize insitu instruments inside cryogenic propellant tanks at supercritical pressures, necessary to obtain accurate temperature measurements of fluids inside the tank, have resulted in unreliable data from, severe damage to, or destruction of these types of instruments. 
Table 1 Selected Empirical Collapse Factor Data for Non-Hydrogen Propellant Tanks

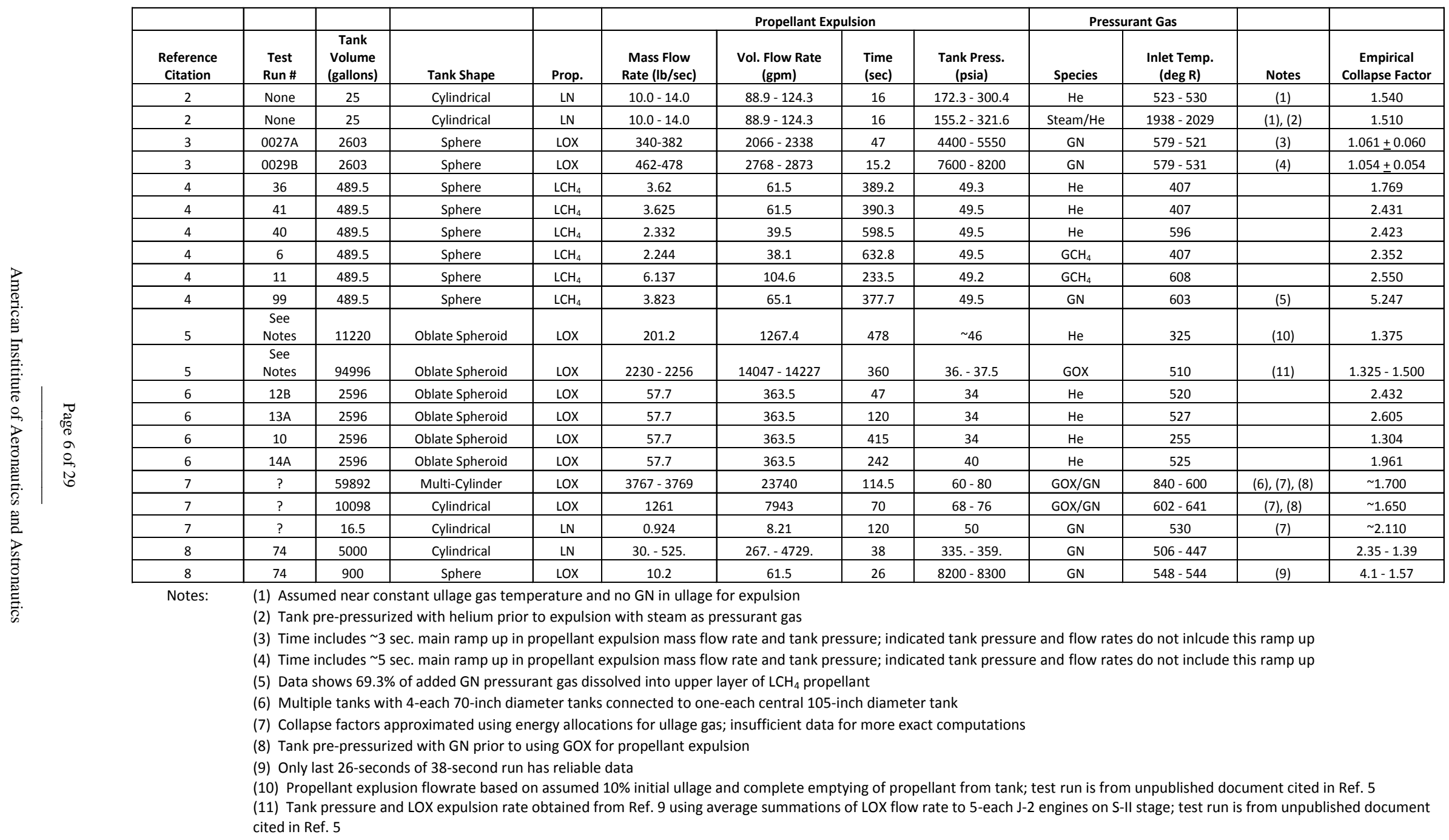

RELEASED - Printed documents may be obsolete; validate prior to use. 
Table 2 Selected Empirical Collapse Factor Data for Hydrogen Propellant Tanks (Continued on Next Page)

\begin{tabular}{|c|c|c|c|c|c|c|c|c|c|c|c|c|}
\hline \multirow[b]{2}{*}{$\begin{array}{c}\text { Reference } \\
\text { Citation }\end{array}$} & \multirow[b]{2}{*}{$\begin{array}{c}\text { Test } \\
\text { Run \# }\end{array}$} & \multirow[b]{2}{*}{$\begin{array}{c}\text { Tank Volume } \\
\text { (gallons) }\end{array}$} & \multirow[b]{2}{*}{ Tank Shape } & \multirow[b]{2}{*}{ Prop. } & \multicolumn{4}{|c|}{ Propellant Expulsion } & \multicolumn{2}{|c|}{ Pressurant Gas } & \multirow[b]{2}{*}{ Notes } & \multirow[b]{2}{*}{$\begin{array}{l}\text { Empirical Collapse } \\
\text { Factor }\end{array}$} \\
\hline & & & & & $\begin{array}{c}\text { Mass Flow } \\
\text { Rate (lb/sec) }\end{array}$ & $\begin{array}{c}\text { Vol. Flow Rate } \\
\text { (gpm) }\end{array}$ & $\begin{array}{l}\text { Time } \\
\text { (sec) }\end{array}$ & $\begin{array}{c}\text { Tank Press. } \\
\text { (psia) }\end{array}$ & Species & $\begin{array}{l}\text { Inlet Temp. } \\
\text { (deg R) }\end{array}$ & & \\
\hline 3 & 004A & 5002.5 & Sphere & LH & $78-108$ & $6100-8560$ & 34 & $7450-8200$ & GH & $619-549$ & (1) & $1.047 \pm 0.037$ \\
\hline 5 & See Notes & 49,472 & Sphere & LH & 60.84 & 6140.5 & 296 & 91.7 & GH & 530 & (16) & 1.64 \\
\hline 5 & See Notes & 246,840 & Multi-Cylinder & LH & 391.4 - 394.1 & $39696-39970$ & 360 & $28.5-30.0$ & $\mathrm{GH}$ & 200 & $(7),(16)$ & $1.15-1.25$ \\
\hline 10 & B-1 & 12 & Cylindrical & $\mathrm{LH}$ & Not Given & Not Given & 62.4 & 39.25 & $\mathrm{GH} / \mathrm{He}$ & 330 & (2) & 3.42 \\
\hline 10 & B-2 & 12 & Cylindrical & 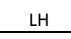 & Not Given & Not Given & 62.4 & 39.25 & $\mathrm{GH} / \mathrm{He}$ & 265 & (2) & 2.16 \\
\hline 10 & B-1 & 12 & Cylindrical & LH & No Expulsion & N/A & N/A & $14.7-44.25$ & $\mathrm{GH}$ & 505 & & 4.45 \\
\hline 10 & B-1 & 12 & Cylindrical & LH & No Expulsion & N/A & N/A & $14.7-61.75$ & GH & 295 & & 3.26 \\
\hline 10 & 2 & 500 & Cylindrical & LH & 2.561 & 259.4 & 100 & 45.5 & GH & 320 & (3), (4) & 2.23 \\
\hline 10 & 5 & 500 & Cylindrical & LH & 2.031 & 205.7 & 99 & 45.5 & $\mathrm{He}$ & 300 & $(3),(4)$ & 1.72 \\
\hline 10 & 7 & 500 & Cylindrical & LH & 2.031 & 205.7 & 105 & 49.3 & $\mathrm{GH}$ & 300 & $(3),(5)$ & 1.74 \\
\hline 10 & 10 & 500 & Cylindrical & LH & 1.833 & 185.7 & 111 & 45 & GH & 300 & (3) & 1.74 \\
\hline 11 & 3 & $\sim 370$ & Cylindrical & LH & 0.939 & 95.1 & 197 & 44.1 & $\mathrm{He}$ & 450 & (6) & $0.878 ; 0.997$ \\
\hline 11 & 6 & $\sim 370$ & Cylindrical & LH & 0.47 & 47.6 & 351 & 44.1 & $\mathrm{He}$ & 450 & (6) & $0.908 ; 1.033$ \\
\hline 11 & 9 & $\sim 370$ & Cylindrical & LH & 0.624 & 63.3 & 352 & 29.4 & $\mathrm{He}$ & 450 & (6) & $1.043 ; 1.187$ \\
\hline 11 & 10 & $\sim 370$ & Cylindrical & LH & 0.939 & 95.1 & 211 & 44.1 & $\mathrm{He}$ & 180 & (6) & $0.48 ; 0.527$ \\
\hline 11 & 11 & $\sim 370$ & Cylindrical & LH & 0.939 & 95.1 & 214 & 44.1 & $\mathrm{GH}$ & 180 & (6) & $1.267 ; 1.277$ \\
\hline 12 & 1 & 500 & Cylindrical & LH & 2.995 & 303.4 & 89 & 45.5 & $\mathrm{GH}$ & 300 & $(4),(17)$ & 1.56 \\
\hline 12 & 2 & 500 & Cylindrical & LH & 2.388 & 262.1 & 103 & 47.6 & $\mathrm{GH}$ & 520 & $(4),(17)$ & 2.23 \\
\hline 12 & 3 & 500 & Cylindrical & LH & 2.22 & 224.8 & 120 & 46.5 & GH & 300 & $(4),(17)$ & 1.8 \\
\hline 12 & 5 & 500 & Cylindrical & $\mathrm{LH}$ & 2.694 & 272.90 & 99 & 45.5 & $\mathrm{He}$ & 300 & (4), (17) & 1.72 \\
\hline 13 & ? & 461.5 & Sphere & SLH & 1.478 & 131 & 190 & 50 & GH & 520 & (8) & 2.568 \\
\hline 13 & ? & 461.5 & Sphere & SLH & 0.552 & 48.9 & 510 & 25 & $\mathrm{GH}$ & 620 & (8) & 10.34 \\
\hline 13 & ? & 461.5 & Sphere & SLH & 0.668 & 59.2 & 420 & 50 & GH & 620 & (8) & 5.973 \\
\hline 14 & 2 of Ref. 33 & 210 & Cylindrical & LH & 1.062 & 106.6 & 93 & 161 & $\mathrm{GH}$ & 210 & & 2.12 \\
\hline 14 & 3 of Ref. 33 & 210 & Cylindrical & LH & 0.346 & 35 & 284 & 57 & GH & 170 & & 3.88 \\
\hline 14 & 8 of Ref. 33 & 210 & Cylindrical & LH & 1.161 & 116.6 & 90 & 159 & $\mathrm{He}$ & 161 & & 2.14 \\
\hline 14 & 10 of Ref. 33 & 210 & Cylindrical & LH & 0.311 & 31.6 & 309 & 40 & $\mathrm{He}$ & 148 & & 5.1 \\
\hline 15 & 4-11 & 600 & Horizontal Cyl & LH & 0.56 & 57 & 420 & 27.5 & GH & $480-549$ & (9) & $1.2-1.25$ \\
\hline 15 & 3 & 600 & Horizontal Cyl & LH & 0.31 & 31 & 1220 & 35 & GH & $480-549$ & (9) & 4.32 \\
\hline 15 & 7 & 600 & Horizontal Cyl & LH & 1.56 & 157 & 340 & 115 & $\mathrm{GH}$ & $480-549$ & (9) & 1.67 \\
\hline 15 & 9 & 600 & Horizontal Cyl & LH & 2.48 & 250 & 560 & 115 & GH & $480-549$ & (9) & 2.20 \\
\hline 15 & 5 & 600 & Horizontal Cyl & LH & 2.53 & 256 & 450 & 65 & GH & $480-549$ & (9) & 2.52 \\
\hline 15 & 6 & 600 & Horizontal Cyl & LH & 0.84 & 85 & 410 & 65 & $\mathrm{GH}$ & $480-549$ & (9) & 1.80 \\
\hline 16 & & 489 & Sphere & LH & 2 & 202 & 130 & 50 & $\mathrm{GH}$ & 500 & & $\sim 2.38$ \\
\hline 16 & & 489 & Sphere & LH & 0.5 & 50.6 & 522 & 50 & GH & 500 & & $\sim 3.33$ \\
\hline 16 & & 8604 & Sphere & LH & 10.3 & 1043 & 446 & 50 & GH & 500 & & $\sim 2.29$ \\
\hline 16 & & 8604 & Sphere & $\mathrm{LH}$ & 4.33 & 438 & 1060 & 50 & $\mathrm{GH}$ & 500 & & $\sim 2.86$ \\
\hline 16 & & 489 & Sphere & LH & 1.89 & 191 & 138 & 50 & GH & 540 & & $\sim 2.76$ \\
\hline 16 & & 8604 & Sphere & LH & 10 & 1012 & 459 & 50 & $\mathrm{GH}$ & 600 & & $\sim 2.33$ \\
\hline 17 & 7 & 489 & Sphere & LH & 0.65 & 65.9 & 453.4 & 50 & $\mathrm{GH}$ & $481-517$ & (10) & $\sim 2.86$ \\
\hline 17 & 10 & 489 & Sphere & LH & 1.86 & 187.9 & 193.2 & 50 & $\mathrm{GH}$ & $481-517$ & (10) & $\sim 2.53$ \\
\hline
\end{tabular}

RELEASED - Printed documents may be obsolete; validate prior to use. 
Table 2 Selected Empirical Collapse Factor Data for Hydrogen Propellant Tanks (Continuation from Previous Page)

\begin{tabular}{|c|c|c|c|c|c|c|c|c|c|c|c|c|}
\hline \multirow[b]{2}{*}{$\begin{array}{l}\text { Reference } \\
\text { Citation }\end{array}$} & \multirow[b]{2}{*}{$\begin{array}{l}\text { Test } \\
\text { Run \# }\end{array}$} & \multirow[b]{2}{*}{$\begin{array}{c}\begin{array}{c}\text { Tank Volume } \\
\text { (gallons) }\end{array} \\
\end{array}$} & \multirow[b]{2}{*}{ Tank Shape } & \multirow[b]{2}{*}{ Prop. } & \multicolumn{4}{|c|}{ Propellant Expulsion } & \multicolumn{2}{|c|}{ Pressurant Gas } & \multirow[b]{2}{*}{ Notes } & \multirow[b]{2}{*}{$\begin{array}{l}\text { Empirical Collapse } \\
\text { Factor }\end{array}$} \\
\hline & & & & & $\begin{array}{c}\text { Mass Flow } \\
\text { Rate (lb/sec) }\end{array}$ & $\begin{array}{l}\text { Vol. Flow Rate } \\
\text { (gpm) }\end{array}$ & $\begin{array}{l}\text { Time } \\
(\mathrm{sec})\end{array}$ & $\begin{array}{c}\text { Tank Press. } \\
\text { (psia) }\end{array}$ & Species & $\begin{array}{l}\text { Inlet Temp. } \\
\text { (deg R) }\end{array}$ & & \\
\hline 17 & 12 & 489 & Sphere & LH & 0.77 & 77.5 & 393.2 & 50 & GH & $481-517$ & (10) & $\sim 3.03$ \\
\hline 17 & 14 & 489 & Sphere & $\mathrm{LH}$ & 0.92 & 92.9 & 337 & 50 & $\mathrm{GH}$ & $481-517$ & (10) & $\sim 2.94$ \\
\hline 17 & 15 & 489 & Sphere & LH & 1.32 & 133.9 & 249.7 & 50 & $\mathrm{GH}$ & $481-517$ & (10) & $\sim 2.70$ \\
\hline 17 & 83 & 489 & Sphere & LH & 0.67 & 67.5 & 428.8 & 50 & GH & $481-517$ & (10) & $\sim 3.20$ \\
\hline 17 & 84 & 489 & Sphere & LH & 0.98 & 98.8 & 307.6 & 50 & $\mathrm{GH}$ & $481-517$ & (10) & 2.73 \\
\hline 17 & 85 & 489 & Sphere & $\mathrm{LH}$ & 1.91 & 193 & 174.4 & 50 & $\mathrm{GH}$ & $481-517$ & (10) & $\sim 2.58$ \\
\hline 18 & 4 & 8604 & Sphere & LH & 9.60 & 972 & 531.6 & 50 & GH & 302 & (10) & 1.85 \\
\hline 18 & 7 & 8604 & Sphere & $\underline{L H}$ & 4.28 & 433 & 1119.3 & 50 & $\mathrm{GH}$ & 302 & (10) & 2.07 \\
\hline 18 & 8 & 8604 & Sphere & LH & 4.66 & 472 & 1037.2 & 50 & GH & 303 & $(9),(10)$ & 2.07 \\
\hline 18 & 15 & 8604 & Sphere & $\mathrm{LH}$ & 10.07 & 1019 & 509.3 & 50 & $\mathrm{GH}$ & 540 & (10) & 2.60 \\
\hline 19 & 5 & 1291 & Oblate Spheroid & $\mathrm{LH}$ & $0.60-0.65$ & 66.3 & 2160 & 54.6 & $\mathrm{GH}$ & 491 & $(11),(15)$ & 5.222 \\
\hline 19 & $5 \mathrm{R}$ & 1291 & Oblate Spheroid & LH & $0.38-0.40$ & 66.3 & 1680 & 54.7 & GH & 491 & $(12),(13)$ & 5.333 \\
\hline 19 & 6 & 1291 & Oblate Spheroid & $\mathrm{LH}$ & $0.60-0.65$ & 40.8 & 2280 & 54.9 & $\mathrm{GH}$ & 491 & $(13),(15)$ & 5.0 \\
\hline 19 & 9 & 1291 & Oblate Spheroid & LH & $0.60-0.65$ & 66.3 & 1620 & 55.0 & GH & 594 & $(14 l,(15)$ & 4.933 \\
\hline 20 & 506 & 1291 & Oblate Spheroid & $\mathrm{LH}$ & $\sim 0.83$ & 83.6 & 760 & 33.9 & $\mathrm{GH}$ & 529 & & 2.46 \\
\hline 20 & 507 & 1291 & Oblate Spheroid & LH & $\sim 0.58$ & 58.5 & 1086 & 44.3 & $\mathrm{GH}$ & 531 & & 2.568 \\
\hline 20 & 508 & 1291 & Oblate Spheroid & LH & $\sim 0.32$ & 32.2 & 1974 & 44 & $\mathrm{GH}$ & 533 & & 2.58 \\
\hline 20 & 509 & 1291 & Oblate Spheroid & LH & $\sim 0.84$ & 84.7 & 741 & 54.3 & $\mathrm{GH}$ & 535 & & 2.85 \\
\hline 20 & 510 & 1291 & Oblate Spheroid & $\mathrm{LH}$ & $\sim 0.58$ & 58.3 & 1089 & 54.9 & $\mathrm{GH}$ & 531 & & 2.74 \\
\hline 20 & 511 & 1291 & Oblate Spheroid & $\mathrm{LH}$ & $\sim 0.32$ & 32.1 & 1978 & 55.1 & $\mathrm{GH}$ & 526 & & 2.86 \\
\hline 21 & $?$ & 489 & Sphere & $\mathrm{SLH}$ & $\sim 0.55$ & 52.3 & 505 & 35 & $\mathrm{He}$ & 540 & (8) & 3.788 \\
\hline 21 & $?$ & 489 & Sphere & $\mathrm{SLH}$ & $\sim 1.26$ & 120.0 & 220 & 35 & $\mathrm{He}$ & 540 & (8) & 3.178 \\
\hline 21 & $?$ & 489 & Sphere & SLH & $\sim 0.54$ & 51.8 & 510 & 35 & $\mathrm{He}$ & 250 & (8) & 2.100 \\
\hline 21 & $?$ & 489 & Sphere & $\mathrm{SLH}$ & $\sim 1.38$ & 132.0 & 200 & 35 & $\mathrm{He}$ & 250 & (8) & 1.591 \\
\hline 21 & $?$ & 489 & Sphere & SLH & $\sim 0.58$ & 55.0 & 480 & 35 & $\mathrm{He} / \mathrm{GH}$ & 540 & (2), (8) & 6.655 \\
\hline 21 & $?$ & 489 & Sphere & $\mathrm{SLH}$ & $\sim 1.32$ & 125.7 & 210 & 35 & $\mathrm{He} / \mathrm{GH}$ & 540 & (2), (8) & 3.727 \\
\hline
\end{tabular}

(1) Time includes $\sim 12$ sec. main ramp up of tank pressure; indicated flow rates are at

(3) Propellant expulsion flow rates approximated by scaling of tank geometry drawings, given initial ullage height, liquid level change in tank with associated time span; Collapse Factor data also reported in Ref. 14

(4) Horizontal sloshing in tank at $0.5-\mathrm{Hz}$ and 0.5 -inch amplitude throughout expulsion

(5) Horizontal sloshing in tank at $0.5-\mathrm{Hz}$ and 0.5 -inch amplitude for last 85 -seconds of expulsion

(6) Two collapse factors; first based on constant ullage gas temperature and pressure throughout expulsion; second based on saturated GH vapor in ullage at one atmosphere before tank pressurization reference

(8) SLH is slush hydrogen, mixute of solid and liquid hydrogen

(9) Pressurant gas inlet temp. not reported; est. based on description of test apparatus and procedures

(10) Initial 30 to $56 \mathrm{sec}$. of the total time is tank pressurization and hold prior to propellant expulsion

(11) Submerged injection of pressurant gas, $21 \mathrm{~min}$. tank pressurization, $15 \mathrm{~min}$. CLH expulsion

(12) Submerged injection of pressurant gas, $13 \mathrm{~min}$. tank pressurization, $15 \mathrm{~min}$. CLH expulsion

(13) Submerged injection of pressurant gas, $13 \mathrm{~min}$. tank pressurization, $25 \mathrm{~min}$. CLH expulsion

(14) Submerged injection of pressurant gas, $12 \mathrm{~min}$. tank pressurization, $15 \mathrm{~min}$. CLH expulsion

(15) Initial 12-to 21-minutes of the total time is tank pressurization and hold prior to propellant expulsion

(16) Test runs are from unpublished report cited in Ref. 5

(17) Test run nos. are from another document cited in Ref. 12

\section{RELEASED - Printed documents may be obsolete; validate prior to use.}




\section{Ullage Gas Region Vertical Temperature Gradients}

Table 3 presents selected references where vertical ullage gas temperature distribution data were obtained from direct temperature measurements within the ullage gas region during tank pressurization and pressurized propellant expulsion processes. The propellant and pressurant gas species and other selected operating conditions are also presented in Table 3.

In a small portion of the cases presented in Table 3, propellant expulsions from the tank were not performed and tank pressurizations were accomplished by closing all valves connected to the tank and using the naturally

Table 3. Selected References Containing Empirical Ullage Gas Region Vertical Temperature Distribution/Gradient Data

\begin{tabular}{|c|c|c|c|c|c|c|c|}
\hline \multirow{2}{*}{$\begin{array}{c}\text { Reference } \\
\text { Citation }\end{array}$} & \multirow[b]{2}{*}{ Test Number } & \multirow[b]{2}{*}{ Prop. } & \multirow{2}{*}{$\begin{array}{c}\text { Press. } \\
\text { Gas }\end{array}$} & \multirow{2}{*}{$\begin{array}{c}\text { Press. Gas } \\
\text { Inlet Temp. } \\
\quad(\operatorname{deg} \mathbf{R})\end{array}$} & \multirow{2}{*}{$\begin{array}{l}\text { Prop. } \\
\text { Expul. } \\
\text { Time } \\
\text { (sec) }\end{array}$} & \multicolumn{2}{|c|}{$\begin{array}{c}\text { Ullage Gas Region } \\
\text { Vertical Temp. } \\
\text { Gradient (deg R) }\end{array}$} \\
\hline & & & & & & Min. & Max. \\
\hline 4 & 8 & $\mathrm{LCH}_{4}$ & $\mathrm{GCH}_{4}$ & 400 & 231 & $?$ & 174.6 \\
\hline 4 & 6 & $\mathrm{LCH}_{4}$ & $\mathrm{GCH}_{4}$ & 400 & 633 & $?$ & 176.4 \\
\hline 4 & 11 & $\mathrm{LCH}_{4}$ & $\mathrm{GCH}_{4}$ & 600 & 234 & ? & 369 \\
\hline 4 & 37 & $\mathrm{LCH}_{4}$ & $\mathrm{He}$ & 400 & 223 & $?$ & 211 \\
\hline 4 & 42 & $\mathrm{LCH}_{4}$ & $\mathrm{He}$ & 600 & 224 & $?$ & 380 \\
\hline 4 & 63 & $\mathrm{LCH}_{4}$ & $\mathrm{GH}$ & 400 & 219 & $?$ & 193 \\
\hline 4 & 68 & $\mathrm{LCH}_{4}$ & $\mathrm{GH}$ & 600 & 222 & $?$ & 398 \\
\hline 10 & 3 & LH & $\mathrm{GH}$ & 300 & 120 & $?$ & 218.5 \\
\hline 10 & 5 & LH & $\mathrm{He}$ & 300 & 99 & $?$ & 223.5 \\
\hline 10 & 7 & LH & GH & 300 & 111 & $?$ & 255.5 \\
\hline 11 & 1 & $\mathrm{LH}$ & $\mathrm{He}$ & 450 & 217 & 342 & 405 \\
\hline 11 & 3 & LH & $\mathrm{He}$ & 450 & 197 & 351 & 405 \\
\hline 11 & 7 & LH & $\mathrm{He}$ & 450 & 375 & 405 & 405 \\
\hline 11 & 11 & LH & GH & 180 & 214 & 149.4 & 193 \\
\hline 12 & 1 (Fig. 5 of Ref.) & LH & GH & 300 & 89 & $\sim 223.5$ & $\sim 248.5$ \\
\hline 16 & $?$ & LH & GH & 520 & 278 & $?$ & $\sim 460$ \\
\hline 16 & $?$ & LH & $\mathrm{GH}$ & 520 & 278 & $?$ & $\sim 305$ \\
\hline 17 & 88 & LH & $\mathrm{GH}$ & 331 & 396 & $?$ & 250 \\
\hline 17 & 85 & LH & $\mathrm{GH}$ & 488 & 137 & $?$ & 445 \\
\hline 17 & 97 & LH & $\mathrm{GH}$ & 603 & 134 & $?$ & 650 \\
\hline 18 & 4 & LH & $\mathrm{GH}$ & 306 & 478 & $?$ & 247 \\
\hline 20 & 509 & $\mathrm{LH}$ & $\mathrm{GH}$ & 531 & 1110 & 245 & 423 \\
\hline 20 & 510 & $\mathrm{LH}$ & $\mathrm{GH}$ & 529 & 741 & $?$ & 405 \\
\hline 20 & 511 & LH & $\mathrm{GH}$ & 526 & 1978 & $?$ & 392 \\
\hline 22 & B-2 & LH & N/A & N/A & N/A & 80.1 & 126 \\
\hline 23 & (Fig. 4 of Ref.) & LOX & GOX & 540 & 100 & 288 & 333 \\
\hline 24 & RT-3 & LN & GN & $\sim 520$ & 175 & 140 & 195 \\
\hline 25 & $2.0-6$ & TPLH & $\mathrm{GH}$ & 540 & $\sim 980$ & 193 & 238 \\
\hline 25 & $2.0-8$ & TPLH & $\mathrm{He} / \mathrm{GH}$ & 144 and 540 & $\sim 870$ & 180 & 211 \\
\hline 26 & $130-15$ & LOX & $\mathrm{He}$ & $500-605$ & 120 & 380 & 405 \\
\hline 27 & $?$ & LH & N/A & N/A & 14400 & 5.4 & 49.5 \\
\hline 27 & $?$ & LH & N/A & N/A & 14400 & 4.5 & 48.6 \\
\hline 28 & $?$ & LH & $\mathrm{GH}$ & $\sim \sim 525$ & 130 & $?$ & $\sim 475$ \\
\hline 28 & $?$ & LH & $\mathrm{GH}$ & $\sim 525$ & 130 & $?$ & $\sim 435$ \\
\hline 28 & $?$ & LH & GH & $\sim 525$ & 130 & $?$ & $\sim 245$ \\
\hline 29 & $130-6$ & LOX & GOX & 540 & 150 & 302 & 372 \\
\hline 29 & $130-9$ & LOX & GOX & 370 & 150 & 147 & 207 \\
\hline 30 & Ex. 1 & LH & $\mathrm{GH}$ & $488-525$ & 90 & $?$ & 428 \\
\hline 30 & Ex. 1 & LH & $\mathrm{GH}$ & $488-525$ & 178 & $?$ & 428 \\
\hline 30 & Ex. 1 & LH & GH & $488-525$ & 320 & $?$ & 428 \\
\hline 30 & Ex. 2 & LH & $\mathrm{GH}$ & $480-515$ & 93 & $?$ & 436 \\
\hline 30 & Ex. 3 & LH & GH & $375-520$ & 284 & $?$ & 450 \\
\hline 30 & Ex. 4 & LH & GH & $450-580$ & 101 & $?$ & 455 \\
\hline 30 & Ex. 5 & LH & GH & $395-273$ & 95 & $?$ & 208 \\
\hline 30 & Ex. 6 & LH & GH & $380-630$ & 88 & $?$ & 575 \\
\hline 30 & $\begin{array}{l}\text { Ex. } 7 \\
\end{array}$ & LH & $\mathrm{He}$ & $525-535$ & 355 & $?$ & 475 \\
\hline 30 & $\begin{array}{l}\text { Ex. } 8 \\
\end{array}$ & LH & $\mathrm{He}$ & $525-530$ & 90 & $?$ & 475 \\
\hline 30 & Ex. 9 & LH & $\mathrm{He}$ & $325-215$ & 100 & $?$ & 165 \\
\hline 30 & Ex. 10 & $\mathrm{LH}$ & $\mathrm{He}$ & $350-610$ & 309 & $?$ & 597 \\
\hline 31 & $\begin{array}{c}\text { AS-203 (Saturn IB } \\
\text { Launch } 7 / 66 \text { ) }\end{array}$ & $\mathrm{LH}$ & N/A & N/A & 22,498 & 7 & 195 \\
\hline
\end{tabular}

occurring heat transfer into the tank or externally supplied heat to vaporize cryogenic liquid propellant and heat all fluids inside the tank. 
Virtually all of the cases presented in Table 3 indicate very large vertical temperature gradients ullage gas region. The differences between maximum and minimum temperatures in this region range from $150 \mathrm{R}$ to $475 \mathrm{R}$.

In the majority of cases, the vertical temperature profiles in the ullage gas regions are more linear at the end of propellant expulsion than during initial tank pressurization and the start of propellant expulsion.

\section{Horizontal Temperature Gradients in Ullage Gas Region}

Although the data are extensive with regards to vertical temperature profiles and gradients in cryogenic propellant tank ullage gas regions, data are limited with regards to horizontal (or radial) temperature gradients. Table 4 contains selected data and includes the literature citations. For the majority of cases, tank wall temperatures are measured at the outside surfaces of the tank wall. While the data in Table 4 do show large temperature differences between the tank vertical centerline and the corresponding tank wall surface at or near the same elevation, there are no data showing the full horizontal temperature distribution from tank vertical centerline to tank wall. Also, for nearly all cases the large horizontal temperature gradients from tank vertical centerline to tank wall are confined to the upper sections of the ullage gas region near the elevations where pressurant gas enters the tank ullage.

Although not supported with data, many of the horizontal temperature gradients are likely to exist in a very thin boundary-layer region near the inner tank wall surface with little or no temperature variations outside this boundary layer. Also, for 20 of the 29 cases cited in Table 4, a moderate-to-significant portion of the horizontal temperature gradients could also be through the thickness of the tank walls since the tank wall temperatures are measured on the external wall surfaces. Although tank walls are thin, less than $1 / 2$-inch thick, for cases shown on Table 4, expulsion times are also relatively short, on the order of 90 seconds to 400 seconds. These short exposure times of colder tank walls to the warmer ullage gas could result in large temperature gradients through the tank wall.

One study ${ }^{20}$ not cited in Table 4 presents horizontal temperature uniformity data for various cryogenic propellant tank pressurization and propellant expulsion processes. For seven of the 14 tests in this study where the LH tank is pressurized with no propellant expulsion, predefined criteria for horizontal ullage gas temperature uniformity are satisfied. These criteria are also satisfied for four of the six LH propellant expulsion tests. For the remaining two LH expulsion tests and for one LH tank pressurization test without propellant expulsion, "approximate" horizontal ullage gas temperature uniformity is observed.

Other references , $16-18,23,26,28,30$ contain discussion about horizontal ullage gas temperature. In References 23 and 28, general statements that temperatures were found to have small variations in radial directions from the tank vertical axis are made, but no further data or information is presented. In References 7, 16, 17, 18, and 30, the tests include the use of horizontal temperature probe rakes at multiple, discrete elevations inside the test tanks.

\section{Multiple Species in Ullage Gas Region}

Although temperature distribution within the ullage gas region of a cryogenic propellant tank nearly always has the dominant effect on the distribution of ullage gas regional properties distribution that ultimately affects pressurant gas requirements, the mass fraction of constituent gases in a multi-component gas mixture within the ullage region can also have significant effects on the fluid property distribution in this region. Mixtures of two or more constituent gas species occur whenever pressurant gases are not the same species as the cryogenic propellant and when one or both of the following conditions exist:

1.) The cryogenic propellant tank is not completely filled with liquid cryogen, such that an ullage gas region exists, prior to the initial pressurization of the tank with externally supplied pressurant gas,

2.) Mass transfer of propellant species from the propellant region to the ullage gas region occurs at any time during initial tank pressurization or pressurized propellant expulsion processes.

For virtually all cases, only one or two pressurant gas species are used for cryogenic propellant tank pressurization and pressurized propellant expulsion processes. When two pressurant gas species are used, one of the two species is generally the same species as the cryogenic propellant. Therefore, for nearly all cases and for purposes of this study, the ullage gas region is occupied by either a single gas species or a two-component (binary) gas mixture. 
Table 4. Selected Empirical Ullage Gas and Adjacent Tank Wall Temperature Data for Approximations of Ullage Gas Region Horizontal Temperature Gradients

\begin{tabular}{|c|c|c|c|c|c|c|c|}
\hline \multirow{2}{*}{$\begin{array}{c}\text { Reference } \\
\text { Citation }\end{array}$} & \multirow{2}{*}{$\begin{array}{c}\text { Test } \\
\text { Number }\end{array}$} & \multirow[b]{2}{*}{ Prop. } & \multirow{2}{*}{$\begin{array}{c}\text { Press. } \\
\text { Gas }\end{array}$} & \multirow{2}{*}{$\begin{array}{l}\text { Press. Gas } \\
\text { Inlet Temp. } \\
\quad(\operatorname{deg} \mathbf{R})\end{array}$} & \multirow{2}{*}{$\begin{array}{l}\text { Expul. } \\
\text { Time } \\
\text { (sec) }\end{array}$} & \multicolumn{2}{|c|}{$\begin{array}{c}\text { Horizontal Temperature } \\
\text { Gradient, Tank Vertical } \\
\text { Centerline to Tank Wall (deg R) }\end{array}$} \\
\hline & & & & & & Minimum & Maximum \\
\hline 4 & 8 & $\mathrm{LCH}_{4}$ & $\mathrm{GCH}_{4}$ & 400 & 231 & 0 & 117 \\
\hline 4 & 6 & $\mathrm{LCH}_{4}$ & $\mathrm{GCH}_{4}$ & 400 & 633 & 0 & 80 \\
\hline 4 & 11 & $\mathrm{LCH}_{4}$ & $\mathrm{GCH}_{4}$ & 600 & 234 & 0 & 281 \\
\hline 4 & 37 & $\mathrm{LCH}_{4}$ & $\mathrm{He}$ & 400 & 223 & 0 & 97 \\
\hline 4 & 42 & $\mathrm{LCH}_{4}$ & $\mathrm{He}$ & 600 & 224 & 0 & 180 \\
\hline 4 & 63 & $\mathrm{LCH}_{4}$ & GH & 400 & 219 & 2 & 99 \\
\hline 4 & 68 & $\mathrm{LCH}_{4}$ & GH & 600 & 222 & 0 & 225 \\
\hline 10 & 3 & LH & GH & 300 & 120 & 0 & $\sim 63$ \\
\hline 10 & 4 & LH & GH & 300 & 87 & 4.5 & $\sim 72$ \\
\hline 10 & 5 & LH & $\mathrm{He}$ & 300 & 99 & 0.5 & 51 \\
\hline 10 & 6 & LH & $\mathrm{He}$ & 300 & 95 & 26 & 95 \\
\hline 10 & 7 & LH & $\mathrm{GH}$ & 300 & 111 & 9 & 71 \\
\hline 11 & 4 & $\mathrm{LH}$ & $\mathrm{He}$ & 450 & 205 & 9 & 107 \\
\hline 11 & 7 & LH & $\mathrm{He}$ & 450 & 375 & 0 & 130 \\
\hline 11 & 9 & $\mathrm{LH}$ & $\mathrm{He}$ & 450 & 352 & $\sim 5$ & 126 \\
\hline 11 & 11 & LH & $\mathrm{He}$ & 180 & 214 & 0 & 59 \\
\hline 11 & 19 & LN & GN & $?$ & N/A & 0 & 107 \\
\hline 12 & 1 & LH & GH & 300 & 89 & 0 & 99 \\
\hline 17 & 88 & LH & $\mathrm{He}$ & 331 & 396 & 2 & 100 \\
\hline 17 & 85 & LH & $\mathrm{He}$ & 488 & 137 & 19 & 282 \\
\hline 17 & 87 & $\mathrm{LH}$ & $\mathrm{He}$ & 603 & 134 & 0 & 540 \\
\hline 18 & 4 & LH & $\mathrm{He}$ & 306 & 478 & 2 & 55 \\
\hline 27 & $?$ & LH & N/A & N/A & N/A & 1 & 29 \\
\hline 30 & Ex. 1 & LH & $\mathrm{GH}$ & $488-520$ & 350 & 15 & 220 \\
\hline 30 & Ex. 4 & LH & $\mathrm{GH}$ & $450-580$ & 101 & 0 & 300 \\
\hline 30 & Ex. 6 & LH & GH & $385-630$ & 88 & 0 & 415 \\
\hline 30 & Ex. 8 & LH & $\mathrm{He}$ & $524-530$ & 90 & $\sim 20$ & 270 \\
\hline
\end{tabular}

Experimental data or the reduction/conversion of this data from References 4, 17, 18, 24, 32, 33, and 34 confirm that mass transfer of propellant species into the ullage gas region does often occur during cryogenic propellant tank pressurization and pressurized propellant expulsion processes.

\section{B. Propellant Region Properties Distribution}

Although not as significant as ullage gas region property distributions, pressurant gas requirements can be affected by the distribution of properties within the cryogenic propellant region of a pressurized tank. In contrast to ullage gas property gradients and distribution, which are likely to have direct and significant effects on collapse factors, the propellant property gradients and distribution are likely to have indirect and less significant effects. In this region, as with the ullage gas region, fluid temperature distribution has the predominant effect on property distributions.

In the propellant region, fluid densities are generally greater, on the order of three times to one thousand times greater depending upon tank pressure and cryogenic propellant species, which means that vertical pressure gradients are much larger than those in the ullage gas region. However, the other fluid properties (including density, thermal conductivity, specific heat, and viscosity) which affect heat and mass transfer processes (and which ultimately affect pressurant gas requirements), are not significantly affected by the spatial pressure distribution within the propellant region. Examination of data from Ref. 35 over a wide range of tank pressures and cryogenic propellant temperatures was performed as part of this study. The results of this examination substantiate the minor effects of pressure variations on fluid properties in the ullage gas and propellant regions. Pressures in these regions vary by less than 50-psia for nitrogen and oxygen and less than 0.2-psia for hydrogen with the typical sizes and geometries of cryogenic tanks.

However, the possible variations in temperature within the cryogenic propellant region does have a much more significant effect on the critical fluid properties affecting heat and mass transfer within and across the boundaries of the cryogenic propellant region. 


\section{Propellant Region Vertical Temperature Distribution}

Table 5 provides a summary of selected references where empirical vertical temperature gradient data is provided for cryogenic propellant regions inside various tanks.

Table 5. References with Empirical Propellant Vertical Temperature Gradient/Profile Data

\begin{tabular}{|c|c|c|c|c|c|c|c|}
\hline \multirow[b]{2}{*}{$\begin{array}{c}\text { Reference } \\
\text { Citation }\end{array}$} & \multirow[b]{2}{*}{$\begin{array}{c}\text { Test } \\
\text { Number }\end{array}$} & \multirow[b]{2}{*}{ Prop. } & \multirow[b]{2}{*}{$\begin{array}{c}\text { Press. } \\
\text { Gas }\end{array}$} & \multicolumn{2}{|c|}{ Propellant Height (ft.) } & \multirow[b]{2}{*}{$\begin{array}{c}\text { Press. Hold } \\
\text { or Expul. } \\
\text { Time } \\
\text { (sec.) }\end{array}$} & \multirow[b]{2}{*}{$\begin{array}{l}\text { Tank } \\
\text { Press. } \\
\text { (psia) }\end{array}$} \\
\hline & & & & Minimum & Maximum & & \\
\hline 4 & 9 & $\mathrm{LCH}_{4}$ & $\mathrm{GCH}_{4}$ & $\sim 0.85$ & $\sim 4.15$ & 638 & 48.6 \\
\hline 4 & 10 & $\mathrm{LCH}_{4}$ & $\mathrm{GCH}_{4}$ & $\sim 0.85$ & $\sim 4.15$ & 410 & 48.9 \\
\hline 4 & 11 & $\mathrm{LCH}_{4}$ & $\mathrm{GCH}_{4}$ & $\sim 0.85$ & $\sim 4.15$ & 234 & 49.2 \\
\hline 4 & 97 & $\mathrm{LCH}_{4}$ & GN & $\sim 0.85$ & $\sim 4.15$ & 568 & 49.5 \\
\hline 4 & 98 & $\mathrm{LCH}_{4}$ & GN & $\sim 0.85$ & $\sim 4.15$ & 232 & 49.5 \\
\hline 10 & 3 & LH & $\mathrm{GH}$ & 1 & 7.25 & 120 & 46.5 \\
\hline 10 & 4 & LH & GH & 0.08 & 6.75 & 87 & 46.6 \\
\hline 12 & 2 & LH & $\mathrm{GH}$ & $<0.50$ & 7.46 & 103 & 47.6 \\
\hline 12 & 5 & LH & $\mathrm{He}$ & $<0.50$ & 7.51 & 99 & 45.5 \\
\hline 12 & 6 & LH & $\mathrm{GH} / \mathrm{He}$ & $<0.50$ & 7.63 & 95 & 47.0 \\
\hline 12 & 7 & LH & $\mathrm{GH}$ & $<0.50$ & 7.33 & 111 & 45.0 \\
\hline 12 & 10 & LH & $\mathrm{GH}$ & $<0.50$ & 7.39 & 105 & 45.5 \\
\hline 27 & $?$ & LH & N/A & 4.59 & 4.59 & 14,400 & $14.7-18.4$ \\
\hline 27 & $?$ & LH & $\mathrm{N} / \mathrm{A}$ & 4.59 & 4.59 & 43,200 & $14.7-27.0$ \\
\hline 36 & $3 \mathrm{~L} / \mathrm{min}$ & Water & $*$ & 1.31 & 3.11 & 840 & $\sim 14.7$ \\
\hline 36 & $15 \mathrm{~L} / \mathrm{min}$ & Water & * & 1.31 & 3.11 & 180 & $\begin{array}{l}14.7 \\
\sim 14\end{array}$ \\
\hline 37 & 2 & $\mathrm{LN}$ & N/A & 3.17 & 3.17 & 60 & 39.7 \\
\hline 37 & 2 & $\mathrm{LN}$ & $\mathrm{N} / \mathrm{A}$ & 3.17 & 3.17 & 360 & 29.7 \\
\hline 37 & 3 & $\mathrm{LN}$ & N/A & 3.17 & $3 / 17$ & 60 & 29.7 \\
\hline 37 & 3 & $\mathrm{LN}$ & $\mathrm{N} / \mathrm{A}$ & 3.17 & 3.17 & 360 & 29.7 \\
\hline 38 & 4 & LH & $\mathrm{He}$ & 13.17 & 13.17 & 119 & $18.7-32.7$ \\
\hline 38 & Fig. 8 & LH & GH & 4.75 & 4.75 & 100 & $?$ \\
\hline 38 & Fig. 8 & LH & GH & 4.75 & 4.75 & 600 & $?$ \\
\hline 39 & 13 & LN & GN & 1.98 & 1.98 & 7200 & 450 \\
\hline 40 & $6.5 \mathrm{~L} / \mathrm{min}$ & Water & * & 5.25 & 6.56 & 1500 & $\sim 14.7$ \\
\hline 40 & $9 \mathrm{~L} / \mathrm{min}$ & Water & $*$ & 5.25 & 6.56 & 1500 & $\sim 14.7$ \\
\hline 41 & B-2 & LH & N/A & 6.02 & 6.02 & 40 & $16.5-17.4$ \\
\hline 41 & B-2 & LH & $\mathrm{N} / \mathrm{A}$ & 6.02 & 6.02 & 152 & $16.5-19.5$ \\
\hline 42 & $?$ & LH & N/A & 3.75 & 8.52 & 20,700 & 19.15 \\
\hline 43 & $?$ & LH & N/A & 18.47 & 18.47 & 136,800 & $18.7-39.1$ \\
\hline 44 & 17 & LH & N/A & 3.91 & 3.91 & 120 & $\sim 27$ \\
\hline 44 & 19 & LH & N/A & 1.38 & 1.38 & 400 & $\sim 31.2$ \\
\hline 44 & 40 & $\overline{\mathrm{LN}}$ & $\mathrm{N} / \mathrm{A}$ & 3.97 & 3.97 & 160 & $\sim 18.0$ \\
\hline 44 & 38 & $\mathrm{LN}$ & $\mathrm{N} / \mathrm{A}$ & 1.27 & 1.27 & 700 & $\sim 18.9$ \\
\hline 45 & 1 & LH & GH & 2.5 & 2.5 & 600 & 54.7 \\
\hline 45 & 3 & LH & $\mathrm{GH}$ & 2.5 & 2.5 & 720 & 22.7 \\
\hline 46 & $?$ & LH & $\mathrm{GH}$ & $?$ & $\sim 2$ & 600 & $14.7-55$ \\
\hline 47 & A-3 & LH & GH & 4.19 & 4.19 & 900 & $125-160$ \\
\hline 47 & B-1 & LH & GH & 3.98 & 3.98 & 104,400 & $15.5-24.7$ \\
\hline 48 & $?$ & LH & $\mathrm{N} / \mathrm{A}$ & 2.36 & 2.36 & 600 & $14.7-73.5$ \\
\hline 48 & $?$ & LH & N/A & 2.21 & 2.21 & 600 & $14.7-73.5$ \\
\hline 48 & $?$ & LH & N/A & 2.30 & 2.30 & 600 & $14.7-73.5$ \\
\hline 48 & $?$ & LH & N/A & 2.14 & 2.14 & 600 & $14.7-73.5$ \\
\hline 49 & $?$ & LH & N/A & 6.50 & 6.50 & 120 & $?$ \\
\hline 49 & $?$ & LH & N/A & 6.50 & 6.50 & 300 & $?$ \\
\hline
\end{tabular}

Cryogenic propellant region vertical temperature gradients are generally on the order of $5 \mathrm{R}$ to $30 \mathrm{R}$. Also, the majority of data from references cited in Table 5 show that the major portion of the vertical temperature gradient has a vertical height that does not exceed $2 \%$ to $20 \%$ of the total propellant region height at the start of propellant expulsion from the tank or when the tank is $80 \%$ to $90 \%$ full of liquid propellant. For larger tanks, this major portion of the vertical temperature gradient extends from three inches to three feet below the interface between propellant and ullage gas; while for smaller tanks this depth below this interface is nominally 6-inches or less. Below these depths, where the major temperature gradient exists, the cryogenic propellant temperature is nearly uniform within $1 \mathrm{R}$. 
Three studies ${ }^{12,38,44}$ present cases where larger vertical temperature gradients occur through more than $20 \%$ of the maximum or initial height of the propellant region. However, for the cases where this phenomenon was observed, high heat fluxes were applied by enhanced heating of tank walls or liquid propellant sloshing was induced by horizontal tank oscillatory motions. However, even for these cases, vertical temperature gradients through the entire cryogenic propellant region are usually less than $5 \mathrm{R}$ and never exceed $10 \mathrm{R}$.

Approximately half of the cases presented in Table 5 are those where a tank is partially filled with cryogenic liquid propellant and no propellant expulsion from the tank is occurring. In most of these cases, tank pressurization is provided by heating and boil-off of liquid propellant through normal heat leak or enhanced heat input into the tank. A few cases involve the use of externally supplied pressurant gas for initial tank pressurization.

References 36 and 40 are cases where tanks are completely filled with water with a region of colder water below a region of warmer water where heated water is supplied into the top of the tank as the cooler water is discharged from the bottom of the tank. These references are presented because they illustrate that most of the temperature gradient for the lower region of cooler water is confined to a small upper portion of this region, even when the upper boundary of this region is in contact with liquid water at higher temperature and having thermal conductivity that is much higher than that of gases.

In addition to references cited in Table 5, a number of other studies ${ }^{32,48,50-53}$ present or discuss similar results with liquid and cold supercritical cryogenic fluids in tanks

\section{2. $\quad$ Propellant Region Horizontal Temperature Distribution}

Empirical data from a number of the cited references in Table 4 indicate zero or extremely small horizontal temperature gradients in the cryogenic propellant region. A large number of graphical plots in these references illustrate both the tank wall and ullage gas temperatures approaching the temperature of the bulk cryogenic propellant, within $0 \mathrm{R}$ to $20 \mathrm{R}$, when traversing from the top of the tank down to the interface between ullage gas and cryogenic propellant.

For cases where the horizontal temperature gradient in the propellant region can have temperature variations as high as $10 \mathrm{R}$ to $40 \mathrm{R}$, there are data from studies that indicate that virtually all of this gradient exists in a very thin thermal boundary layer adjacent to the tank walls.

\section{Multiple Species in Propellant Region}

For the cases where the pressurant gas is not the same species as the cryogenic propellant, the pressurant gas species can dissolve or condense into the cryogenic propellant region. This phenomenon has the net effect of making a portion of the fluid in the propellant region a mixture of pressurant gas and propellant species where both can be liquids, supercritical fluids, or solution of vapor dissolved within the liquid propellant. When this condition occurs, there is also a variation of fluid properties within the cryogenic propellant region caused by mass fraction variations of the constituent fluid species. Mass fraction of pressurant gas species is likely to be highest at the ullage-gas-to-propellant interface, and the mass fraction generally decreases as the vertical depth below this interface increases.

Although actual empirical data are very limited, a number of studies ${ }^{4,10,17,18,34,54-56}$ do report findings where pressurant gas species is present within the cryogenic propellant where the cryogenic propellant and pressurant gas are different species. 


\section{Tank Wall Temperature Distribution}

The distributions of temperatures through the tank walls have not been directly measured for cryogenic tanks. A number of studies include measurement of tank wall temperatures at discrete locations on the outer or inner wall surface in addition to discrete temperature measurements within the propellant and ullage gas regions (usually near the tank's vertical axis centerline). Table 4, presented earlier in this chapter, cites most of the studies where this was done. Two studies ${ }^{34,57}$ also include empirical tank wall temperature data.

The predominant simplifying assumption with regards to analytical modeling of heat and mass transfer processes in cryogenic propellant tanks is that of a negligibly small temperature gradient through the tank wall thickness normal to the inner wall local tangent plane. Virtually all of the data from prior studies, ${ }^{4,11,17,18,27,30,34}$ indicate that either this is a valid assumption or that the resultant errors in determining pressurant gas requirements are negligible or acceptably small.

The studies cited above also compare analytically predicted tank wall temperatures with experimentally measured tank wall temperatures. References 4, 11, and 17 provide experimental outer wall temperature data where measured temperatures are generally $5 \mathrm{R}$ to $20 \mathrm{R}$ colder than analytically computed temperatures, except for a few cases in Ref. 11 where experimentally measured temperatures were $45 \mathrm{R}$ colder. Two studies ${ }^{18,34}$ report experimentally measured tank outer wall temperatures to be $0 \mathrm{R}$ to $10 \mathrm{R}$ warmer than analytically computed temperatures. With the exception of a few isolated cases, data from all studies indicate that temperature gradients through the tank wall thickness have temperature differences of less than $20 \mathrm{R}$ between inner and outer surfaces of the tank walls. This holds true even in a study ${ }^{27}$ where external heat fluxes were applied to the outer tank wall surface for one to 14 hour durations.

In addition to the temperature distributions through the tank wall normal to the plane tangent to each local inner wall surface (through thickness of the wall), the temperature distribution parallel to the tank wall inner and outer surfaces needs to be considered. Many of the studies cited in Table 4 also present data confirming that the outer and inner tank wall surface temperature varies significantly with respect to vertical position from the top of a tank downward to the interface between ullage gas and cryogenic propellant. The general trends show the wall surface temperature decreasing in either a near-linear or highly non-linear fashion when traversing from top of tank downward to the vertical position of the ullage-gas-to-propellant interface. These data indicate that the tank wall surfaces have a much colder temperature than the ullage gas at the same corresponding vertical position where the range of typical temperature differences are shown in Table 4.

For all of the cited references in Table 4 where vertical ullage gas and tank wall temperature profile are shown, the general trend shows that the difference between ullage gas temperature and tank wall surface temperature decreases when traversing from the top of the tank or from the elevation(s) where pressurant gas enters the tank ullage downward to the aforementioned interface. When approaching this interface from above the ullage gas temperature and tank wall temperature both converge to nearly the same temperature that is nearly equal to, within $10 \mathrm{R}$ and usually within $1 \mathrm{R}$ to $2 \mathrm{R}$ of, the bulk cryogenic propellant temperature.

Regarding tank wall temperature profiles in the vicinity of the interface between ullage gas and cryogenic propellant regions, the empirical data all indicate that heat conduction through the tank wall parallel to the inner tank wall surface tends to "smooth out" or eliminate the occurrence of any abrupt temperature changes through the tank wall.

The phenomena described in the above two paragraphs are supported or confirmed with data presented various references ${ }^{4,11,17,18,27,30,34,51}$. Two studies ${ }^{27,51}$ indicate that these phenomena exist also when tank outer wall surfaces are heated with a constant heat flux.

No empirical tank wall temperature data were found in the research of studies for cases where tank pressures where near critical or supercritical nor for cases with heavy walled cryogenic propellant tanks with wall thicknesses above $1 / 2$-inch. 


\section{Effects of Mass Transfer on Pressurant Gas Requirements}

Most of the studies cited in the "Multiple Species in Ullage Gas Region" and "Multiple Species in Propellant Region" subsections acknowledge the potential for mass transfer processes between ullage gas and cryogenic propellant regions to have significant effects on required mass transfer of pressurant gas into the tank ullage. A number of the studies also conclude that this mass transfer can have effects that either increase or decrease the requirements depending on a number of parameters and operating conditions. However, there are also a number of prior studies that report very accurate predictions of requirements from analytical models when treating mass transfer between ullage gas and cryogenic propellant as negligible. The data from Ref. 30 is one example. On the other hand, studies where enhanced mass transfer between ullage gas and cryogenic propellant is known to have occurred (usually due to induced propellant sloshing) state significant increases in collapse factors over those where no propellant sloshing occurred. The data of Ref. 4 are examples indicating this occurrence. For other selected studies, the results are mixed where enhanced mass transfer due to propellant sloshing increases collapse factors significantly in some cases and has minor or negligible effects in other cases. The data of Ref. 10 as reported by Ref. 14 are examples where mixed results occurred.

Perhaps the studies that most clearly demonstrate the significance of mass transfer effects on collapse factors are in References 4 and 6 . In the latter reference, the second test series has empirical collapse factors that are nominally two to three times lower than collapse factors from similar and corresponding tests from the first test series. The cause of this very significant collapse factor reduction is greatly enhanced vaporization of the LOX propellant and mass transfer of this vaporized propellant into the tank ullage gas region when helium gas is bubbled up through this propellant. On the other hand, Ref. 4 reports very high collapse factors due to significant mass transfer of GN pressurant into $\mathrm{LCH}_{4}$ propellant where 60 to $75 \%$ of the pressurant gas supplied to the tanks is dissolved into the propellant. Further analyses and tests presented in this study indicate the density of $\mathrm{LCH}_{4}$ with dissolved GN increases as the concentration of GN increases which enhanced the buoyancy driven mixing of GN into a large portion of the propellant region. The use of GN pressurant gas was subsequently rejected as a cost savings option to replace helium.

The net result from the data in prior studies is that there is no consistent trend regarding the magnitude and direction of mass transfer across the interface between ullage gas and cryogenic propellant regions. The same is likely to be true for mass transfer of propellant species within the ullage gas region when pressurant gas and cryogenic propellant are different species, but there is insufficient empirical data to substantiate this. There is also no consistent trend or level of influence with regards to how this mass transfer ultimately affects collapse factors.

With respect to cryogenic propellant tanks operating at supercritical and high subcritical pressures, no empirical data for mass transfer across the ullage-gas-to-propellant interface have been found. From the studies researched, the effects of this mass transfer on collapse factors have not been evaluated in depth for the higher tank operating pressure conditions.

\section{E. Pressurant Gas Entry Effects}

The controlling-parameter that generally has one of the strongest influences on pressurant gas requirements and associated collapse factors in cryogenic propellant tanks is fluid flow conditions within and across volume boundaries in the tank. These conditions are predominantly influenced by pressurant gas flow velocity vectors at the point(s) of entry into the tank ullage gas region. Extensive empirical data indicate that these velocity vectors can yield two to six fold increases in convection heat transfer between the ullage gas and tank walls as well as between the ullage gas and cryogenic propellant. Additionally, these velocity vectors can provide forced mixing within the ullage gas region to create more uniform temperatures within most, or all, of the upper ullage gas region which can have either a beneficial effect in reducing ullage collapse or a detrimental effect by increasing this collapse. Pressurant gas inlet velocity vectors directed downward into the tank ullage and along tank walls can cause moderate to high levels of forced mixing between the ullage gas and cryogenic propellant.

Eleven studies ${ }^{12,19,58-66}$ provide data, observed cases, or indications where enhanced mixing between ullage gas and propellant increases pressurant gas mass transfer requirements and associated collapse factors, often by factors of two or three.

Page 15 of 29

American Instititute of Aeronautics and Astronautics 
A number of other studies ${ }^{16,45,61,67}$ support the concept of reducing ullage collapse by prevention of forced mixing between ullage gas and cryogenic propellant, but they report or conclude that enhanced mixing within the ullage gas region, rather than keeping this region stratified, also serves to reduce collapse factors.

In addition to the studies described above for cryogenic tank pressurization followed by pressurized propellant expulsion processes, there are a number of studies where methods to intentionally increase ullage gas collapse are employed to reduce or eliminate the need to vent (and lose) ullage gas from a cryogenic fluid tank during long term storage. The main end-use applications for these studies are onboard spacecraft cryogenic liquid tank systems to reduce quantities of lost and wasted fluids as much as possible. All of these studies provide strong indications that enhanced heat and mass transfer between ullage gas and cryogenic liquid propellant does cause significant collapsing (with associated pressure reduction) of the ullage gas. A number of studies ${ }^{68-78}$ provides empirical data showing ullage gas collapse through this enhanced heat and mass transfer.

In summary, the effects of pressurant gas entry velocities and conditions into cryogenic propellant tanks on collapse factors are not always consistent. While some data indicates that enhanced mixing within the ullage gas region to attain more uniform properties within this region reduces collapse factors, other data indicates that maintaining a thermally stratified ullage gas region lowers collapse factors.

With the exception of cases where helium pressurant gas is bubbled up through $\mathrm{LOX}$ and $\mathrm{LCH}_{4}$ propellant at low (50-psia nominal) subcritical pressures, enhanced mixing between ullage gases and cryogenic propellants results in increased pressurant gas requirements and associated collapse factors. The requirements tend to increase when the effects of ullage gas temperature reduction dominate over the effects of mass addition to the ullage gas region when vaporized propellant transfers to this region. This dominant effect appears to be the case most of the time. The exceptions appear to be cases where the effects of added propellant mass dominate.

A consistent trend observed in all studies is the reduction of mass transfer across the ullage-gas-to-cryogenicpropellant interface to very low or negligible levels when this interface is not disturbed with enhanced mixing of fluids across this interface and when the molecular weight of the pressurant gas species is less than that of the propellant species or helium pressurant gas is used.

Another consistent trend supported by all studies cited in this section where ullage-gas-to-tank-wall heat transfer is evaluated indicates the reduction of this heat transfer is a primary method to reduce ullage collapse and the resulting pressurant gas requirements.

As with much of the empirical data, there are no data regarding pressurant gas entry effects on its mass transfer and flow rate requirements for cryogenic propellant tanks operating at supercritical and high subcritical pressures.

\section{Analytical Methods and Models to Predict Collapse Factor}

A wide variety of analytical models and computational techniques have been devised to predict or to provide reliable and practical methods in determining collapse factors and the associated mass and mass flow rate requirements of cryogenic propellant tank pressurant gases. Initial work, starting in the late 1950's, has been focused on analytical methods that would consistently and reliably predict pressurant gas requirements that were sufficiently higher than actual requirements such that a conservative safety margin was always provided for design of pressurant gas subsystems. Through the 1960's as launch vehicle liquid propulsion systems were being developed for the space program and their cryogenic propellant tanks grew in size, the prediction of pressurant gas requirements with reduced margins of conservatism and errors grew in importance. For the larger flight vehicles weight reductions including those of the cryogenic liquid propellant tank pressurant gases and their supply subsystems, was of premium importance. This resulted in the development of elaborate computer based programs or empirically based computation methods to determine collapse factors.

In the late 1980's and early 1990's analytical work was performed to predict collapse factors more accurately for supercritical tank pressure applications. The work presented in References 79 and 80, with the reduction of

Page 16 of 29 
empirical data from Ref. 8, are the major efforts in this area. From these efforts, predicted collapse factors ranged nominally from 1.05 to 1.40 and empirically obtained collapse factors ranged from 1.42 to 4.10 with the higher values occurring at the start of propellant expulsion reducing to cumulative collapse factors between 1.05 and 1.60 at the end of this expulsion process.

In this article, the presented studies are mostly limited to cases where cryogenic propellant tanks are on the Earth's surface and where the model can be readily adapted to tanks on accelerating flight vehicles. However, selected studies performed for micro-gravity conditions are also mentioned where they provide selected characteristics and insights.

\section{A. "Saturation Rule"}

For the earlier pressurized cryogenic liquid tank expulsion and transfer studies performed in the late 1950's and early 1960's, analytical techniques using the "Saturation Rule" have been employed to predict or provide a conservative estimate of pressurant gas requirements. The "Saturation Rule" is based on the assumption that the ullage gas is always at a density corresponding to the saturation temperature of the cryogenic propellant and the tank pressure. If the ullage gas is the same species as the propellant, then the ullage gas is assumed to be a saturated vapor. The initial and final ullage gas volumes and densities are then used to compute the net addition of mass to the ullage region.

Use of the "Saturation Rule" is presented in References 55, 62, and 81 for LN and LOX expulsions with nitrogen and oxygen pressurant gases. When comparing the saturation rule results with test data, the analysis results had errors ranging from $16.3 \%$ under-predicted to $10.0 \%$ over-predicted in Ref. 55.

In Ref. 62 use of the "Saturation Rule" is combined with evaluation of ullage gas condensation along cylindrical tank walls where the tank was immersed in a bath of LN at near atmospheric pressure (LN bath temperature near $320 \mathrm{~F} \cong 140 \mathrm{R})$. When comparisons of empirical data to analytically predicted data are made in this reference, the predicted pressurant gas requirements are consistently higher than those from empirical data with errors within $11 \%$ for most of the time duration of each liquid cryogen expulsion process. However, the predicted pressurant gas mass flow rate data near the start of cryogenic liquid expulsions are nearly two times higher than data from experimental tests.

\section{B. Modifications and Enhancements to the "Saturation Rule"}

Subsequent studies ${ }^{15,24}$ found that analytical results using the "Saturation Rule" were excessively conservative (predicted pressurant gas requirements were four to ten times higher than those from actual tests) or resulted in physically impossible conditions for LH expulsions using hydrogen pressurant gas. Ref. 15 presents a revised technique using the "Worst Case Rule" which is based on the following assumptions:

1.) The tank is completely full of liquid cryogen at the start of expulsion ( $0 \%$ initial ullage gas volume),

2.) The pressurant gas exits the supply source and enters the tank at constant inlet enthalpy,

3.) The tank is at constant and uniform internal pressure,

4.) All pressurant gas that enters the tank displaces all of the liquid cryogen initially in the tank,

5.) All pressurant gas in the tank at the end of liquid cryogen expulsion is in the saturated vapor state.

Ref. 24 presents an alternative analytical method to the methods using the "Saturation Rule," although this method involves more steps and increased complexity as compared to that of Ref. 15. The method in the former reference is called the "Equivalent Mass Model."

Results obtained from use of the "Equivalent Mass Model" show 10.0\% under-prediction to $12.8 \%$ over-prediction of pressurant gas required as compared to data. The "Equivalent Mass Model" proved to yield more accurate pressurant gas requirement results than both the "Saturation Rule" and "Worst Case Rule" analytical methods, but the computation processes are more complex and involved. Additionally the "Equivalent Mass Model" provides good comparisons with empirical data for a wide range of cryogenic liquid tank geometries and sizes from 3 to 28,000 gallons. 


\section{Semi-Empirical Curve-fit Models}

After the development of the "Equivalent Mass Model," semi-empirical models were developed, tested, and used for ground-based tank systems. These models were utilized for a large variety of tank sizes, diameter-to-height ratios, and combinations of liquid cryogen propellant and pressurant gases. Efforts were made to derive a single equation or a series of simple equations, that included a set of empirically-derived constants, where collapse factors and the associated pressurant gas requirements were computed explicitly. The equations all used various ullage gas, incoming pressurant gas, and tank wall material properties, tank geometric data, and either known heat transfer rates or thermal boundary-layer film temperature gradients with user input or computed convection heat transfer coefficients. The main purpose for development of the semi-empirical curve-fit models was to provide methods that enabled sufficiently accurate, with error less than $10 \%$ to $15 \%$, computation of collapse factors and pressurant gas requirements without having to rely on the large and expensive mainframe computers that were needed in the 1960's for running the high fidelity and more complex computer program analysis tools used to predict collapse factors at that time.

Another semi-empirical computation method is presented in Ref. 54 in which six simultaneous equations are solved numerically by an iterative procedure. The net result is a computed final mean ullage gas temperature used to determine final mean ullage gas density and total mass. The collapse factors can then be computed. Errors of predictions for final mean ullage gas region temperatures are as large as $52 \%$.

Two studies ${ }^{5,57}$ present a single semi-empirical correlation to directly compute cumulative collapse factors and required total mass of pressurant gas at the end of propellant expulsion processes. Errors of collapse factors predicted by the correlation when compared to those obtained empirically are all less than $12 \%$ with most falling between 5\% and 6\%. Also, the majority of results show that the correlation errs on the conservative side; i.e., the correlation predicts collapse factors higher than actual collapse factors from tests for most cases.

Later work presented in one study ${ }^{82}$ provides enhancements to the collapse factor correlation described above. These enhancements include:

1.) Addition of new correlations to adjust parameters for cases where initial ullage gas volume is less than $20 \%$ of total tank volume,

2.) Addition of correlations to adjust parameters for cases where a large residual propellant volume remains in the tank at the end of propellant expulsion,

3.) Addition of a new correlation to compute an improved equivalent tank wall thickness and specific heat capacity for cases when the tank has highly non-uniform wall thicknesses including heavy walled nozzles and flange connections as well as accessory hardware inside the tank volume;

4.) Improved correlation to compute equivalent tank diameter, based on vertical cylindrical tanks geometries, for spherical and ellipsoidal tanks,

5.) Addition of revised and improved empirical constants for LH propellant expulsions.

Additionally, the study presented in Ref. 82 investigated the effects of mass transfer between cryogenic liquid propellant and ullage gas. The study concluded that evaporated propellant into the ullage gas region must be less than $26 \%$ of the total mass of pressurant gas supplied to the tank for the collapse factor correlation to be valid. The author also concludes that no more than $19 \%$ of the pressurant gas supplied to the tank ullage can condense into the propellant region to maintain validity of the collapse factor correlation.

An alternate and more comprehensive correlation is presented in Ref. 29 where final mean ullage gas temperature, at the end of cryogenic propellant expulsion, is computed by use of 19 fluid property, tank wall property, tank geometry, and pressurant gas inlet properties, and pressurant gas inlet flow condition variables.

The information presented in Ref. 83 is nearly identical to that of Ref. 29, but the former study contains added discussion about the computation of equivalent tank radius for non-cylindrical tanks. No comparisons between analytically computed and empirically obtained data are presented in either of these references. 


\section{Upper and Lower Bound Analyses}

More recent work performed in the middle 1980's through the early 1990's include upper and lower bound analyses in order to predict more realistic maximum and minimum possible mass requirements for pressurant gas in the expulsion of cryogenic propellants from tanks. A major focus of the upper and lower bound analyses is the ability to evaluate pressurant gas requirements for tanks operating at supercritical pressures.

The study presented in Ref. 15 can be classified as the original early version of an upper and lower bound analysis method. Subsequent works ${ }^{66,84-86}$ provide analytical methods for determining upper and lower bounds of pressurant gas requirements.

The upper- and lower-bound analytical techniques have been shown to be consistently reliable in providing the possible ranges of cumulative collapse factors. However, the ranges are quite wide and the actual collapse factors and associated pressurant gas requirements are often well below upper-bound values even though the more recent studies have brought the upper bounds to more realistic and less conservative values.

\section{E. Lumped Mass Fluid Region Models}

In parallel to development and use of the modeling methods described in the previous subsections of this chapter, models using numerical techniques to model intra-tank heat and mass transfer processes and requiring iterative computation methods have also been developed. When developed and utilized in the 1960's these models were in the form of computer programs. These computer programs involve the solution to two or more complex simultaneous equations where each contains and utilizes a number of dependent variables and where numerical techniques and multiple iteration routines are needed to arrive at converged solutions. The dependent variables mainly include selected thermal and transport properties of ullage gas and incoming pressurant gas, a limited number of cryogenic (liquid) propellant properties, selected tank wall geometric parameters, and selected tank wall material properties.

Table 6 provides a summation of data and selected details for the Lumped-Mass Fluid Region (LMFR) models researched for this study. Included in this table are general descriptions of the heat and mass transfer computation methods used at regional boundaries and the comparison of analytical model results with empirical results where the actual test conditions and parameters correspond to those modeled analytically.

With the exception of two studies ${ }^{79,80}$ the tank wall is assumed to have a negligible temperature gradient through the thickness of the tank wall.

To account for non-uniform temperatures through thick tank walls, Ref. 80 models the inner $70 \%$ of the tank wall thickness to be uniformly heated by ullage gas while the remaining $30 \%$ of wall thickness is thermally isolated from the heated wall.

The model presented in Ref. 79 utilizes an explicit finite-difference technique from Ref. 87 to map the tank wall temperature distribution through the tank wall thickness at discrete time steps. The explicit finite-difference method is used because the thermal properties of cryogenic tank wall materials vary very widely and in a highly non-linear fashion with respect to temperature in the cryogenic temperature regimes.

Regarding vertical tank wall temperature distributions or the vertical component of the tank wall temperature profile parallel to the tank wall inner surface, the analytical models presented in references cited in Table 6 each employ one of two methods. The simpler method treats the entire section of tank wall in contact with ullage gas at each discrete time step as a lumped mass having a uniform temperature, or in the case of Ref. 79 a uniform temperature profile through the tank wall thickness. 
Table 6 Summary Data for Lumped Mass Fluid Region (LMFR) Models

\begin{tabular}{|c|c|c|c|c|c|c|}
\hline \multirow{2}{*}{$\begin{array}{c}\text { Reference } \\
\text { Citation }\end{array}$} & \multicolumn{4}{|c|}{ Heat Transfer } & \multirow{2}{*}{$\begin{array}{c}\text { Mass Transfer } \\
\text { Ullage Gas to Propellant }\end{array}$} & \multirow[b]{2}{*}{ Model Errors Compared to Empirical Data } \\
\hline & Ullage Gas to Wall & Propellant to Wall & Ullage Gas to Propellant & External Tank Wall & & \\
\hline 12 & $\begin{array}{l}\text { NLC, Correlation for Conv. H.T. } \\
\text { Coeff. not provided }\end{array}$ & $\begin{array}{l}\text { Based on H.T. from wall } \\
\text { boiling liquid propellant }\end{array}$ & Not Discussed & $\begin{array}{l}\text { NLC, Correlation for Conv. } \\
\text { H.T. Coeff. not shown }\end{array}$ & Not Discussed & $\begin{array}{l}\text { Range: - }-9.6 \text { to } 7.8 \% \text {; Mean: } 1.11 \% ; \text { Std. Dev. } 5.0 \% ; 10 \\
\text { Tests Compared }\end{array}$ \\
\hline 14 & NLC, NC, Note 7 & Assumed Negligible & Assumed Negligible & Not Discussed & Assumed No Mass Transfer & $\begin{array}{l}\text { Range: }-10.4 \text { to } 18.5 \% \text {; Mean: 0.65\%; Std. Dev. } 7.74 \% \text {; } \\
18 \text { Tests Compared }\end{array}$ \\
\hline 33 & NLC, NC, Note 9 & Assumed Negligible & Not Modeled & Modeled as Adiabatic & Determined from Empirical Data & $\begin{array}{l}\text { Range: }-9.0 \text { to } 8.4 \% \text {; Mean: } 0.34 \% ; \text { Std. Dev. } 4.57 \% ; 12 \\
\text { Tests Compared }\end{array}$ \\
\hline 79 & $\begin{array}{l}\text { NLC, NC, VP \& HP [Ref. } 87 \\
\text { Correlations] }\end{array}$ & $\begin{array}{l}\text { NLC, NC, VP \& HP [Ref. } 87 \\
\text { Correlations] }\end{array}$ & $\begin{array}{l}\text { NLC, NC, HPCSU [Ref. } 87 \\
\text { Correlations] }\end{array}$ & Modeled as Adiabatic & Assumed Negligible & $\begin{array}{l}\text { Pressurant gas supply bottle press. And temp. show }< \\
1 \mathrm{~K} \text { and }<0.5 \mathrm{MPa} \text { error for part of Test } 74 \text { on E-8 Test } \\
\text { Stand }\end{array}$ \\
\hline 80 & $\begin{array}{l}\text { NLC, NC\& FC, Notes } 3 \text { and } 5 \\
\text { [Ref. } 34 \text { Corrrelations] }\end{array}$ & Assumed Negligible & $\begin{array}{l}\text { NLC, NC \& FC, Notes } 3 \text { and } 6 \\
\text { [Ref. } 34 \text { Correlations] }\end{array}$ & $\begin{array}{l}\text { Modeled as Adiabatic, Note } \\
5\end{array}$ & $\begin{array}{l}\text { None, equivalent mass transfer } \\
\text { modeled by added H.T., Note } 6\end{array}$ & $\begin{array}{l}\text { No comparisons presented; model predicts Collapse } \\
\text { Factor of } 1.20 \text { to } 1.24\end{array}$ \\
\hline 88 & Notes 1 and 3 & Note 2 & Note 4 & Note 1 & Note 1 & $\begin{array}{l}\text { Range: }-9.3 \text { to } 13.1 \% \text {; Mean: 2.75\%; Std. Dev. 5.74\%; } \\
11 \text { Tests Compared }\end{array}$ \\
\hline 89 & NLC, NC & NLC, NC & Not Discussed & Not Discussed & Not Discussed & $\sim 10$ to $12 \%$ estimated from UG Press. \& Temp. data \\
\hline 90 & NLC, NC, HPCSD & EC & NLC, NC, HPCSU & Not Discussed & Not Discussed & $\begin{array}{l}18 \text { to } 30 \% \text { based on comparison with model data in } \\
\text { Epstein and Anderson (1968) }\end{array}$ \\
\hline 91 & NLC, NC, Note 7 & Assumed Negligible & NLC, NC, HPCSU [from Ref. 92] & Not Discussed & (1) and (2) & $\begin{array}{l}-14.1,4.7,-1.8,0 \% \text { for GH over LH; }-2.5,-8.7,6.7,- \\
2.5 \% \text { for } G \text { He over } L H\end{array}$ \\
\hline 92 & $N L C, N C, V P \&$ FC & $\mathrm{NLC}, \mathrm{NC}, \mathrm{VP} \& \mathrm{HP}, \mathrm{FC}$ & NLC,NC, HPCSU & NLC, FC \& Radiation & (1), (6), and Note 8 & No Comparisons Presented \\
\hline
\end{tabular}

Key: $\quad$ NLC $=$ Newton's Law of Cooling

$N C=$ Natural (Free) Convec

$\mathrm{FC}=$ Forced Convection

PP = Horizontal Patural Convection Correlations)

Colations), Cold Side Down

TCSU = Horizontations), Cold Side Up

(1) = fivalent Conduction, themal conductivity and slope of temperature gradient across finite segment/element at boundary

(1)

(6) = Sixth Mass Transfer Computation Technique, from "Mass Tran

Notes: $\quad 1$. An energy balance equation using propellant, mean ullage gas, entering pressurant gas, and tank wall temperatures; temperature differentials; and empirically determined coefficients is used to calculate rate of change of ullage gas temperature at discrete time steps.

2. A condensation or evaporation energy balance equation, whichever has highest magnitude, using propellant, mean ullage gas, and tank wall temperatures; temperature differentials; and

empirically determined coefficients is used to calculate rate of change of liquid propellant temperature at discrete time steps.
3. Ullage gas is divided into two regions; the lower region contains only the initial mass of ullage gas prior to entry of pressurant gas and the upper region contains only pressurant gas supplied from external source.

4. External tank heating is assumed to heat and evaporate liquid propellant only. Evaporation rate of propellant is calculated from heat transfer equation using tank wall and liquid propellant temperatures, heat transfer areas, latent heat of vaporization, and empirically determined coefficients.

5. To simulate effects of transient and non-uniform temperatures through thick tank walls, the wall is modeled as having uniform temperature through $70 \%$ of the actual wall thickness where heat is transferred from the ullage gas; $30 \%$ of the wall thickness is modeled as thermally isolated from remianing wall.

6. $740 \mathrm{BTU} / \mathrm{hr}-\mathrm{ft2}-\mathrm{R}$ for $\mathrm{GH}$ over $\mathrm{LH}$ and $520 \mathrm{BTU} / \mathrm{hr}$-ft2-R for GN over LOX added to calculated convective heat transfer coefficient from Ref. 34 correlations to simulate effects of mixing between

ullage gas and cryogenic propellant; these resulted in approximate $10 \%$ increase in required pressurant gas.

7. Ullage gas modeled as having linear vertical temperature profile with temperature at top of region equal to entering pressurant gas temperature and temperature at bottom of region equal to saturation temperature of propellant; Mean ullage gas temperature used to calculate heat transfer at ullage gas boundaries with tank wall is average of temperatures at top and bottom of ullage

gas region.
8uring rapid change in tank pressure, mass transfer across ullage-gas-to-cryogenic-propellant interface is product of ullage volume and ullage gas density change based on net difference between new tank pressure and propellant saturation pressure.

9. Natural convection correlation used with time of pressurant gas entry, thermal properties of ullage gas and tank wall, tank wall thickness and inside diameter to compute ratio of actual to maximum total heat in tank wall; Maximum total heat in tank wall is when all of tank wall is at temperature of the incoming pressurant gas; Coefficients and exponents in the correlation to compute
ratio of actual to maximum total heat in tank wall are derived from curvefits of empirical data.

RELEASED - Printed documents may be obsolete; validate prior to use. 
Three studies ${ }^{14,88,91}$ employ a more complex method for modeling the temperature of the tank wall section in contact with ullage gas. For the models presented in these studies, the tank wall is modeled as finite discrete segments vertically stacked from the top to the bottom of the tank. Those tank segments in contact with liquid propellant are set at temperatures equal to that of the liquid propellant. The tank segments in contact with the ullage gas are each modeled as nodes with each having uniform temperature and thermal properties.

All models presented by reference citations in Table 6 were used for subcritical tank pressure conditions with the exception of References 79 and 80.

\section{F. Multiple Discrete Fluid Segment Models}

In contrast, and as an intended enhancement to the LMFR computer models, other models have been developed and used where one or more intra-tank fluid regions are subdivided into discrete horizontal segments in order to provide a more accurate representation of temperature gradients in the intra-tank fluid regions. Each segment is treated as a small bulk mass of fluid having uniform properties throughout.

Table 7 presents a listing of studies where subdivision of the ullage gas region, cryogenic (liquid) propellant region, or both regions into discrete finite segments was employed in computer programs used to predict pressurant gas requirements or pressure rise rates in cryogenic propellant tanks for pressurization or pressurized propellant expulsion processes. With the exception of Ref. 93, all of the Multiple Discrete Fluid Segment (MDFS) Models cited in Table 7 subdivide the ullage gas region into vertically stacked discrete finite horizontal segments. Each segment is modeled as having uniform properties where a portion of the pressurant gas entering the ullage uniformly mixes with gas already in this segment. This was done in order to provide a more accurate representation of the vertical temperature gradients known from empirical data to exist in the cryogenic tank ullage gas regions and adjacent tank walls, as illustrated in references cited in Tables 3 and 4.

Although the MDFS models involve a higher level of computer program complexity, significantly increased numbers of repetitive and iterative calculations, increased computing time, and increases in computer memory requirements, the developers of these models deemed that this was necessary to provide consistently accurate model results for a wide variety of cryogenic tank sizes and geometries as well as for a wide variety of operating conditions.

The majority of MDFS computer models in Table 7 treat the cryogenic (liquid) propellant region as a single lumped mass having uniform properties throughout the region. Most of these models also apply the assumption of negligible heat transfer between propellant region and adjacent tank walls due to a negligible temperature difference between propellant region and tank walls adjacent to this region.

With regards to the modeling of transient heat conduction in the tank walls, all models presented by the cited references on Table 7 apply the assumption of near zero temperature gradient through the thickness of the tank wall.

For all of the models referenced in Table 7, except Ref. 93, the tank wall is subdivided into vertically-stacked finite segments. For all of these models, the heat transfer between any two adjacent wall segments is assumed to be negligible.

Results obtained with the MDFS computer program models referenced in Table 7 provide good to excellent predictions of pressurant gas requirements and associated collapse factors when compared to corresponding empirical data. For all models, predicted pressurant gas flow rates or collapse factors are generally within $14 \%$ of corresponding empirical data.

When initially comparing Tables 6 and 7, the MDFS models (cited in Table 7) appear to provide little or no improvements over the LMFR models (cited in table 6). However, the former models are evaluated for accuracy for a much wider range of tank geometries and sizes ranging from 17.7-gallons to thousands and tens of thousands of gallons while the latter models were only evaluated for vertical cylinder tanks of 500- gallon and smaller 
Table 7 Summary Data for Multiple Discrete Fluid Segment (MDFS) Models

\begin{tabular}{|c|c|c|c|c|c|c|c|c|c|}
\hline \multirow[b]{2}{*}{$\begin{array}{c}\text { Reference } \\
\text { Citation }\end{array}$} & \multicolumn{6}{|c|}{ Heat Transfer } & \multicolumn{2}{|c|}{ Mass Transfer } & \multirow[b]{2}{*}{$\begin{array}{l}\text { Model Errors Compared to } \\
\text { Empirical Data }\end{array}$} \\
\hline & $\begin{array}{l}\text { Ullage Gas to } \\
\text { Wall }\end{array}$ & $\begin{array}{c}\text { Propellant to } \\
\text { Wall }\end{array}$ & $\begin{array}{l}\text { Ullage Gas to } \\
\text { Propellant }\end{array}$ & $\begin{array}{c}\text { Intra-Ullage- } \\
\text { Gas Segment- } \\
\text { to-Segment }\end{array}$ & $\begin{array}{l}\text { Intra-Propellant } \\
\text { Segment-to- } \\
\text { Segment }\end{array}$ & $\begin{array}{c}\text { External Tank } \\
\text { Wall }\end{array}$ & $\begin{array}{l}\text { Ullage Gas to } \\
\text { Propellant }\end{array}$ & $\begin{array}{l}\text { Intra-Ullage-Gas } \\
\text { Segment-to- } \\
\text { Segment } \\
\end{array}$ & \\
\hline 3 & NLC, NC \& FC & $\mathrm{NLC}, \mathrm{NC}$ & $\mathrm{NLC}, \mathrm{NC}, \mathrm{FC}$ & EC \& EFC & $\mathrm{EC}$ & $\begin{array}{c}\text { Adiabatic Outer } \\
\text { Wall } \\
\text { Modeled } \\
\end{array}$ & $\begin{array}{l}\mathrm{N} / \mathrm{A}, \text { Assumed } \\
\text { to be Zero }\end{array}$ & $\begin{array}{c}\text { No Mass Transfer } \\
\text { other than } \\
\text { Pressurant Gas Entry }\end{array}$ & $\begin{array}{l}-13.0 \text { to }+1.0 \% \text { for Test } 004 \mathrm{~A} \\
+2.9 \text { to }+14.0 \% \text { for Test } 0027 \mathrm{~A} \\
-2.7 \text { to }+9.1 \% \text { for Test } 0029 \mathrm{~B} \\
\end{array}$ \\
\hline 17 and 18 & $\mathrm{NLC}, \mathrm{NC}$ & $\begin{array}{l}\text { N/A, No Heat } \\
\text { Transfer } \\
\text { Assumed }\end{array}$ & $\begin{array}{c}\text { NLC, NC (Same } \\
\text { correlation as } \\
\text { Ref. 91) } \\
\end{array}$ & $E C$ & $\begin{array}{c}\text { N/A, Uniform } \\
\text { Propellant Region } \\
\text { Modeled } \\
\end{array}$ & $\begin{array}{l}\text { Adiabatic Outer } \\
\text { Wall Modeled }\end{array}$ & (1) & $\begin{array}{c}\text { No Mass Transfer } \\
\text { other than } \\
\text { Pressurant Gas Entry } \\
\end{array}$ & $\begin{array}{l}\text { Range: }-2.73 \text { to } 19.48 \% \text {; Mean: } \\
\text { 5.29\%; Std. Dev.: } 5.56 \% ; 19 \text { Tests } \\
\text { Compared }\end{array}$ \\
\hline 23 & $\mathrm{NLC}, \mathrm{NC}$ & $\mathrm{NLC}, \mathrm{NC}$ & EC & EC & EC & NLC, NC, Note 2 & (1) & (6) & $<5 \%$ \\
\hline 30 & NLC, NC & $\begin{array}{l}\text { N/A, No Heat } \\
\text { Transfer } \\
\text { Assumed }\end{array}$ & NLC, NC & $\begin{array}{l}\text { N/A, No Heat } \\
\text { Transfer } \\
\text { Assumed }\end{array}$ & $\begin{array}{l}\text { N/A, Uniform } \\
\text { Propellant Region } \\
\text { Modeled }\end{array}$ & Input Heat Flux & $\begin{array}{l}\mathrm{N} / \mathrm{A} \text {, Assumed } \\
\text { to be Zero }\end{array}$ & $\begin{array}{l}\text { No Mass Transfer } \\
\text { other than } \\
\text { Pressurant Gas Entry }\end{array}$ & $\begin{array}{l}\text { Range: }-8.23 \text { to } 12.04 \% \text {; Mean: } \\
\text { 2.22\%; Std. Dev.: } 6.05 \% ; 10 \text { Tests } \\
\text { Compared }\end{array}$ \\
\hline 34 & NLC, NC \& FC & NLC, NC & NLC, NC \& FC & EC & EC & \begin{tabular}{|c|} 
NLC, NC \& \\
Radiation, Note \\
1 \\
\end{tabular} & (6) & (6) & $\begin{array}{l}\text { Range: Approx. }-30 \text { to } 12 \% \text {; Mean: } \\
0.1 \text { to } 2.3 \% \text {; Std. Dev.: } 10.9 \text { to } 8.5 \% \text {; } \\
11 \text { Tests Compared }\end{array}$ \\
\hline 93 & $\begin{array}{l}\text { No Heat } \\
\text { Transfer } \\
\text { Assumed }\end{array}$ & $E C$ & $\begin{array}{l}\text { EC (liquid side } \\
\text { only) }\end{array}$ & $\mathrm{N} / \mathrm{A}$ & $\mathrm{EC}$ & Input Heat Flux & (1) & $\begin{array}{l}\text { N/A; Ullage Gas at } \\
\text { Uniform Temp. }\end{array}$ & No Comparisons Presented \\
\hline 94 & NLC, NC \& FC & $\mathrm{NLC}, \mathrm{NC}$ & NLC, NC \& FC & $E C$ & $E C$ & $\begin{array}{c}\text { NLC, NC \& } \\
\text { Radiation, Note } \\
1\end{array}$ & (1) and (6) & (6) & $\begin{array}{l}\text { Comparisons not presented; 10\% } \\
\text { Max. Cumulative Error; } \sim 20 \% \text { Max. } \\
\text { Instantaneous Error from Nein and } \\
\text { Thompson (1966) }\end{array}$ \\
\hline 95 & NLC, NC \& FC & NLC, NC & NLC, NC \& FC & EC & EC & Unknown & (1) & Unknown & $\begin{array}{l}\sim 10 \% \text { for Test } 130-9 ; \sim 10 \text { to } 12 \% \text { for } \\
\text { Test } 130-6 ; \sim 5 \% \text { for Test } 6 \mathrm{E}\end{array}$ \\
\hline 96 & NLC, NC \& FC & $\begin{array}{l}\text { No Heat } \\
\text { Transfer } \\
\text { Assumed }\end{array}$ & $\begin{array}{l}\text { NLC, NC (Same } \\
\text { correlation as } \\
\text { Ref. 91) }\end{array}$ & EC & $\begin{array}{l}\text { N/A, Uniform } \\
\text { Propellant Region } \\
\text { Modeled }\end{array}$ & Input Heat Flux & Not Discussed & $\begin{array}{l}\text { No Mass Transfer } \\
\text { other than } \\
\text { Pressurant Gas Entry }\end{array}$ & $\begin{array}{l}0.5 \text { to } 16.0 \% \text { Error for Tank } \\
\text { Pressurization; } 7.0 \text { to } 12.4 \% \text { Error } \\
\text { for Propellant Expulsion }\end{array}$ \\
\hline
\end{tabular}

Key:

NLC = Newton's Law of Cooling

$\mathrm{NC}=$ Natural (Free) Convection; Ref. 34 correlations unless noted otherwise

FC = Forced Convection; correlation presented in "Combined Natural and Forced Convection Correlations" section

$\mathrm{EC}=$ Equivalent Conduction; thermal conductivity and slope of temperature gradient across finite segment/element at boundary

EFC = Equivalent Forced Convection (and Mixing); similar to correlation presetned in "Combined Natural and Forced Convection Correlations" section

(1) = First Mass Transfer Computation Technique, from "Mass Transfer Correlations" Section of Chapter II in Ref. 3

(6) = Sixth Mass Transfer Computation Technique, from "Mass Transfer Correlations" Section of Chapter II in Ref. 3

Notes:

1. Equivalent conductance based on natural convection and radiation heat transfer is used; this parameter is calculated from equation using empirically derived constants, bottle wall temperature and ambient air temperature, and these temperatures raised to the fourth power

2. Equivalent conductance based on natural convection only; correlation not presented 
capacities, except for the one 2400-gallon spherical LH tank expulsion test in one study ${ }^{79}$. Also, each of the studies cited in Table 6 where error ranges are more favorable, employed correlations with coefficients and exponents determined to provide best results for a single tank configuration and a limited range of test conditions. Therefore, the MDFS collapse factor analysis computer programs generally provide a much better assurance that "good" to "excellent" collapse factor predictions will result.

\section{G. Internal Tank Heat Transfer Correlations}

Many of the models described herein involve the computation and use of heat transfer rates across fluid regional boundaries. The majority of these models utilize correlations that determine heat transfer rates at the ullage-gas-totank-wall boundaries while considering heat transfer at the interface between ullage gas and cryogenic (liquid) propellant to be negligibly small. A smaller select group of models employ correlations for heat transfer across this interface. An even smaller select group of models evaluate and account for heat transfer rates across boundaries between cryogenic propellant and tank walls, but the vast majority of models are either based on the assumption of negligible heat transfer at cryogenic-propellant-to-tank-wall boundaries where temperatures of propellant and adjacent tank walls or wall segments are considered to be virtually equal.

\section{Natural Convection Correlations}

For the majority of LMFR and MDFS computer models, natural or free convection heat transfer is treated as being the only mode of heat transfer at ullage gas and cryogenic propellant region boundaries.

A general natural convection correlation is utilized in virtually all of the models cited in Sections IV.C. through IV.F. It is based on Nusselt number equated as the product of an empirically derived constant and the Rayleigh number raised to an exponential power. The constants and exponential powers are those used for heated or cooled horizontal, vertical, and inclined vertical flat plate correlations as well as correlations used for domed enclosures in some cases. A number of the references cited on Tables 3, 4, 5, 6, and 7 as well as in Sections IV.C. through IV.F. state the values used for constants and exponential powers.

In addition to the general natural convection Nusselt number correlation described above, a number of other Nusselt number correlations of different forms have been developed and presented in prior literature ${ }^{17,18,44,79,97-102}$. All of the presented Nusselt number correlations generally use fluid properties and characteristic dimensions.

\section{Combined Natural and Forced Convection Correlations}

The majority of numerical finite difference computer models presented by studies cited in Tables 6 and 7 are based on all natural convection heat transfer at all or selected fluid regional boundaries. The reference citations in Table 7 that indicate natural and forced convection ("NC" and "FC") for ullage-gas-to-wall heat transfer combine the effects of natural and forced convection at boundaries of the discrete horizontal segments in the ullage gas region as indicated by this table. For these models, the total equivalent convective heat transfer coefficients (or Nusselt numbers) at ullage-gas-to-tank-wall and at ullage-gas-to-cryogenic-propellant boundaries are equated as the sum of forced and natural convection components.

In contrast, two studies ${ }^{92,103}$ recommend using the higher of the natural and forced convective heat transfer coefficients to determine rate of heat transfer at ullage-gas-to-wall and ullage-gas-to-propellant boundaries. For combined forced and natural convection heat transfer processes, Ref. 87 recommends the following Nusselt number correlation

$$
N u_{T}=\left[N u_{L}{ }^{n}+N u_{F}{ }^{n}\right]^{1 / n}
$$

For the above correlation, the subscripts "F," "L," and "T" represent forced, natural (free), and total equivalent combined (forced and natural) convection respectively. In Ref. 87, the exponent " $n$ " is generally taken to have a value of three (for non-transverse flows) while selected studies in Table 7, where "NC \& FC" are column entries, essentially set " $n$ " to unity. For cases where the forced convection effects oppose the natural convection effects 
(forced convection alone would cause fluid to flow in direction opposite to flow direction if natural convection was acting alone), the plus sign in Equation (1) would change to a minus sign.

In the references in Table 7 where forced convection heat transfer effects are modeled for heat transfer between ullage gas and tank walls, the forced convective heat transfer coefficient is based on a Nusselt number correlation. This correlation equates Nusselt number to the product of a constant, Reynolds and Prandtl numbers of entering pressurant gas raised to exponential powers of 0.8 and 0.33 respectively, and an exponential decay factor. The exponential decay factor is based on the horizontal and vertical distances between location(s) on tank wall under evaluation and closest point where pressurant gas enters the tank ullage. As either or both of these distances increase, this factor decreases in value.

For references in Table 7 where effects of forced convection are modeled at the boundary between ullage gas and cryogenic (liquid) propellant, a similar correlation is used to calculate the forced convective heat transfer coefficient on the ullage gas side of this boundary.

\section{Conclusion}

Empirical collapse factor data as well as methods and computer based models used to analytically determine/predict collapse factors in cryogenic propellant tanks have been presented. Additionally, other phenomena, including temperature distributions and inter-region mass transfer which affect collapse factors, have been described. Results show that collapse factors vary widely depending on tank size and configuration, propellant and pressurant gas species, and operating conditions. Methods and models used to analytically determine collapse factors also show varied levels of accuracy when compared with empirically determined collapse factors. The LMFR and MDFS models show the best results with the latter model providing best accuracy over a wide variety of conditions as it accounts for most or all phenomena known to significantly affect collapse factors.

Nearly all collapse factor studies to date cover cases where cryogenic tank operating pressures are well below the critical pressure of the cryogenic propellant, so this propellant is in the liquid phase and a distinct liquid-to-gas boundary exists between propellant and ullage gas. A few selected cases cover operating pressures that are near or above this critical pressure where a distinct boundary between propellant and ullage gas may not exist. Collapse factor data for these cases are limited.

\section{Acknowledgements}

The authors would like to acknowledge many of the authors who produced the works listed in the references, Mississippi State University, NASA Stennis Space Center, key faculty and staff in these organizations, and family members and friends who have provided key support in making this article possible.

\section{References}

${ }^{1}$ Sutton, G. P., Rocket Propulsion Elements; An Introduction to the Engineering of Rockets, $6{ }^{\text {th }}$ Edition, John Wiley \& Sons, New York, NY, 1992.

${ }^{2}$ Barber. H. E., "Advanced Pressurization Systems Technology Program Final Report," Technical Report AFRPL-TR-66-278, Edwards, CA, 1966.

${ }^{3}$ de Quay, L., "Validated Prediction of Pressurant Gas Requirements in Cryogenic Run Tanks at Subcritical and Supercritical Pressures," UMI Dissertation Publishing, Number 3386300, ProQuest LLC, Ann Arbor, MI, 2009.

${ }^{4}$ DeWitt, R. L., \& McIntire, T. O., "Pressurant Requirements for Discharge of Liquid Methane from a 1.52Meter- (5-ft-) Diameter Spherical Tank Under Both Static and Slosh Conditions,” NASA-TN-D-7638, 1974. 
${ }^{5}$ Epstein, M., \& Anderson, R. E., “An Equation for the Prediction of Cryogenic Pressurant Requirements for Axisymmetric Propellant Tanks," Advances in Cryogenic Engineering, Vol. 13, ed. Timmerhaus, K. D., Plenum Press, New York, NY, 1968, pp. 207-214.

${ }^{6}$ Lacovic, R. F., "Comparison of Experimental and Calculated Helium Requirements for Pressurization of a Centaur Liquid Oxygen Tank," NASA-TM-X-2013, 1970.

${ }^{7}$ Nein, M. E., \& Head, R. R., "Experiences with Pressurized Discharge of Liquid Oxygen from Large Flight Vehicle Propellant Tanks," Advances in Cryogenic Engineering, Vol. 7, ed. Timmerhaus, K. D., Plenum Press, New York, NY, 1962, pp. 244-250.

${ }^{8}$ Shelburne, L., "E-8 Turbopump Testing" Facsimile Transmission dated June 4, 1990, Pratt and Whitney Advanced Launch System Space Transportation Engine Program Coordination Memo No. NSO-020-14, 1990.

${ }^{9}$ Cowart, E. G., "Saturn V S-II Final Propulsion System Performance Prediction Flight SA-503, Vol. II of III," Boeing Space Division Document No. D5-15530-3A, July 1968.

10“Main Propellant Tank Pressurization System Study and Test Program, Vol. I, Liquid Hydrogen and Liquid Oxygen," Lockheed Report ER-5238, 1961.

${ }^{11}$ Bourgarel, M., Clement, R., Segel, M., “A Cryogenic Propellant Tank Pressurization Analysis,” Proceedings of the $2^{\text {nd }}$ International Cryogenic Engineering Conference, Iliffe Science and Technology Publications, Guildford, UK, 1968, pp. 89-101.

${ }^{12}$ Coxe, E. F., \& Tatom, J.W., "Analysis of the Pressurizing Gas Requirements for an Evaporated Propellant Pressurization System," Advances in Cryogenic Engineering, Vol. 7, ed. Timmerhaus, K. D., Plenum Press, New York, NY, 1962, pp. 234-243.

${ }^{13}$ Hardy, T. L., \& Whalen, M. V., "Slush Hydrogen Propellant Production, Transfer, and Expulsion Studies at the NASA K-Site Facility," AIAA Paper 1991-3550, Also NASA-TM-105191, 1991.

${ }^{14}$ Mandell, D. A., \& Roudebush, W. H., "Parametric Investigation of Liquid Hydrogen Tank Pressurization During Outflow," NASA-TN-D-2797, 1965.

${ }^{15}$ Moore, R. W., Fowle, A. A., Bailey, B. M., Ruccia, F. E., \& Reid, R. C., "Gas Pressurized Transfer of Liquid Hydrogen," Advances in Cryogenic Engineering, Vol. 5, ed. Timmerhaus, K. D., Plenum Press, New York, NY, 1960, pp. 450-459.

${ }^{16}$ Stochl, R. J., \& DeWitt, R. L., "Pressurant Gas Requirements for the Pressurized Discharge of Liquid Hydrogen from Propellant Tanks," AIAA Paper 1969-526, 1969.

${ }^{17}$ Stochl, R. J., Maloy, J. E., Masters, P. A., \& DeWitt, R. L., "Gaseous-Helium Requirements for the Discharge of Liquid Hydrogen from a 1.52-Meter- (5-Ft-) Diameter Spherical Tank," NASA-TN-D-5621, 1970.

${ }^{18}$ Stochl, R. J., Maloy, J. E., Masters, P. A., \& DeWitt, R. L., "Gaseous-Helium Requirements for the Discharge of Liquid Hydrogen from a 3.96-Meter- (13-Ft-) Diameter Spherical Tank," NASA-TN-D-7019, 1970.

${ }^{19}$ Stochl, R. J., Van Dresar, N. T., \& Lacovic, R. F., “Autogenous Pressurization of Cryogenic Vessels Using Submerged Vapor Injection,” Advances in Cryogenic Engineering, Vol. 37, Part B, ed. Fast, R. W., Plenum Press, New York, NY, pp. 1273-1280; Also NASA-TM-104516, 1991.

${ }^{20}$ Van Dresar, N. T. \& Stochl, R. J., "Pressurization and Expulsion of a Flightweight Liquid Hydrogen Tank," AIAA Paper 1993-1966, Also NASA-TM-106427, 1993.

${ }^{21}$ Whalen, M. V., \& Hardy, T. L., "Slush Hydrogen Pressurized Expulsion Studies at the NASA K-Site Facility," AIAA Paper 1992-3385, Also NASA-TM-105597, 1992.

${ }^{22}$ Arnett, R. W. \& Voth, R. O., "A Computer Program for the Calculation of Thermal Stratification and SelfPressurization in a Liquid Hydrogen Tank," NASA-CR-2026, 1972.

${ }^{23}$ Baral, H. S., "Liquid Propellant Pressurization System," Journal of the Institution of Engineers, Mechanical Engineering Division, Calcutta, India, Vol. 68, No. 5, 1988, pp. 127-131.

${ }^{24}$ Bowersock, D. C., \& Reid, R. C., "An Analytical Method for Estimating Gas Requirements in the Pressurization and Transfer of Cryogenic Fluids," Advances in Cryogenic Engineering, Vol. 6, ed. Timmerhaus, K. D., Plenum Press, New York, NY, 1961, pp. 261-271.

${ }^{25}$ Cady, E. C., Flaska, T. L., \& Worrell, P. K., "In-Tank Thermodynamics of Slush Hydrogen for the National Aerospace Plane," Advances in Cryogenic Engineering, Vol. 35, Part B, ed. Fast, R. W., Plenum Press, New York, NY, 1990, pp. 1755-1766.

${ }^{26}$ Clark, J. A., "A Review of Pressurization, Stratification, and Interfacial Phenomena," International Advances in Cryogenic Engineering, Vol. 11, ed. Timmerhaus, K.D., Plenum Press, New York, NY, 1965, pp. $259-283$.

${ }^{27}$ Hasan, M. M. \& Lin, C. S., "A Numerical Study of the Direct Contact Condensation on a Horizontal Surface,” AIAA Paper 1991-1307, Also NASA-TM-102437, 1991.

${ }^{28}$ Kendle, D. W., "Ullage Mixing Effects on Tank Pressurization Performance,” AIAA Paper 1970-681, 1970.

Page 25 of 29 
${ }^{29}$ Nein, M. E., \& Thompson, J. F., "Experimental and Analytical Studies of Cryogenic Propellant Tank Pressurization," Proceedings of the Conference on Propellant Tank Pressurization and Stratification, Vol. 2, NASA Marshall Space Flight Center, Huntsville, AL, 1965, pp. 29-54.

${ }^{30}$ Roudebush, W. H., "An Analysis of the Problem of Tank Pressurization During Outflow," NASA-TN-D$2585,1965$.

${ }^{31}$ Swalley, F. E., Ward, W. D., \& Toole, L. E., "Low Gravity Fluid Behavior and Heat Transfer Results from the S-IVB-203 Flight," Proceedings of the Conference on Long Term Cryo-Propellant Storage in Space, Oct. 1213, 1966, NASA Marshall Space Flight Center, Huntsville, AL, 1966, pp. 213-232.

${ }^{32}$ Beduz, C., Rebiai, R., \& Scurlock, R. G., "Thermal Overfill, And The Surface Vaporisation of Cryogenic Liquids Under Storage Conditions," Advances in Cryogenic Engineering, Vol. 29, ed. Fast, R. W., 1984, pp. 793803.

${ }^{33}$ Gluck, D. F., \& Kline, J. F., "Gas Requirements in Pressurized Transfer of Liquid Hydrogen," Advances in Cryogenic Engineering, Vol. 7, ed. Timmerhaus, K. D., Plenum Press, New York, NY, 1962, pp. 219-233.

${ }^{34}$ Nein, M. E., \& Thompson, J. F., "Experimental and Analytical Studies of Cryogenic Propellant Tank Pressurant Requirements," NASA-TN-D-3177, 1966.

${ }^{35}$ Lemmon, E. W., Huber, M. L., \& Mc Linden, M. O., "Reference Fluid Thermodynamic and Transport Properties (REFPROP),” NIST Standard Reference Database 23, Version 8.0, April 2007.

${ }^{36}$ Al-Najem, N. M., Al-Marafie, A. M., \& Ezuddin, K. Y., "Analytical and Experimental Investigation of Thermal Stratification in Storage Tanks," International Journal of Energy Research, Vol. 17, 1993, pp. 77-88.

${ }^{37}$ Barnett, D. O., "Liquid Nitrogen Stratification Analysis and Experiments in a Partially Filled, Spherical Container," Advances in Cryogenic Engineering, Vol. 13, ed. Timmerhaus, K. D., Plenum Press, New York, NY, 1967, pp. 174-187.

${ }^{38}$ Barnett, D. O., Winstead, J. W., \& McReynolds, L. S., "An Investigation of Liquid-Hydrogen Stratification in a Large Cylindrical Tank of the Saturn Configuration," Advances in Cryogenic Engineering, Vol. 11, ed. Timmerhaus, K. D., Plenum Press, New York, NY, 1964, pp. 314-324.

${ }^{39}$ Fan, B. C., Chu, J. C., \& Scott, L. E., "Thermal Stratification in Closed Cryogenic Containers," Advances in Cryogenic Engineering, Vol. 14, ed. Timmerhaus, K. D., Plenum Press, New York, NY, 1969, pp. 249-257.

${ }^{40}$ Ghaddar, N. K., Al-Marafie, A. M., \& Al-Kandari, A., "Numerical Simulation of Stratification Behavior in Thermal Storage Tanks," Applied Energy, Vol. 32, No. 3, Applied Science Publishers, Barking, UK, 1989, pp. 225239.

${ }^{41}$ Gursu, S., Sherif, S. A., Veziroglu, T. N., \& Sheffield, J. W., "Analysis and Optimization of Thermal Stratification and Self-Pressurization Effects in Liquid Hydrogen Storage Systems - Part 1: Model Development and Part 2: Model Results and Conclusions," Journal of Energy Resources Technology, Vol. 115, No. 3, Sept. 1993, pp. 221-231.

${ }^{42}$ Kharin, V. M., Ryazhskikh, V. I., Zavadskikh, R. M., "Stratification of a Cryogenic Liquid in a Reservoir in the Case of Circulation Cooling," Journal of Engineering Physics, Vol. 60, No. 3, March 1991, Plenum Publishing Corporation, 1991, pp. 336-338.

${ }^{43}$ Liebenburg, D. H., \& Edeskuty, F. J., "Pressurization Analysis of a Large-Scale Liquid Hydrogen Dewar," International Advances in Cryogenic Engineering, Vol. 11, ed. Timmerhaus, K. D., Plenum Press, New York, NY, 1965, pp. 284-289.

${ }^{44}$ Neff, B. D., \& Chiang, C. W., "Free Convection in a Container of Cryogenic Fluid," Advances in Cryogenic Engineering, Vol. 12, ed. Timmerhaus, K. D., Plenum Press, New York, NY, 1967, pp. 112-124.

${ }^{45}$ Olsen, W. A., "Experimental and Analytical Investigation of Interfacial Heat and Mass Transfer in a Pressurized Tank Containing Liquid Hydrogen," NASA-TN-D-3219, 1966.

${ }^{46}$ Ordin, P. M., Weiss, S., \& Christenson, H., "Pressure-Temperature Histories of Liquid Hydrogen Under Pressurization and Venting Conditions," Advances in Cryogenic Engineering, Vol. 5, ed. Timmerhaus, K. D., Plenum Press, New York, NY, 1960, pp. 481-486.

${ }^{47}$ Schmidt, A. F., Purcell, J. R., Wilson, W. A., \& Smith, R. V., "An Experimental Study Concerning the Pressurization and Stratification of Liquid Hydrogen," Advances in Cryogenic Engineering, Vol. 5, ed. Timmerhaus, K. D., Plenum Press, New York, NY, 1960, pp. 487-497.

${ }^{48}$ Segel, M. F., "Experimental Study of the Phenomena of Stratification and Pressurization of Liquid Hydrogen," International Advances in Cryogenic Engineering, Vol. 11, ed. Timmerhaus, K. D., Plenum Press, New York, NY, 1965, pp. 308-313. 
${ }^{49}$ Tanyun, Z., Zhongping, H., \& Shimo Li (1996). "Numerical Simulation of Thermal Stratification in Liquid Hydrogen," Advances in Cryogenic Engineering, Vol. 41, Part A, ed. Kittel, P., Plenum Press, New York, NY, pp. 155-161.

${ }^{50}$ Atkinson, M. C. M., Beduz, C., Rebiai, R., \& Scurlock, R. G., "Heat and Evaporative Mass Transfer Correlation at the Liquid-Vapour Interface of Cryogenic Liquids," Proceedings of the $10^{\text {th }}$ Cryogenic Engineering Conference, ed. Collan, et al., Butterworth Publishing Co., Northamptonshire, UK, 1984, pp. 95-97.

${ }^{51}$ Clark, J. A., Van Wylen, G. J., \& Fenster, S. K., "Transient Phenomena Associated with the Pressurized Discharge of a Cryogenic Liquid from a Closed Vessel," Advances in Cryogenic Engineering, Vol. 5, ed. Timmerhaus, K. D., Plenum Press, New York, NY, 1960, pp. 467-480.

${ }^{52}$ Tuttle, J., DiPirro, M. J., \& Shirron, "Thermal stratification of liquid helium in the SHOOT Dewars," Cryogenics, Vol. 34, No. 5, Butterworth-Heinemann, Oxford, UK, 1994, pp. 369-374.

${ }^{53}$ Zenner, G. H., "The Storage and Handling of Cryogenic Liquids," Progress in Cryogenics, Vol. 2, ed. Mendelssohn, K., Academic Press, Inc., New York, NY, 1960.

54،Main Propellant Tank Pressurization System Study and Test Program, Vol. III, Design Handbook," Lockheed Report ER-5296, Vol. III, 1961.

${ }^{55}$ Bowersock, D. C., Gardner, R. W., \& Reid, R. C., "Pressurized Transfer of Cryogenic Liquids," Advances in Cryogenic Engineering, Vol. 4, ed. Timmerhaus, K. D., Plenum Press, New York, NY, 1960, pp. 342-356.

${ }^{56}$ Greenfield, S., "Dilution of Cryogenic Liquid Rocket Propellants During Pressurized Transfer," Proceedings of the 1957 Cryogenic Engineering Conference, ed. Timmerhaus, K. D., National Bureau of Standards, Boulder, CO, 1958, pp. 136-148.

${ }^{57}$ Epstein, M., "Prediction of Liquid Hydrogen and Oxygen Pressurant Requirements," International Advances in Cryogenic Engineering, Vol. 11, ed. Timmerhaus, K. D., Plenum Press, New York, NY, 1965, pp. 303-307.

${ }^{58}$ Bailey, W. J., Weiner, S. P., Beckman, D. H., Dennis, M. F., \& Martin, T. A., "Cryogenic On-Orbit Liquid Depot Storage, Acquisition and Transfer Satellite (COLD-SAT),” NASA-CR-185247, 1990.

${ }^{59}$ Bailey, W. J. \& Arif, H., "Cryogenic Fluid Management Investigations Using the CONE Flight Experiment," Cryogenics, Vol. 32, No. 2, 1992, pp. 220-229.

${ }^{60}$ Blatt, M. H., "Empirical Correlations for Pressure Rise in Closed Cryogenic Containers," Journal of Spacecraft and Rockets, Vol. 5, No. 6, 1968, pp. 733-735.

${ }^{61}$ Denisov, K. P., Lukovskij, A. P., Ledneva, L. P., Chuherov, A. I., Federov, V. I., "Experimental Study of the Effect of Gas Injection Velocity on Heat and Mass Transfer in the Gas Volume of a Tank," Aviatsionnaia Tekhnika, No. 1, 1981, pp. 84-86.

${ }^{62}$ Humphrey, J. C., "Pressurized Transfer of Cryogenic Fluids from Tanks in Liquid Nitrogen Baths," Advances in Cryogenic Engineering, Vol. 6, ed. Timmerhaus, K. D., Plenum Press, New York, NY, 1961, pp. $281-292$.

${ }^{63}$ Kamat, D. V., \& Abraham, W. H., "Pressure Collapse in Oxygen Storage under Zero-g," Journal of Spacecraft and Rockets, Vol. 5, No. 2, February 1968, pp. 184-188.

${ }^{64}$ Rotenburg, Y., "Numerical Simulation of Self Pressurization in a Small Cryogenic Tank," Advances in Cryogenic Engineering, Vol. 31, ed. Fast, R. W., Plenum Press, New York, NY, 1986, pp. 963-971.

${ }^{65}$ Van Dresar, N. T., Lin, C. S., \& Hasan, M. M., "Self-Pressurization of a Flightweight Liquid Hydrogen Tank: Effects of Fill Level at Low Wall Heat Flux," AIAA Paper 1992-0818, Also NASA-TM-105411, 1992.

${ }^{66}$ Van Dresar, N. T., \& Haberbusch, M. S., "Thermodynamic Models for Bounding Pressurant Mass Requirements of Cryogenic Tanks," Advances in Cryogenic Engineering, Vol. 39, Part B, ed. Kittel, P., Plenum Press, New York, NY, 1994, pp. 1907-1914.

${ }^{67}$ Smith, I. E., "Cryogenic Rocket Propellants," Progress in Cryogenics, Vol. 3, ed. Mendelssohn, K., Academic Press, New York, NY, 1961.

${ }^{68}$ Aydelott, J. C., "Modeling of Space Vehicle Propellant Mixing," NASA-TP-2107, 1983.

${ }^{69}$ Bentz, M. D., Meserole, J. S., \& Knoll, R. H., "Tank Pressure Control Experiment - A Low-G Mixing Investigation,” AIAA Paper 1990-2376, 1990.

${ }^{70}$ Bentz, M. D., Meserole, J. S., \& Knoll, R. H., "Jet Mixing in Low Gravity - Results of the Tank Pressure Control Experiment," AIAA Paper 1992-3060, 1992.

${ }^{71}$ Bentz, M. D. (1993). “Tank Pressure Control in Low Gravity by Jet Mixing,” NASA-CR-191012.

${ }^{72}$ Chato, D.J., "Ground Testing on the Nonvented Fill Method of Orbital Propellant Transfer: Results of Initial Test Series," AIAA Paper 1991-2326, 1991.

${ }^{73}$ Chato, D. J., "Ground Testing for the No-Vent Fill of Cryogenic Tanks: Results of Tests for a 71 Cubic Foot Tank,” AIAA Paper 1993-1967, 1993. 
${ }^{74}$ Meserole, J. S., Jones, O. S., \& Fortini, A., "Mixing-Induced Fluid Destratification and Ullage Condensation," NASA Lewis Research Center Microgravity Fluid Management Symposium Proceedings, April 1, 1987, pp. 101-117.

${ }^{75}$ Moran, M. E., Nyland, T. W., \& Driscoll, S. L., "Hydrogen No-Vent Fill Testing in a 34 Liter (1.2 Cubic Foot) Tank," Advances in Cryogenic Engineering, Vol. 37, Part B, ed. Fast, R. W., Plenum Press, New York, NY, 1991, pp. 1257-1264.

${ }^{76}$ Reaser, W. W., Wilson, E. L., \& Smith, D. A., "Design of Cryogenic Fluid Systems in the S-IV Stage Propulsion System," Annals of Reliability and Maintainability, Fourth Annual Reliability and Maintainability Conference, 1965, pp. 367-374.

${ }^{77}$ Schmidt, G. R., Carrigan, R. W., Hahs, J. E., Vaughan, D. A., \& Foust, D. C., "No-Vent Fill Pressurization Tests Using a Cryogen Simulant," NASA-TM-103561, 1991.

${ }^{78}$ Vaughan, D. A., Foust, D. C., \& Schmidt, G. R., "Enhancement of the No-Vent Fill Process," AIAA Paper 1991-1842, 1991.

${ }^{79}$ Hodge, B. K., \& Koenig, K., “A PC-Based Collapse Factor Analysis for High Pressure Cryogenic Systems,” dated July 1992, NASA Stennis Space Center Contract NAS13-330 Order No. 30., 1992 (shorter version with same title is also presented in AIAA Paper 1992-3683)

${ }^{80}$ Ludwig, K. A., \& Houghton, P. A. "Collapse Factor Analysis Final Report," Air Products and Chemicals, Inc. Report to NASA Stennis Space Center for CTF Project, June 20, 1989.

${ }^{81}$ Vance, R. W., \& Duke, W. M., Applied Cryogenic Engineering, John Wiley \& Sons, New York, NY, 1962.

${ }^{82}$ Van Dresar, N. T., "Prediction of Pressurant Mass Requirements for Axisymmetric Liquid Hydrogen Tanks," AIAA Paper 1995-2964, Also NASA-TM-106973, 1995.

${ }^{83}$ Thompson, J. F., \& Nein, M. E., "Prediction of Propellant Tank Pressurization Requirements by Dimensional Analysis," NASA-TM-X-53218, 1965.

${ }^{84}$ Van Dresar, N. T. \& Stochl, R. J., "Pressurization and Expulsion of Cryogenic Liquids: Generic Requirements for a Low-Gravity Experiment," NASA-TM-104417, 1991.

${ }^{85}$ Wapato, P. G., Keeley, A. W., Jew, L. N., and Young, C. F., "Study of External Pressurization Systems for Cryogenic Storage Systems," NASA-CR-115205, 1971.

${ }^{86}$ Riemer, D. H., \& Scarlotti, R., "Supercritical Hydrogen Expulsion Utilizing an External Pressurization System," Advances in Cryogenic Engineering, Vol. 29, ed. Fast, R. W., Plenum Press, New York, NY, 1984 , pp. 741-747.

${ }^{87}$ Incropera, F. P., \& DeWitt, D. P., Introduction to Heat Transfer, $2^{\text {nd }}$ Edition, John Wiley \& Sons, New York, NY, 1990.

88،Main Propellant Tank Pressurization System Study and Test Program, Vol. IV, Computer Program," Lockheed Report ER-5296, Vol. IV, 1961.

${ }^{89}$ Anderson, J. E., Scott, O. L., \& Brady, H. F., "Advanced Pressurization Systems for Cryogenic Propellants," NASA-CR-54467, 1967.

${ }^{90}$ Majumdar, A., \& Steadman, T., "Numerical Modeling of Pressurization of a Propellant Tank," Draft Paper for the $37^{\text {th }}$ AIAA Aerospace Sciences Meeting, 1998.

${ }^{91}$ Momenthy, A. M., "Propellant Tank Pressurization-System Analysis," Advances in Cryogenic Engineering, Vol. 9, ed. Timmerhaus, K. D., Plenum Press, New York, NY, 1964, pp. 273-283.

${ }^{92}$ Ring, E., Rocket Propellant and Pressurization Systems, Prentice-Hall, Englewood Cliffs, NJ, 1964.

${ }^{93}$ Lin, C. S., \& Hasan, M. M., "Self-Pressurization of a Spherical Liquid Hydrogen Storage Tank in a Microgravity Environment,” AIAA Paper 1992-0363, Also NASA-TM-105372, 1992.

94"FORTRAN Program for the Analysis of a Single Propellant Tank Pressurization System," Rocketdyne Report R-3936-1. Also NASA-CR-53305, 1963.

${ }^{95}$ Epstein, M., Georgius, H. K., \& Anderson, R. E., “A Generalized Propellant Tank-Pressurization Analysis,” International Advances in Cryogenic Engineering, Vol. 11, ed. Timmerhaus, K. D., Plenum Press, New York, NY, 1965, pp. 290-302.

${ }^{96}$ Masters, P. A., "Computer Programs for Pressurization (Ramp) and Pressurized Expulsion from a Cryogenic Liquid Propellant Tank," NASA-TN-D-7504, 1974.

${ }^{97}$ Chen, I. M. \& Anderson, R. E., "A Thermal Stratification Model of a Cryogenic Tank at Supercritical Pressures," Advances in Cryogenic Engineering, Vol. 17, ed. Timmerhaus, K. D., Plenum Press, New York, NY, 1972, pp. 475-486.

${ }^{98}$ Ede, A. J., "Advances in Free Convection,” Advances in Heat Transfer, Vol. 4, eds. Irvine, T. F., \& Hartnett, J. P., Academic Press, New York, NY, 1967, pp. 1-47. 
${ }^{99}$ Gebhart, B., "Natural Convection Flows and Stability," Advances in Heat Transfer, Vol. 9, eds. Irvine, T. F., \& Hartnett, J. P., Academic Press, New York, NY, 1973, pp. 273-297.

${ }^{100}$ Ostrach, S., "Natural Convection in Enclosures," Advances in Heat Transfer, Vol. 8, eds. Hartnett, J. P. \& Irvine, T. F., Academic Press, Inc., New York, NY, 1972, pp. 161-227.

${ }^{101}$ Polyakov, A. F., "Heat Transfer under Supercritical Pressures," Advances in Heat Transfer, Vol. 21, eds. Hartnett, J. P., Irvine, T. F., Cho, Y. I., Academic Press, New York, NY, 1991.

${ }^{102}$ Raithby, G. D., \& Hollands, K. G. T., "A General Method of Obtaining Approximate Solutions to Laminar and Turbulent Free Convection Problems," Advances in Heat Transfer, Vol. 11, eds. Irvine, T. F. \& Hartnett, J. P., Academic Press, New York, NY, 1975, pp.265-315.

${ }^{103}$ Wulff, W., \& Schipma, P., "Design Guide for Pressurized Gas Systems; Task 7," ITT Research Institute Report No, ITTRI-C6070-20, 1967. 


\section{A HISTORY OF COLLAPSE FACTOR MODELING AND EMPIRICAL DATA FOR CRYOGENIC PROPELLANT TANKS}

Authors: Laurence de Quay, Ph.D., P.E., NASA Stennis Space Center B. Keith Hodge, Ph.D., P.E., Mississippi State University 
The contents of this presentation are based on portions of a Ph.D. dissertation by the principal author, Laurence de Quay, while a student at Mississippi State University 
The purpose of this paper is to present a summary and selected details of prior literature that document the ullage and pressurant gas collapse phenomenon, collapse factor, associated with cryogenic propellant tanks. Additionally, other literature that present studies and results of heat and mass transfer processes, related to or providing important insights or analytical methods for the studies of collapse factor, are presented. 
Background: Liquid Propellant Rocket Propulsion System; GG Cycle, Single Turbine

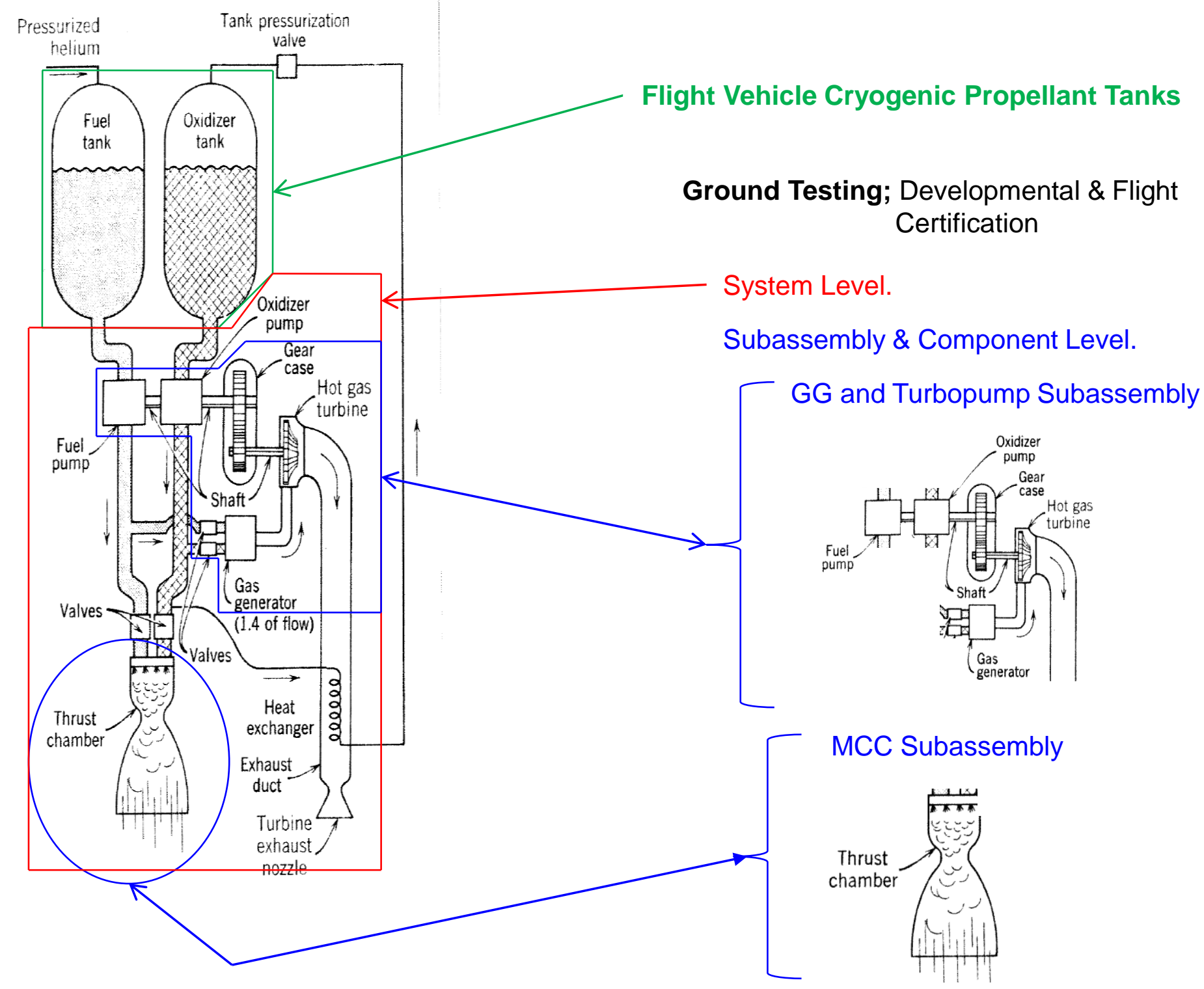




\section{Background: Ground Test Facility Run System (Simplified) Schematic}

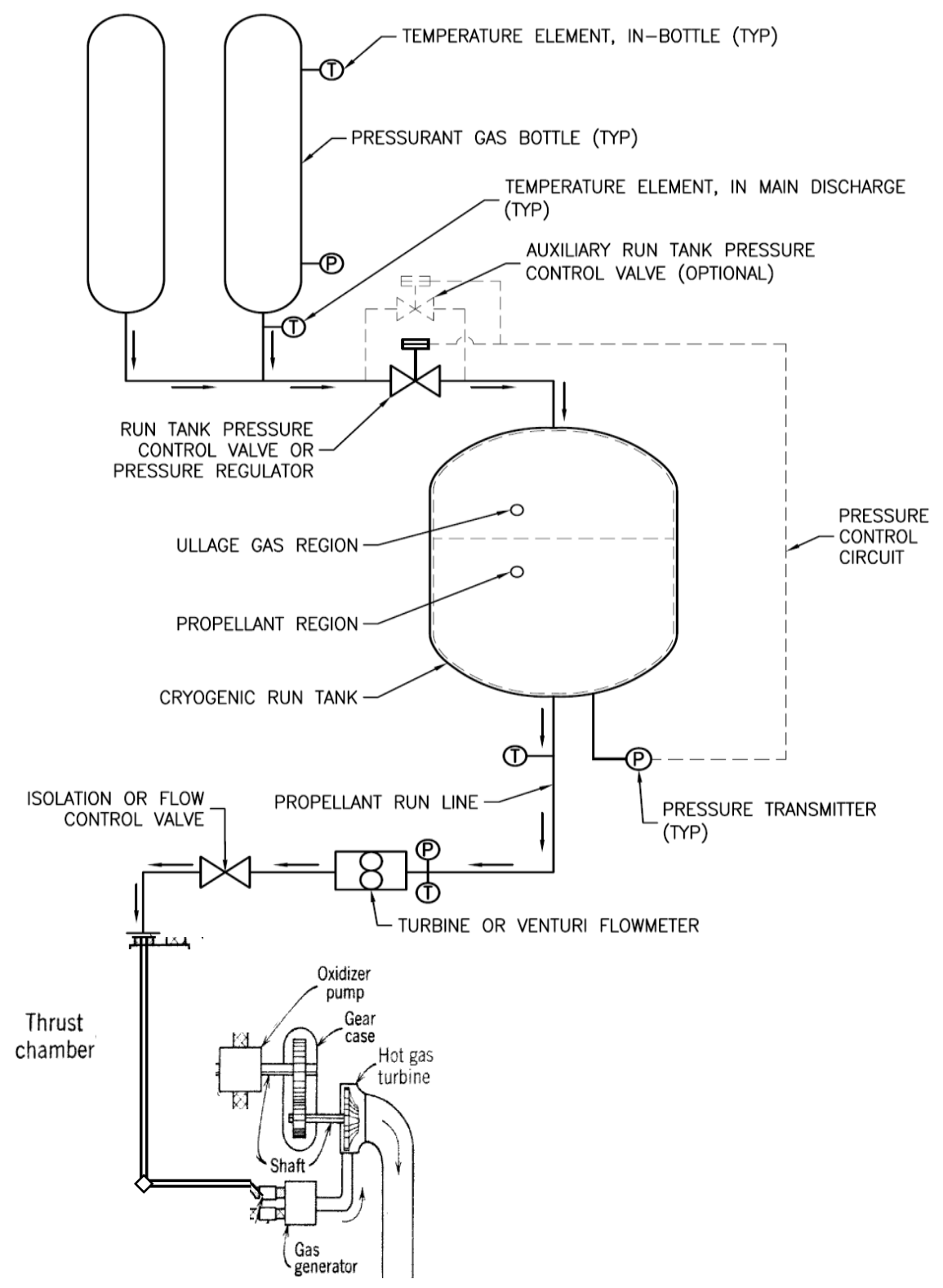




\section{The Cryogenic Propellant Tank}

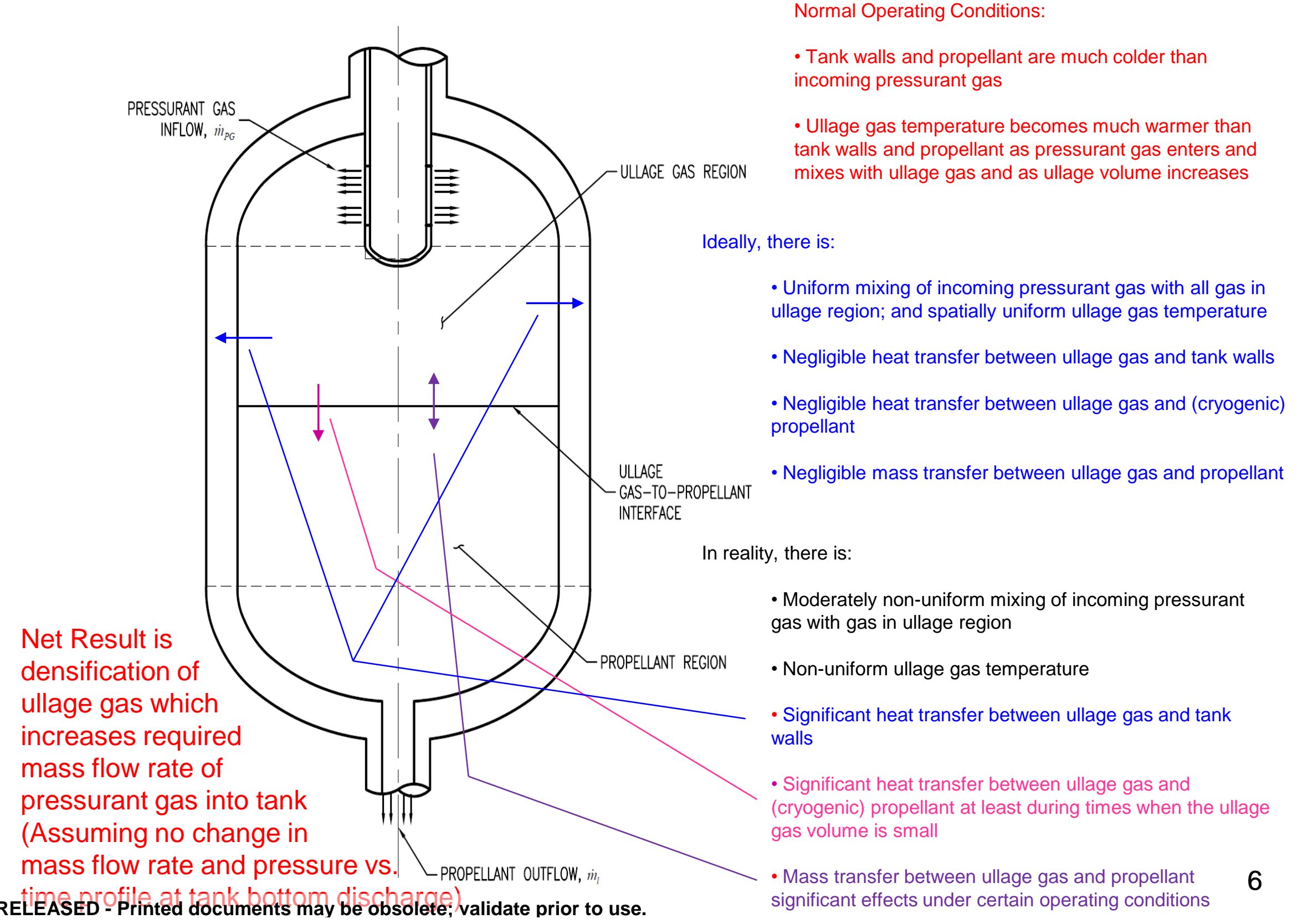




\section{Collapse Factor Defined:}

- Instantaneous

Collapse Factor: Actual Mass Flow Rate Divided by Ideal Mass Flow Rate of Pressurant Gas into Tank Ullage at a Particular Time

- Cumulative Collapse Factor: Actual Total Mass Divided by Ideal Total Mass of Pressurant Gas Transferred into Tank Ullage 


\begin{tabular}{|c|c|c|c|c|c|c|c|c|c|c|c|c|}
\hline \multirow[b]{2}{*}{$\begin{array}{c}\text { Reference } \\
\text { Citation }\end{array}$} & \multirow[b]{2}{*}{$\begin{array}{c}\text { Test } \\
\text { Run \# }\end{array}$} & \multirow{2}{*}{$\begin{array}{c}\text { Tank } \\
\text { Volume } \\
\text { (gallons) }\end{array}$} & \multirow[b]{2}{*}{ Tank Shape } & \multirow[b]{2}{*}{ Prop. } & \multicolumn{4}{|c|}{ Propellant Expulsion } & \multicolumn{2}{|c|}{ Pressurant Gas } & \multirow[b]{2}{*}{ Notes } & \multirow[b]{2}{*}{$\begin{array}{c}\text { Empirical } \\
\text { Collapse Facto }\end{array}$} \\
\hline & & & & & $\begin{array}{c}\text { Mass Flow } \\
\text { Rate (lb/sec) }\end{array}$ & $\begin{array}{c}\text { Vol. Flow Rate } \\
\text { (gpm) }\end{array}$ & $\begin{array}{l}\text { Time } \\
(\mathrm{sec})\end{array}$ & $\begin{array}{c}\text { Tank Press. } \\
\text { (psia) }\end{array}$ & Species & $\begin{array}{c}\text { Inlet Temp. } \\
\text { (deg R) }\end{array}$ & & \\
\hline 2 & None & 25 & Cylindrical & $\mathrm{LN}$ & $10.0-14.0$ & $88.9-124.3$ & 16 & $172.3-300.4$ & $\mathrm{He}$ & $523-530$ & (1) & 1.540 \\
\hline 2 & None & 25 & Cylindrical & LN & $10.0-14.0$ & $88.9-124.3$ & 16 & $155.2-321.6$ & Steam $/ \mathrm{He}$ & $1938-2029$ & $(1),(2)$ & 1.510 \\
\hline 3 & 0027A & 2603 & Sphere & LOX & $340-382$ & $2066-2338$ & 47 & $4400-5550$ & GN & $579-521$ & (3) & $1.061 \pm 0.060$ \\
\hline 3 & 0029B & 2603 & Sphere & LOX & $462-478$ & $2768-2873$ & 15.2 & $7600-8200$ & GN & $579-531$ & (4) & $1.054+0.054$ \\
\hline 4 & 36 & 489.5 & Sphere & $\mathrm{LCH}_{4}$ & 3.62 & 61.5 & 389.2 & 49.3 & $\mathrm{He}$ & 407 & & 1.769 \\
\hline 4 & 41 & 489.5 & Sphere & $\mathrm{LCH}_{4}$ & 3.625 & 61.5 & 390.3 & 49.5 & $\mathrm{He}$ & 407 & & 2.431 \\
\hline 4 & 40 & 489.5 & Sphere & $\mathrm{LCH}_{4}$ & 2.332 & 39.5 & 5985 & 49.5 & $\mathrm{He}$ & 596 & & 2.423 \\
\hline 4 & 6 & 489.5 & Sphere & $\mathrm{LCH}_{4}$ & 2.244 & 38.1 & 632.8 & 49.5 & $\mathrm{GCH}_{4}$ & 407 & & 2.352 \\
\hline 4 & 11 & 489.5 & Sphere & $\mathrm{LCH}_{4}$ & 6.137 & 104.6 & 233.5 & 49.2 & $\mathrm{GCH}_{4}$ & 608 & & 2.550 \\
\hline 4 & 99 & 489.5 & Sphere & $\mathrm{LCH}_{4}$ & 3.823 & 65.1 & 377.7 & 49.5 & GN & 603 & (5) & 5.247 \\
\hline 5 & $\begin{array}{c}\text { See } \\
\text { Notes }\end{array}$ & 11220 & Oblate Spheroid & LOX & 201.2 & 1267.4 & 478 & $\sim 46$ & $\mathrm{He}$ & 325 & (10) & 1.375 \\
\hline 5 & $\begin{array}{c}\text { See } \\
\text { Notes }\end{array}$ & 94996 & Oblate Spheroid & LOX & $2230-2256$ & 14047 - 14227 & 360 & $36-37.5$ & GOX & 510 & (11) & $1.325-1.500$ \\
\hline 6 & $12 \mathrm{~B}$ & 2596 & Oblate Spheroid & LOX & 57.7 & 363.5 & 47 & 34 & $\mathrm{He}$ & 520 & & 2.432 \\
\hline 6 & $13 \mathrm{~A}$ & 2596 & Oblate Spheroid & LOX & 57.7 & 363.5 & 120 & 34 & $\mathrm{He}$ & 527 & & 2.605 \\
\hline 6 & 10 & 2596 & Oblate Spheroid & LOX & 57.7 & 363.5 & 415 & 34 & $\mathrm{He}$ & 255 & & 1.304 \\
\hline 6 & $14 \mathrm{~A}$ & 2596 & Oblate Spheroid & LOX & 57.7 & 363.5 & 242 & 40 & $\mathrm{He}$ & 525 & & 1.961 \\
\hline 7 & $?$ & 59892 & Multi-Cylinder & LOX & $3767-3769$ & 23740 & 114.5 & $60-80$ & GOX/GN & $840-600$ & $(6),(7),(8)$ & $\sim 1.700$ \\
\hline 7 & $?$ & 10098 & Cylindrical & LOX & 1261 & 7943 & 70 & $68-76$ & GOX/GN & $602-641$ & $(7),(8)$ & $\sim 1.650$ \\
\hline 7 & $?$ & 16.5 & Cylindrical & $\mathrm{LN}$ & 0.924 & 8.21 & 120 & 50 & GN & 530 & (7) & $\sim 2.110$ \\
\hline 8 & 74 & 5000 & Cylindrical & $\mathrm{LN}$ & 30. -525. & 267. -4729. & 38 & 335. - 359. & $\mathrm{GN}$ & $506-447$ & & $2.35,1.39$ \\
\hline 8 & 74 & 900 & Sphere & LOX & 10.2 & 61.5 & 26 & $8200-8300$ & GN & $548-544$ & (9) & $4.1-1.57$ \\
\hline
\end{tabular}

Notes: (1) Assumed near constant ullage gas temperature and no GN in ullage for expulsion

(2) Tank pre-pressurized with helium prior to expulsion with steam as pressurant gas

(3) Time includes $\sim 3 \mathrm{sec}$. main ramp up in propellant expulsion mass flow rate and tank pressure; indicated tank pressure and flow rates do not inlcude this ramp up

(4) Time includes $\sim 5 \mathrm{sec}$. main ramp up in propellant expulsion mass flow rate and tank pressure; indicated tank pressure and flow rates do not include this ramp up

(5) Data shows $69.3 \%$ of added $\mathrm{GN}$ pressurant gas dissolved into upper layer of $\mathrm{LCH}_{4}$ propellant

(6) Multiple tanks with 4-each 70-inch diameter tanks connected to one-each central 105-inch diameter tank

(7) Collapse factors approximated using energy allocations for ullage gas; insufficient data for more exact computations

$=$ Maximum Values

(8) Tank pre-pressurized with GN prior to using GOX for propellant expulsion

(9) Only last 26-seconds of 38-second run has reliable data

$=$ High Subcritical \& Other Supercritical Pressures

(10) Propellant explusion flowrate based on assumed $10 \%$ initial ullage and complete emptying of propellant from tank; test run is from unpublished document cited in Ref. 5

(11) Tank pressure and LOX expulsion rate obtained from Ref. 9 using average summations of LOX flow rate to 5 -each J-2 engines on S-II stage; test run is from unpublished document

cited in Ref. 5 
Table 2 Selected Empirical Collapse Factor Data for Hydrogen Propellant Tanks (Continued on Next Page)

\begin{tabular}{|c|c|c|c|c|c|c|c|c|c|c|c|c|}
\hline \multirow[b]{2}{*}{$\begin{array}{c}\text { Reference } \\
\text { Citation }\end{array}$} & \multirow[b]{2}{*}{$\begin{array}{c}\text { Test } \\
\text { Run\# }\end{array}$} & \multirow[b]{2}{*}{$\begin{array}{l}\text { Tank Volume } \\
\text { (gallons) }\end{array}$} & \multirow[b]{2}{*}{ Tank Shape } & \multirow[b]{2}{*}{ Prop. } & \multicolumn{4}{|c|}{ Propellant Expulsion } & \multicolumn{2}{|c|}{ Pressurant Gas } & \multirow[b]{2}{*}{ Notes } & \multirow[b]{2}{*}{$\begin{array}{l}\text { Empirical Collapse } \\
\text { Factor }\end{array}$} \\
\hline & & & & & $\begin{array}{c}\text { Mass Flow } \\
\text { Rate (Ib/sec) }\end{array}$ & $\begin{array}{l}\text { Vol. Flow Rate } \\
\text { (gpm) }\end{array}$ & $\begin{array}{l}\text { Time } \\
(\mathrm{sec})\end{array}$ & $\begin{array}{c}\text { Tank Press. } \\
\text { (psia) }\end{array}$ & Species & $\begin{array}{l}\text { Inlet Temp. } \\
\text { (deg R) }\end{array}$ & & \\
\hline 3 & $004 \mathrm{~A}$ & 5002.5 & Sphere & LH & $78-108$ & $6100-8560$ & 34 & $7450-8200$ & GH & $619-549$ & (1) & $1.047 \pm 0.037$ \\
\hline 5 & See Notes & 49.472 & Sphere & $\mathrm{LH}$ & 60.84 & 6140.5 & 296 & 91.7 & GH & 530 & $(16)$ & 1.64 \\
\hline 5 & See Notes & 246,840 & Multi-Cylinder & $\mathrm{LH}$ & $391.4-394.1$ & $39696-39970$ & 360 & $28.5-30.0$ & GH & 200 & $(7),(16)$ & $1.15-1.25$ \\
\hline 10 & B-1 & 12 & Cylindrical & $\mathrm{LH}$ & Not Given & Not Given & 62.4 & 39.25 & $\mathrm{GH} / \mathrm{He}$ & 330 & (2) & 3.42 \\
\hline 10 & B-2 & 12 & Cylindrical & $\mathrm{LH}$ & Not Given & Not Given & 62.4 & 39.25 & $\mathrm{GH} / \mathrm{He}$ & 265 & (2) & 2.16 \\
\hline 10 & B-1 & 12 & Cylindrical & $\mathrm{LH}$ & No Expulsion & $\mathrm{N} / \mathrm{A}$ & $\mathrm{N} / \mathrm{A}$ & $14.7-44.25$ & $\mathrm{GH}$ & 505 & & 4.45 \\
\hline 10 & B-1 & 12 & Cylindrical & $\mathrm{LH}$ & No Expulsion & $\mathrm{N} / \mathrm{A}$ & $\mathrm{N} / \mathrm{A}$ & $14.7-61.75$ & $\mathrm{GH}$ & 295 & & 3.26 \\
\hline 10 & 2 & 500 & Cylindrical & $\mathrm{LH}$ & 2.561 & 259.4 & 100 & 45.5 & $\mathrm{GH}$ & 320 & $(3),(4)$ & 2.23 \\
\hline 10 & 5 & 500 & Cylindrical & $\mathrm{LH}$ & 2.031 & 205.7 & 99 & 45.5 & $\mathrm{He}$ & 300 & $(3),(4)$ & 1.72 \\
\hline 10 & 7 & 500 & Cylindrical & $\mathrm{LH}$ & 2.031 & 205.7 & 105 & 49.3 & GH & 300 & $(3),(5)$ & 1.74 \\
\hline 10 & 10 & 500 & Cylindrical & $\mathrm{LH}$ & 1.833 & 185.7 & 111 & 45 & $\mathrm{GH}$ & 300 & (3) & 1.74 \\
\hline 11 & 3 & $\sim 370$ & Cylindrical & $\mathrm{LH}$ & 0.939 & 95.1 & 197 & 44.1 & $\mathrm{He}$ & 450 & (6) & $0.878 ; 0.997$ \\
\hline 11 & 6 & $\sim 370$ & Cylindrical & $\mathrm{LH}$ & 0.47 & 47.6 & 351 & 44.1 & $\mathrm{He}$ & 450 & (6) & $0.908 ; 1.033$ \\
\hline 11 & 9 & $\sim 370$ & Cylindrical & LH & 0.624 & 63.3 & 352 & 29.4 & $\mathrm{He}$ & 450 & (6) & $1.043 ; 1.187$ \\
\hline 11 & 10 & $\sim \sim 370$ & Cylindrical & $\mathrm{LH}$ & 0.939 & 95.1 & 211 & 44.1 & $\mathrm{He}$ & 180 & (6) & $0.48 ; 0.527$ \\
\hline 11 & 11 & $\sim 370$ & Cylindrical & $\mathrm{LH}$ & 0.939 & 95.1 & 214 & 44.1 & GH & 180 & (6) & $1.267 ; 1.277$ \\
\hline 12 & 1 & 500 & Cylindrical & $\mathrm{LH}$ & 2.995 & 303.4 & 89 & 45.5 & GH & 300 & $(4),(17)$ & 1.56 \\
\hline 12 & 2 & 500 & Cylindrical & $\mathrm{LH}$ & 2.388 & 262.1 & 103 & 47.6 & $\mathrm{GH}$ & 520 & $(4),(17)$ & 2.23 \\
\hline 12 & 3 & 500 & Cylindrical & $\mathrm{LH}$ & 2.22 & 224.8 & 120 & 46.5 & $\mathrm{GH}$ & 300 & $(4),(17)$ & 1.8 \\
\hline 12 & 5 & 500 & Cylindrical & $\mathrm{LH}$ & 2.694 & 272.90 & 99 & 45.5 & $\mathrm{He}$ & 300 & $(4),(17)$ & 1.72 \\
\hline 13 & $?$ & 461.5 & Sphere & , - Slㅂ﹎ _ & 1.478 & 131 & 190 & 50 & $\mathrm{GH}$ & 520 & (8) & 2568 \\
\hline 13 & $?$ & 461.5 & Sphere & SLH I & 0.552 & 48.9 & 510 & 25 & $\mathrm{GH}$ & 620 & (8) & 10.34 \\
\hline 13 & $?$ & 461.5 & Sphere & $\mathrm{SLH}$ & 0.668 & 59.2 & 420 & 50 & $\mathrm{GH}$ & 620 & (8) & 5.973 \\
\hline 14 & 2 of Ref. 33 & 210 & Cylindrical & $\overline{\mathrm{LH}}^{-}$ & $1 . \overline{0} 6 \overline{2}$ & $10 \overline{6} .6$ & $\overline{9} \overline{-}$ & 161 & $\overline{\mathrm{G}} \overline{\mathrm{H}}$ & $\overline{210^{-}}$ & & 2.12 \\
\hline 14 & 3 of Ref. 33 & 210 & Cylindrical & $\mathrm{LH}$ & 0.346 & 35 & 284 & 57 & $\mathrm{GH}$ & 170 & & 3.88 \\
\hline 14 & 8 of Ref. 33 & 210 & Cylindrical & $\mathrm{LH}$ & 1.161 & 116.6 & 90 & 159 & $\mathrm{He}$ & 161 & & 2.14 \\
\hline 14 & 10 of Ref. 33 & 210 & Cylindrical & $\mathrm{LH}$ & 0.311 & 31.6 & 309 & 40 & $\mathrm{He}$ & 148 & & 5.1 \\
\hline 15 & $4-11$ & 600 & Horizontal Cyl & $\mathrm{LH}$ & 0.56 & 57 & 420 & 27.5 & GH & $480-549$ & (9) & $1.2-1.25$ \\
\hline 15 & 3 & 600 & Horizontal Cyl & $\mathrm{LH}$ & 0.31 & 31 & 1220 & 35 & $\mathrm{GH}$ & $480-549$ & (9) & 4.32 \\
\hline 15 & 7 & 600 & Horizontal Cyl & LH & 1.56 & 157 & 340 & 115 & $\mathrm{GH}$ & $480-549$ & (9) & 1.67 \\
\hline 15 & 9 & 600 & Horizontal Cyl & $\mathrm{LH}$ & 2.48 & 250 & 560 & 115 & $\mathrm{GH}$ & $480-549$ & (9) & 2.20 \\
\hline 15 & 5 & 600 & Horizontal Cyl & $\mathrm{LH}$ & 2.53 & 256 & 450 & 65 & $\mathrm{GH}$ & $480-549$ & (9) & 2.52 \\
\hline 15 & 6 & 600 & Horizontal Cyl & $\mathrm{LH}$ & 0.84 & 85 & 410 & 65 & $\mathrm{GH}$ & $480-549$ & (9) & 1.80 \\
\hline 16 & & 489 & Sphere & $\mathrm{LH}$ & 2 & 202 & 130 & 50 & GH & 500 & & $\sim 2.38$ \\
\hline 16 & & 489 & Sphere & LH & 0.5 & 50.6 & 522 & 50 & GH & 500 & & $\sim 3.33$ \\
\hline 16 & & 8604 & Sphere & $\mathrm{LH}$ & 10.3 & 1043 & 446 & 50 & $\mathrm{GH}$ & 500 & & $\sim 2.29$ \\
\hline 16 & & 8604 & Sphere & $\mathrm{LH}$ & 4.33 & 438 & 1060 & 50 & GH & 500 & & $\sim 2.86$ \\
\hline 16 & & 489 & Sphere & $\mathrm{LH}$ & 1.89 & 191 & 138 & 50 & $\mathrm{GH}$ & 540 & & $\sim 2.76$ \\
\hline 16 & & 8604 & Sphere & $\mathrm{LH}$ & 10 & 1012 & 459 & 50 & $\mathrm{GH}$ & 600 & & $\sim 2.33$ \\
\hline 17 & 7 & 489 & Sphere & $\mathrm{LH}$ & 0.65 & 65.9 & 453.4 & 50 & GH & $481-517$ & (10) & $\sim 2.86$ \\
\hline 17 & 10 & 489 & Sphere & $\mathrm{LH}$ & 1.86 & 187.9 & 193.2 & 50 & $\mathrm{GH}$ & $481-517$ & (10) & $\sim 2.53$ \\
\hline
\end{tabular}


Table 2 Selected Empirical Collapse Factor Data for Hydrogen Propellant Tanks (Continuation from Previous Page)

\begin{tabular}{|c|c|c|c|c|c|c|c|c|c|c|c|c|}
\hline \multirow[b]{2}{*}{$\begin{array}{l}\text { Reference } \\
\text { Citation }\end{array}$} & \multirow[b]{2}{*}{$\begin{array}{c}\text { Test } \\
\text { Run \# }\end{array}$} & \multirow[b]{2}{*}{$\begin{array}{c}\text { Tank Volume } \\
\text { (gallons) }\end{array}$} & \multirow[b]{2}{*}{ Tank Shape } & \multirow[b]{2}{*}{ Prop. } & \multicolumn{4}{|c|}{ Propellant Expulsion } & \multicolumn{2}{|c|}{ Pressurant Gas } & \multirow[b]{2}{*}{ Notes } & \multirow[b]{2}{*}{$\begin{array}{l}\text { Empirical Collapse } \\
\text { Factor }\end{array}$} \\
\hline & & & & & $\begin{array}{c}\text { Mass Flow } \\
\text { Rate (lb/sec) }\end{array}$ & $\begin{array}{l}\text { Vol. Flow Rate } \\
\text { (gpm) }\end{array}$ & $\begin{array}{l}\text { Time } \\
\text { (sec) }\end{array}$ & $\begin{array}{c}\text { Tank Press. } \\
\text { (psia) }\end{array}$ & Species & $\begin{array}{l}\text { Inlet Temp. } \\
\text { (deg R) }\end{array}$ & & \\
\hline 17 & 12 & 489 & Sphere & LH & 0.77 & 77.5 & 393.2 & 50 & $\mathrm{GH}$ & $481-517$ & (10) & $\sim 3.03$ \\
\hline 17 & 14 & 489 & Sphere & LH & 0.92 & 92.9 & 337 & 50 & $\mathrm{GH}$ & $481-517$ & (10) & $\sim 2.94$ \\
\hline 17 & 15 & 489 & Sphere & $\mathrm{LH}$ & 1.32 & 133.9 & 249.7 & 50 & $\mathrm{GH}$ & $481-517$ & (10) & $\sim 2.70$ \\
\hline 17 & 83 & 489 & Sphere & $\mathrm{LH}$ & 0.67 & 67.5 & 428.8 & 50 & $\mathrm{GH}$ & $481-517$ & (10) & $\sim 3.20$ \\
\hline 17 & 84 & 489 & Sphere & LH & 0.98 & 98.8 & 307.6 & 50 & GH & $481-517$ & (10) & $\sim 2.73$ \\
\hline 17 & 85 & 489 & Sphere & LH & 1.91 & 193 & 174.4 & 50 & $\mathrm{GH}$ & $481-517$ & (10) & $\sim 2.58$ \\
\hline 18 & 4 & 8604 & Sphere & LH & 9.60 & 972 & 531.6 & 50 & GH & 302 & (10) & 1.85 \\
\hline 18 & 7 & 8604 & Sphere & $\mathrm{LH}$ & 4.28 & 433 & 1119.3 & 50 & $\mathrm{GH}$ & 302 & (10) & 2.07 \\
\hline 18 & 8 & 8604 & Sphere & LH & 4.66 & 472 & 1037.2 & 50 & GH & 303 & (9), (10) & 2.07 \\
\hline 18 & 15 & 8604 & Sphere & LH & 10.07 & 1019 & 509.3 & 50 & $\mathrm{GH}$ & 540 & (10) & 260 \\
\hline 19 & 5 & 1291 & Oblate Spheroid & LH & $0.60-0.65$ & 66.3 & 2160 & 54.6 & GH & 491 & $(11),(15)$ & 5.222 \\
\hline 19 & $5 \mathrm{R}$ & 1291 & Oblate Spheroid & $\mathrm{LH}$ & $0.38-0.40$ & 66.3 & 1680 & 54.7 & $\mathrm{GH}$ & 491 & $(12),(13)$ & 5.333 \\
\hline 19 & 6 & 1291 & Oblate Spheroid & LH & $0.60-0.65$ & 40.8 & 2280 & 54.9 & GH & 491 & $(13),(15)$ & 5.0 \\
\hline 19 & 9 & 1291 & Oblate Spheroid & $\mathrm{LH}$ & $0.60-0.65$ & 66.3 & 1620 & 55.0 & $\mathrm{GH}$ & 594 & $(14(,(15)$ & 4.933 \\
\hline 20 & 506 & 1291 & Oblate Spheroid & $\mathrm{LH}$ & $\sim 0.83$ & 83.6 & 760 & 33.9 & $\mathrm{GH}$ & 529 & & 2.46 \\
\hline 20 & 507 & 1291 & Oblate Spheroid & $\mathrm{LH}$ & $\sim 0.58$ & 58.5 & 1086 & 44.3 & GH & 531 & & 2.568 \\
\hline 20 & 508 & 1291 & Oblate Spheroid & $\mathrm{LH}$ & $\sim 0.32$ & 32.2 & 1974 & 44 & $\mathrm{GH}$ & 533 & & 2.58 \\
\hline 20 & 509 & 1291 & Oblate Spheroid & $\mathrm{LH}$ & $\sim 0.84$ & 84.7 & 741 & 54.3 & $\mathrm{GH}$ & 535 & & 2.85 \\
\hline 20 & 510 & 1291 & Oblate Spheroid & LH & $\sim 0.58$ & 58.3 & 1089 & 54.9 & GH & 531 & & 2.74 \\
\hline 20 & 511 & 1291 & Oblate Spheroid & $\mathrm{LH}$ & $\sim 0.32$ & 32.1 & 1978 & 55.1 & $\mathrm{GH}$ & 526 & & 2.86 \\
\hline 21 & ? & 489 & Sphere & SLH & $\sim 0.55$ & 52.3 & 505 & 35 & $\mathrm{He}$ & 540 & (8) & 3.788 \\
\hline 21 & $?$ & 489 & Sphere & SLH & $\sim 1.26$ & 120.0 & 220 & 35 & $\mathrm{He}$ & 540 & (8) & 3.178 \\
\hline 21 & ? & 489 & Sphere & SLH & $\sim 0.54$ & 51.8 & 510 & 35 & $\mathrm{He}$ & 250 & (8) & 2.100 \\
\hline 21 & $?$ & 489 & Sphere & SLH & $\sim 1.38$ & 132.0 & 200 & 35 & $\mathrm{He}$ & 250 & (8) & 1.591 \\
\hline 21 & ? & 489 & Sphere & SLH & $\sim 0.58$ & 55.0 & 480 & 35 & $\mathrm{He} / \mathrm{GH}$ & 540 & (2), (8) & 6.655 \\
\hline 21 & $?$ & 489 & Sphere & SLH & $\sim 1.32$ & 125.7 & 210 & 35 & $\mathrm{He} / \mathrm{GH}$ & 540 & (2), (8) & 3.727 \\
\hline
\end{tabular}

Notes: (1) Time includes $\sim 12$ sec. main ramp up of tank pressure; indicated flow rates are at main stage after this ramp up

(2) Pre-pressurized with helium followed by expulsion with hydrogen pressurant gas

(3) Propellant expulsion flow rates approximated by scaling of tank geometry drawings, given initial ullage height, liquid level change in tank with associated time span; Collapse Factor data also reported in Ref. 14

(4) Horizontal sloshing in tank at $0.5-\mathrm{Hz}$ and 0.5 -inch amplitude throughout expulsion

(5) Horizontal sloshing in tank at $0.5-\mathrm{Hz}$ and 0.5 -inch amplitude for last 85 -seconds of expulsion

(6) Two collapse factors; first based on constant ullage gas temperature and pressure throughout expulsion; second based on saturated GH vapor in ullage at one atmosphere before tank pressurization

(7) Propellant mass flow rate data obtained from average LH propellant consumption of 5-each $\mathrm{J}-2$ rocket engines on Saturn launch vehicle S-II stage from Ref. 9; tank pressure also obtained from this reference

(8) SLH is slush hydrogen, mixute of solid and liquid hydrogen

(9) Pressurant gas inlet temp. not reported; est. based on description of test apparatus and procedures

(10) Initial 30 to $56 \mathrm{sec}$. of the total time is tank pressurization and hold prior to propellant expulsion

(11) Submerged injection of pressurant gas, 21 min. tank pressurization, $15 \mathrm{~min}$. CLH expulsion

(12) Submerged injection of pressurant gas, 13 min. tank pressurization, $15 \mathrm{~min}$. CLH expulsion

(13) Submerged injection of pressurant gas, $13 \mathrm{~min}$. tank pressurization, $25 \mathrm{~min}$. CLH expulsion

(14) Submerged injection of pressurant gas, 12 min. tank pressurization, $15 \mathrm{~min}$. CLH expulsion

(15) Initial 12- to 21-minutes of the total time is tank pressurization and hold prior to propellant expulsion

(16) Test runs are from unpublished report cited in Ref. 5

(17) Test run nos. are from another document cited in

RELEASED - Printed documents may be obsolete; validate prior to use. 


\section{- Vertical Temperature Gradient in Ullage Gas Region}

- Significant Effects on Collapse Factor

- Fluid Density and Transport Properties Affected by Temperature

- Pressure Distribution (Caused by Elevation Head) has Negligible Effects

-Vertical Temperature Gradients Measured Empirically in Some Studies

- Limited to Low Subcritical Tank Pressures

- Instrument Rakes Damaged or Destroyed at Higher Tank Pressures

- Ullage Gas Region Vertical Temperature Gradients, Empirical Data (Next Slide) 
Table 3. Selected References Containing Empirical Ullage Gas Region Vertical Temperature Distribution/Gradient Data

\begin{tabular}{|c|c|c|c|c|c|c|c|}
\hline \multirow[b]{2}{*}{ Reference Citation } & \multirow{2}{*}{$\begin{array}{c}\text { Test } \\
\text { Number }\end{array}$} & \multirow[b]{2}{*}{ Prop. } & \multirow{2}{*}{$\begin{array}{c}\text { Press. } \\
\text { Gas }\end{array}$} & \multirow{2}{*}{$\begin{array}{c}\text { Press. Gas } \\
\text { Inlet Temp. } \\
\text { (deg R) }\end{array}$} & \multirow{2}{*}{$\begin{array}{l}\text { Prop. } \\
\text { Expul. } \\
\text { Time } \\
\text { (sec) }\end{array}$} & \multicolumn{2}{|c|}{$\begin{array}{c}\text { Ullage Gas Region } \\
\text { Vertical Temp. } \\
\text { Gradient (deg R) }\end{array}$} \\
\hline & & & & & & Min. & Max. \\
\hline Lockheed Report ER-5238 (1961) & 3 & $\mathrm{LH}$ & GH & 300 & 120 & $?$ & 218.5 \\
\hline Lockheed Report ER-5238 (1961) & 5 & LH & $\mathrm{He}$ & 300 & 99 & $?$ & 223.5 \\
\hline Lockheed Report ER-5238 (1961) & 7 & $\mathrm{LH}$ & $\mathrm{GH}$ & 300 & 111 & $?$ & 255.5 \\
\hline Arnett and Voth (1972) & B-2 & $\mathrm{LH}$ & $\mathrm{N} / \mathrm{A}$ & $\mathrm{N} / \mathrm{A}$ & N/A & 80.1 & 126 \\
\hline Baral (1988) & (Fig. 4) & LOX & GOX & 540 & 100 & 288 & 333 \\
\hline Bouregal (1968) & 1 & LH & $\mathrm{He}$ & 450 & 217 & 342 & 405 \\
\hline Bouregal (1968) & 3 & LH & $\mathrm{He}$ & 450 & 197 & 351 & 405 \\
\hline Bouregal (1968) & 7 & LH & $\mathrm{He}$ & 450 & 375 & 405 & 405 \\
\hline Bouregal (1968) & 11 & LH & GH & 180 & 214 & 149.4 & 193 \\
\hline Bowersock, et al. (1960) & RT-3 & $\mathrm{LN}$ & $\mathrm{GN}$ & $\sim 520$ & 175 & 140 & 195 \\
\hline Cady, et al. (1990) & $2.0-6$ & TPLH & $\mathrm{GH}$ & 540 & $\sim 980$ & 193 & 238 \\
\hline Cady, et al. (1990) & $2.0-8$ & TPLH & $\mathrm{He} / \mathrm{GH}$ & 144 and 540 & $\sim 870$ & 180 & 211 \\
\hline Clark (1965) & $130-15$ in Ref. 2 & LOX & $\mathrm{He}$ & $500-605$ & 120 & 380 & 405 \\
\hline Coxe and Tatum (1962) & 1 (Fig. 5) & LH & GH & 300 & 89 & $\sim 223.5$ & $\sim 248.5$ \\
\hline DeWitt and McIntire (1974) & 8 & $\mathrm{LCH}_{4}$ & $\mathrm{GCH}_{4}$ & 400 & 231 & $?$ & 174.6 \\
\hline DeWitt and McIntire (1974) & 6 & $\mathrm{LCH}_{4}$ & $\mathrm{GCH}_{4}$ & 400 & 633 & $?$ & 176.4 \\
\hline DeWitt and Mclntire (1974) & 11 & $\mathrm{LCH}_{4}$ & $\mathrm{GCH}_{4}$ & 600 & 234 & $?$ & 369 \\
\hline DeWitt and McIntire (1974) & 37 & $\mathrm{LCH}_{4}$ & $\mathrm{He}$ & 400 & 223 & $?$ & 211 \\
\hline DeWitt and McIntire (1974) & 42 & $\mathrm{LCH}_{4}$ & $\mathrm{He}$ & 600 & 224 & $?$ & 380 \\
\hline DeWitt and McIntire (1974) & 63 & $\mathrm{LCH}_{4}$ & GH & 400 & 219 & $?$ & 193 \\
\hline DeWitt and McIntire (1974) & 68 & $\mathrm{LCH}_{4}$ & GH & 600 & 222 & $?$ & 398 \\
\hline Hasan, et al. (1991) & $?$ & $\mathrm{LH}$ & $\mathrm{N} / \mathrm{A}$ & $\mathrm{N} / \mathrm{A}$ & 14400 & 5.4 & 49.5 \\
\hline Hasan, et al. (1991) & $?$ & $\mathrm{LH}$ & $\mathrm{N} / \mathrm{A}$ & $\mathrm{N} / \mathrm{A}$ & 14400 & 4.5 & 48.6 \\
\hline Kendle (1970) & $?$ & LH & GH & $\sim 525$ & 130 & $?$ & $\sim 475$ \\
\hline Kendle (1970) & $?$ & LH & GH & $\sim 525$ & 130 & $?$ & $\sim 435$ \\
\hline Kendle (1970) & $?$ & $\mathrm{LH}$ & GH & $\sim 525$ & 130 & $?$ & $\sim 245$ \\
\hline Nein and Thompson (1965) & $130-6$ & LOX & GOX & 540 & 150 & 302 & 372 \\
\hline Nein and Thompson (1965) & 130.9 & LOX & GOX & 370 & 150 & 147 & 207 \\
\hline Roudebush (1965) & Ex. 1 & $\mathrm{LH}$ & GH & $488-525$ & 90 & $?$ & 428 \\
\hline Roudebush (1965) & Ex. 1 & LH & GH & $488-525$ & 178 & $?$ & 428 \\
\hline Roudebush (1965) & Ex. 1 & $\mathrm{LH}$ & GH & $488-525$ & 320 & $?$ & 428 \\
\hline Roudebush (1965) & Ex. 2 & $\mathrm{LH}$ & GH & $480-515$ & 93 & $?$ & 436 \\
\hline Roudebush (1965) & Ex. 3 & $\mathrm{LH}$ & GH & $375-520$ & 284 & $?$ & 450 \\
\hline Roudebush (1965) & Ex. 4 & LH & GH & $450-580$ & 101 & ? & 455 \\
\hline Roudebush (1965) & Ex. 5 & LH & $\mathrm{GH}$ & $395-273$ & 95 & $?$ & 208 \\
\hline Roudebush (1965) & Ex. 6 & $\mathrm{LH}$ & GH & $380-630$ & 88 & $?$ & 575 \\
\hline Roudebush (1965) & Ex. 7 & LH & $\mathrm{He}$ & $525-535$ & 355 & $?$ & 475 \\
\hline Roudebush (1965) & Ex. 8 & $\mathrm{LH}$ & $\mathrm{He}$ & $525-530$ & 90 & $?$ & 475 \\
\hline Roudebush (1965) & Ex. 9 & $\mathrm{LH}$ & $\mathrm{He}$ & $325-215$ & 100 & $?$ & 165 \\
\hline Roudebush (1965) & Ex. 10 & LH & $\mathrm{He}$ & $350-610$ & 309 & $?$ & 597 \\
\hline Stochl, et al (1970) NASA TN-D-5621 & 88 & $\mathrm{LH}$ & GH & 331 & 396 & $?$ & 250 \\
\hline Stochl, et al (1970) NASA TN-D-5621 & 85 & LH & GH & 488 & 137 & $?$ & 445 \\
\hline Stochl, et al (1970) NASA TN-D-5621 & 97 & $\mathrm{LH}$ & GH & 603 & 134 & $?$ & 650 \\
\hline Stochl, et al (1970) NASA TN-D-7019 & 4 & LH & GH & 306 & 478 & $?$ & 247 \\
\hline Stochl and DeWitt (1969) & $?$ & $\mathrm{LH}$ & GH & 520 & 278 & $?$ & $\sim 460$ \\
\hline Stochl and DeWitt (1969) & $?$ & LH & GH & 520 & 278 & $?$ & $\sim 305$ \\
\hline Swalley (1966) & $\begin{array}{l}\text { AS-203 (Saturn } \\
\text { IB Launch 7/66) }\end{array}$ & LH & $\mathrm{N} / \mathrm{A}$ & $\mathrm{N} / \mathrm{A}$ & 22,498 & 7 & 195 \\
\hline Van Dressar and Stochl (1993) & 509 & $\mathrm{LH}$ & GH & 531 & 1110 & 245 & 423 \\
\hline Van Dressar and Stochl (1993) & 510 & LH & GH & 529 & 741 & $?$ & 405 \\
\hline Van Dressar and Stochl (1993) & 511 & LH & GH & 526 & 1978 & $?$ & 392 \\
\hline
\end{tabular}




\section{- Horizontal Temperature Gradient in Ullage Gas Region}

- Known to Exist from Empirical Data

- Temperature Probe Rakes and Instruments on Inner or Outer Tank Wall

- Most of Gradient Appears to be in Thin Boundary Layer Near Tank Wall, but little or no Empirical Data to Validate or Support

- Empirical Data Limited to Low Subcritical Pressure Cases

- Selected Tabular Empirical Data:

Table 4. Selected Empirical Ullage Gas and Adjacent Tank Wall Temperature Data for Approximations of Ullage Gas Region Horizontal Temperature Gradients

\begin{tabular}{|c|c|c|c|c|c|c|c|}
\hline \multirow[t]{2}{*}{ Reference Citation } & \multirow[t]{2}{*}{$\begin{array}{c}\text { Test } \\
\text { Number }\end{array}$} & \multirow[t]{2}{*}{ Prop. } & \multirow[t]{2}{*}{$\begin{array}{c}\text { Press. } \\
\text { Gas }\end{array}$} & \multirow[t]{2}{*}{$\begin{array}{l}\text { Press. Gas } \\
\text { Inlet Temp. } \\
\text { (deg R) }\end{array}$} & \multirow[t]{2}{*}{$\begin{array}{l}\text { Expul. } \\
\text { Time } \\
\text { (sec) }\end{array}$} & \multicolumn{2}{|c|}{\begin{tabular}{|c|} 
Horizontal Temperature \\
Gradient, Tank Vertical \\
Centerline to Tank Wall (deg R) \\
\end{tabular}} \\
\hline & & & & & & Minimum & Maximum \\
\hline Lockheed Report ER-5238 (1961) & 3 & $\mathrm{LH}$ & GH & 300 & 120 & 0 & $\sim 63$ \\
\hline Lockheed Report ER-5238 (1961) & 4 & $\mathrm{LH}$ & $\mathrm{GH}$ & 300 & 87 & 4.5 & $\sim 72$ \\
\hline Lockheed Report ER-5238 (1961) & 5 & $\mathrm{LH}$ & $\mathrm{He}$ & 300 & 99 & 0.5 & 51 \\
\hline Lockheed Report ER-5238 (1961) & 6 & $\mathrm{LH}$ & $\mathrm{He}$ & 300 & 95 & 26 & 95 \\
\hline Lockheed Report ER-5238 (1961) & 7 & LH & $\mathrm{GH}$ & 300 & 111 & 9 & 71 \\
\hline Bourgarel, et al. (1968) & 4 & $\mathrm{LH}$ & $\mathrm{He}$ & 450 & 205 & 9 & 107 \\
\hline Bourgarel, et al. (1968) & 7 & $\mathrm{LH}$ & $\mathrm{He}$ & 450 & 375 & 0 & 130 \\
\hline Bourgarel, et al. (1968) & 9 & $\mathrm{LH}$ & $\mathrm{He}$ & 450 & 352 & $\sim 5$ & 126 \\
\hline Bourgarel, et al. (1968) & 11 & $\mathrm{LH}$ & $\mathrm{He}$ & 180 & 214 & 0 & 59 \\
\hline Bowersock, et al. (1960) & 19 & $\mathrm{LN}$ & GN & $?$ & $\mathrm{~N} / \mathrm{A}$ & 0 & 107 \\
\hline Coxe and Tatom (1962) & 1 & $\mathrm{LH}$ & $\mathrm{GH}$ & 300 & 89 & 0 & 99 \\
\hline DeWitt and McIntire (1974) & 8 & $\mathrm{LCH}_{4}$ & $\mathrm{GCH}_{4}$ & 400 & 231 & 0 & 117 \\
\hline DeWitt and McIntire (1974) & 6 & $\mathrm{LCH}_{4}$ & $\mathrm{GCH}_{4}$ & 400 & 633 & 0 & 80 \\
\hline DeWitt and McIntire (1974) & 11 & $\mathrm{LCH}_{4}$ & $\mathrm{GCH}_{4}$ & 600 & 234 & 0 & 281 \\
\hline DeWitt and McIntire (1974) & 37 & $\mathrm{LCH}_{4}$ & $\mathrm{He}$ & 400 & 223 & 0 & 97 \\
\hline DeWitt and McIntire (1974) & 42 & $\mathrm{LCH}_{4}$ & $\mathrm{He}$ & 600 & 224 & 0 & 180 \\
\hline DeWitt and McIntire (1974) & 63 & $\mathrm{LCH}_{4}$ & $\mathrm{GH}$ & 400 & 219 & 2 & 99 \\
\hline DeWitt and McIntire (1974) & 68 & $\mathrm{LCH}_{4}$ & $\mathrm{GH}$ & 600 & 222 & 0 & 225 \\
\hline Hasan, et al. (1991) & $?$ & $\mathrm{LH}$ & N/A & $\mathrm{N} / \mathrm{A}$ & $\mathrm{N} / \mathrm{A}$ & 1 & 29 \\
\hline Roudebush (1965) & Ex. 1 & $\mathrm{LH}$ & $\mathrm{GH}$ & $488-520$ & 350 & 15 & 220 \\
\hline Roudebush (1965) & Ex. 4 & LH & GH & $450-580$ & 101 & 0 & 300 \\
\hline Roudebush (1965) & Ex. 6 & $\mathrm{LH}$ & $\mathrm{GH}$ & $385-630$ & 88 & 0 & 415 \\
\hline Roudebush (1965) & Ex. 8 & $\mathrm{LH}$ & $\mathrm{He}$ & $524-530$ & 90 & $\sim 20$ & 270 \\
\hline Stochl, et al. (1970), NASA TN-D-7019 & 4 & $\mathrm{LH}$ & $\mathrm{He}$ & 306 & 478 & 2 & 55 \\
\hline Stochl, et al (1970) NASA TN-D-5621 & 88 & $\mathrm{LH}$ & $\mathrm{He}$ & 331 & 396 & 2 & 100 \\
\hline Stochl, et al (1970) NASA TN-D-5621 & 85 & $\mathrm{LH}$ & $\mathrm{He}$ & 488 & 137 & 19 & 282 \\
\hline Stochl, et al (1970) NASA TN-D-5621 & 87 & $\mathrm{LH}$ & $\mathrm{He}$ & 603 & 134 & 0 & 540 \\
\hline
\end{tabular}


- Vertical Temperature Gradients in the Cryogenic Propellant Region Can Affect Collapse Factor, But to a Much Lesser Extent than Vertical Temperature Gradients in the Ullage Gas Region

- Pressure gradients in the propellant region are higher than those in the ullage gas region, but have negligible effects on fluid density and other properties

- Empirical data for cryogenic (liquid) propellant vertical temperature gradients are much more extensive than data for ullage gas vertical temperature gradients

- Vertical temperature gradients in propellant region range from 5 to $30 \mathrm{R}$

- Most of the gradient is in the Upper 2 to $20 \%$ of Initial Propellant Region Height

-3-in. to 3-ft. depth below liquid surface for larger tanks

- Less than 6" height for smaller tanks

- Prior studies with Vertical Temperature Gradients in Propellant Region (Next Slide) 
Table 5. References with Empirical Propellant Vertical Temperature Gradient/Profile Data

\begin{tabular}{|c|c|c|c|c|c|c|c|}
\hline \multirow[b]{2}{*}{ Reference Citation } & \multirow[b]{2}{*}{ Test Number } & \multirow[b]{2}{*}{ Prop. } & \multirow[b]{2}{*}{$\begin{array}{c}\text { Press. } \\
\text { Gas }\end{array}$} & \multicolumn{2}{|c|}{ Propellant Height (ft.) } & \multirow[b]{2}{*}{$\begin{array}{c}\text { Press. Hold or } \\
\text { Expul. Time } \\
\text { (sec.) }\end{array}$} & \multirow[b]{2}{*}{$\begin{array}{l}\text { Tank } \\
\text { Press. } \\
\text { (psia) }\end{array}$} \\
\hline & & & & Minimum & Maximum & & \\
\hline Lockheed Report - ER-5238 (1981) & 3 & $\mathrm{LH}$ & GH & 1 & 7.25 & 120 & 46.5 \\
\hline Lockheed Report - ER-5238 (1981) & 4 & $\mathrm{LH}$ & $\mathrm{GH}$ & 0.08 & 6.75 & 87 & 46.6 \\
\hline Al-Najem, et al. (1993) & $3 \mathrm{~L} / \mathrm{min}$ & Water & * & 1.31 & 3.11 & 840 & $\sim 14.7$ \\
\hline Al-Najem, et al. (1993) & $15 \mathrm{~L} / \mathrm{min}$ & Water & $*^{*}$ & 1.31 & 3.11 & 180 & $\sim 14.7$ \\
\hline Barnett (1967) & 2 & $\mathrm{LN}$ & N/A & 3.17 & 3.17 & 60 & 39.7 \\
\hline Barnett (1967) & 2 & $\mathrm{LN}$ & $\mathrm{N} / \mathrm{A}$ & 3.17 & 3.17 & 360 & 29.7 \\
\hline Barnett (1967) & 3 & $\mathrm{LN}$ & $\mathrm{N} / \mathrm{A}$ & 3.17 & $3 / 17$ & 60 & 29.7 \\
\hline Barnett (1967) & 3 & $\mathrm{LN}$ & $\mathrm{N} / \mathrm{A}$ & 3.17 & 3.17 & 360 & 29.7 \\
\hline Barnett, et al. (1964) & 4 & $\mathrm{LH}$ & $\mathrm{He}$ & 13.17 & 13.17 & 119 & $18.7-32.7$ \\
\hline Barnett, et al. (1964) & 4 & $\mathrm{LH}$ & $\mathrm{He}$ & 13.17 & 13.17 & 119 & $18.7-32.7$ \\
\hline Barnett, et al. (1964) & Fig. 8 & $\mathrm{LH}$ & $\mathrm{GH}$ & 4.75 & 4.75 & 100 & $?$ \\
\hline Barnett, et al. (1964) & Fig.8 & $\mathrm{LH}$ & GH & 4.75 & 4.75 & 600 & $?$ \\
\hline Coxe and Tatom (1962) & 2 & $\mathrm{LH}$ & $\mathrm{GH}$ & $<0.50$ & 7.46 & 103 & 47.6 \\
\hline Coxe and Tatom (1962) & 5 & LH & $\mathrm{He}$ & $<0.50$ & 7.51 & 99 & 45.5 \\
\hline Coxe and Tatom (1962) & 6 & $\mathrm{LH}$ & $\mathrm{GH} / \mathrm{He}$ & $<0.50$ & 7.63 & 95 & 47.0 \\
\hline Coxe and Tatom (1962) & 7 & $\mathrm{LH}$ & $\mathrm{GH}$ & $<0.50$ & 7.33 & 111 & 45.0 \\
\hline Coxe and Tatom (1962) & 10 & $\mathrm{LH}$ & $\mathrm{GH}$ & $<0.50$ & 7.39 & 105 & 45.5 \\
\hline DeWitt and McIntire (1974) & 9 & $\mathrm{LCH}_{4}$ & $\mathrm{GCH}_{4}$ & $\sim 0.85$ & $\sim 4.15$ & 638 & 48.6 \\
\hline DeWitt and McIntire (1974) & 10 & $\mathrm{LCH}_{4}$ & $\mathrm{GCH}_{4}$ & $\sim 0.85$ & $\sim 4.15$ & 410 & 48.9 \\
\hline DeWitt and Mclntire (1974) & 11 & $\mathrm{LCH}_{4}$ & $\mathrm{GCH}_{4}$ & $\sim 0.85$ & $\sim 4.15$ & 234 & 49.2 \\
\hline DeWitt and Mclntire (1974) & 97 & $\mathrm{LCH}_{4}$ & GN & $\sim 0.85$ & $\sim 4.15$ & 568 & 49.5 \\
\hline DeWitt and McIntire (1974) & 98 & $\mathrm{LCH}_{4}$ & GN & $\sim 0.85$ & $\sim 4.15$ & 232 & 49.5 \\
\hline Fan, et al (1969) & 13 & $\mathrm{LN}$ & GN & 1.98 & 1.98 & 7200 & 450 \\
\hline Ghaddar, et al. (1989) & $6.5 \mathrm{~L} / \mathrm{min}$ & Water & * & 5.25 & 6.56 & 1500 & $\sim 14.7$ \\
\hline Ghaddar, et al. (1989) & $9 \mathrm{~L} / \mathrm{min}$ & Water & * & 5.25 & 6.56 & 1500 & $\sim 14.7$ \\
\hline Gursu, et al. (1993) & $B-2$ & $\mathrm{LH}$ & $\mathrm{N} / \mathrm{A}$ & 6.02 & 6.02 & 40 & $16.5-17.4$ \\
\hline Gursu, et al. (1993) & $B-2$ & $\mathrm{LH}$ & $\mathrm{N} / \mathrm{A}$ & 6.02 & 6.02 & 152 & $16.5-19.5$ \\
\hline Hasan, et al. (1991) & $?$ & LH & $\mathrm{N} / \mathrm{A}$ & 4.59 & 4.59 & 14,400 & $14.7-18.4$ \\
\hline Hasan, et al. (1991) & $?$ & $\mathrm{LH}$ & N/A & 4.59 & 4.59 & 43,200 & $14.7-27.0$ \\
\hline Kharin, et al. (1991) & $?$ & $\mathrm{LH}$ & N/A & 3.75 & 8.52 & 20,700 & 19.15 \\
\hline Liebenburg and Edeskuty (1965) & $?$ & LH & $\mathrm{N} / \mathrm{A}$ & 18.47 & 18.47 & 136,800 & $18.7-39.1$ \\
\hline Neff and Chiang (1967) & 17 & $\mathrm{LH}$ & $\mathrm{N} / \mathrm{A}$ & 3.91 & 3.91 & 120 & $\sim 27$ \\
\hline Neff and Chiang (1967) & 19 & $\mathrm{LH}$ & N/A & 1.38 & 1.38 & 400 & $\sim 31.2$ \\
\hline Neff and Chiang (1967) & 40 & $\mathrm{LN}$ & N/A & 3.97 & 3.97 & 160 & $\sim 18.0$ \\
\hline Neff and Chiang (1967) & 38 & $\mathrm{LN}$ & N/A & 1.27 & 1.27 & 700 & $\sim 18.9$ \\
\hline Olsen (1966) & 1 & $\mathrm{LH}$ & $\mathrm{GH}$ & 2.5 & 2.5 & 600 & 54.7 \\
\hline Olsen (1966) & 3 & $\mathrm{LH}$ & $\mathrm{GH}$ & 2.5 & 2.5 & 720 & 22.7 \\
\hline Ordin, et al. (1960) & $?$ & $\mathrm{LH}$ & GH & $?$ & $\sim 2$ & 600 & $14.7-55$ \\
\hline Schmidt, et al. (1960) & $\mathrm{A}-3$ & $\mathrm{LH}$ & $\mathrm{GH}$ & 4.19 & 4.19 & 900 & $125-160$ \\
\hline Schmidt, et al. (1960) & B-1 & $\mathrm{LH}$ & $\mathrm{GH}$ & 3.98 & 3.98 & 104,400 & $15.5-24.7$ \\
\hline Segel (1965) & $?$ & $\mathrm{LH}$ & N/A & 2.36 & 2.36 & 600 & $14.7-73.5$ \\
\hline Segel (1965) & $?$ & $\mathrm{LH}$ & $\mathrm{N} / \mathrm{A}$ & 2.21 & 2.21 & 600 & $14.7-73.5$ \\
\hline Segel (1965) & $?$ & $\mathrm{LH}$ & $\mathrm{N} / \mathrm{A}$ & 2.30 & 2.30 & 600 & $14.7-73.5$ \\
\hline Segel (1965) & $?$ & $\mathrm{LH}$ & $\mathrm{N} / \mathrm{A}$ & 2.14 & 2.14 & 600 & $14.7-73.5$ \\
\hline Tanyun, et al. (1996) & $?$ & $\mathrm{LH}$ & $\mathrm{N} / \mathrm{A}$ & 6.50 & 6.50 & 120 & $?$ \\
\hline Tanyun, et al. (1996) & $?$ & $\mathrm{LH}$ & N/A & 6.50 & 6.50 & 300 & $?$ \\
\hline
\end{tabular}




\section{- Horizontal Temperature Gradients in Propellant Region}

- Empirical data is limited

- Data shows small horizontal temperature gradient in most cases

- All data indicates all or most of the gradient is in thin thermal boundary layer near the tank inner wall

- Propellant temperature is nearly equal to that of adjacent tank wall in nearly all cases

\section{- Multiple Fluid Species in Ullage Gas and Cryogenic Propellant Regions}

- Limited to Cases where pressurant gas species is different from cryogenic propellant species

- Nitrogen pressurant gas over $\mathrm{LCH}_{4}$ or LOX propellant

- Helium pressurant gas over $\mathrm{LH}, \mathrm{LCH}_{4}$, or LOX propellant

- Known to exist in both ullage gas and propellant regions

- Always have propellant species in near saturated vapor state in initial ullage region prior to tank pressurization

- Quantitative empirical data (distribution of species mass fractions) is limited to a few studies

- Most existing data and stated conclusions of prior studies indicate that virtually all mixing of pressurant gas species in the propellant region is near (no more than one or two inches below) the interface between ullage gas and propellant regions

- One exception is in DeWitt and Mclntire (1974) where nitrogen gas over liquid methane was tested

- Other exceptions are found in studies where helium gas was bubbled up through LH or LOX propellant 
- Multiple Fluid Species in Ullage Gas and Cryogenic Propellant Regions (continued)

- Quantitative measurements for multiple species in ullage gas region show:

- Increased mass fraction of propellant when traversing from top to bottom of region

- High propellant mass fractions concentrated in and restricted to lowermost one to two foot height in ullage gas region or lowermost 5 to $15 \%$ of ullage volume

- Above findings occur when:

1. Only one gas species used for tank pressurization and propellant expulsion

2. Pressurant gas inlet diffuser is designed to reduce or prevent mixing of pressurant and ullage gases

- Supercritical and High Subcritical Tank Operating Pressures are expected to have minimal/negligible mass fraction of propellent throughout ullage gas region if diffuser design and operating conditions assure minimal forced mixing at ullage-gas-to-propellant interface

- $\quad$ Not proven, but supported, by results of the few studies covering and presenting collapse factor data with tanks operating at high supercritical pressures. 


\section{- Other Effects on Collapse Factor:}

- Temperature Distribution Through Thickness of Tank Wall

- Treated as uniform for all but a few studies

- Tank wall temperature distribution is not directly determined with direct temperature instrumentation measurements in any study

- Selected studies use directly measured outer tank wall surface temperatures

- Small minority of studies use directly measured inner tank wall surface temperatures

- Tank wall less than $1 / 2$-inch thick in all these studies

- Assumption of uniform temperature through the tank wall appears to be valid analytical approach that adds slight conservatism (increases) to collapse factor results

- The assumption is probably not valid for thick walled tanks and expected to yield overly conservative results

- One study for thick walled tanks operating at high supercritical pressures models inner $30 \%$ of wall thickness at uniform temperature with remaining $70 \%$ treated as an adiabatic boundary

- Two studies for thick walled tanks operating at high supercritical pressures use numerical-finite-difference method with temperature dependent wall material properties 
- Other Effects on Collapse Factor (continued):

- $\quad$ Pressurant Gas Entry Effects

- Direction and Magnitudes of Velocity Vectors at Locations where

Pressurant Gas Enters the Ullage

- The Major Effect on:

1. Temperature gradients in ullage gas region (previously described)

2. Heat transfer across all ullage gas region boundaries

3. Mass transfer across interface between ullage gas and propellant

- Lesser effects on heat transfer across propellant region boundaries

- As a Result, Pressurant Gas Entry Effects Have the Predominant Influence on Collapse Factors

- Configuration and Location of Pressurant Gas Inlet Diffuser can be Optimized to Reduce Collapse Factors

1. Reduce magnitude of all velocity vectors; large total cross-section flow area (where pressurant gas enters the diffuser)

2. Horizontal and/or upward direction of velocity vectors; away from ullage-gas-to-propellant interface

3. Provide maximum velocity jet dispersion before impinging on or flowing along tank walls (increase distance between entry points and tank walls)

4. Certain tank geometries and severe operating conditions can limit attainable reduction in collapse factors 


\section{- Analytical Methods and Models to Predict Collapse Factor}

- "Saturation Rule"

- Ullage gas density based on temperature equal to saturation temperature of cryogenic liquid (propellant)

- Ullage gas is at saturated vapor density if ullage and pressurant gas are same species as cryogenic liquid

- Good to very good results in some cases when compared to empirical

- results, but often overly conservative over-predicting by factors as high as ten

- Modifications and Enhancements to the "Saturation Rule"

- "Worst Case Rule" and "Equivalent Mass Model"

- Addition of assumptions and basic heat transfer correlations and approximations to reduce excessively high conservatism in results

- "Equivalent Mass Model" provided 10\% under-prediction to $12.8 \%$ over-prediction of collapse factor

- Studies limited to one horizontal cylindrical tank configuration and size 


\section{- Analytical Methods and Models to Predict Collapse Factor}

(Continued)

- Semi-Empirical Curve-Fit Models

- A single equation or simultaneous set of equations

- Ullage gas, incoming pressurant gas, propellant temperature, and tank wall properties used in equations(s)

- Constants and exponents derived from empirical data developed and used in equation(s)

- Model presented in two studies, Epstein and Anderson (1968) and Epstein (1965), had collapse factor prediction errors below $12 \%$, most errors around 5 to $6 \%$

- Enhancements made, VanDresar (1995), to models from above two studies

- Equivalent dimension parameters developed for spherical and oblate spheroid tanks

- Revised constants for liquid hydrogen propellant expulsions

- Methods added to adjust for cases with initial ullage volumes $<20 \%$, large final propellant volumes, and internal tank hardware 
- Analytical Methods and Models to Predict Collapse Factor (Continued)

- Upper and Lower Bound Analyses

- Developed in mid-1980's though early 1990's

- Major focus to evaluate pressurant gas requirements (collapse factors) at supercritical and high subcritical tank pressures

- Accomodate no distinction between liquid and gas phases or possibility of two-phase region

- Upper bound based on complete mixing of all fluids in tank

- Lower bound based on separate ullage gas and cryogenic propellant regions with no heat or mass transfer at boundaries (except where pressurant gas enters the ullage and cryogenic propellant is discharged)

- Ullage-gas-to-propellant interface modeled as horizontal plane

- Empirical collapse factor data always fell between the upper and lower bound collapse factor data (but this was often a very wide range)

- Lumped Mass Fluid Region (LMFR) Models

(presented on following slides)

- Multiple Discrete Fluid Segment (MDFS) Models

(presented on slides that follow those for LMFR Models) 


\begin{tabular}{|c|c|c|c|c|c|c|c|}
\hline \multirow{2}{*}{ Year } & \multirow{2}{*}{$\begin{array}{l}\text { Reference } \\
\text { Citation }\end{array}$} & \multicolumn{4}{|c|}{ Heat Transfer } & \multirow{2}{*}{$\begin{array}{c}\text { Mass Transfer } \\
\text { Ullage Gas to Propellant }\end{array}$} & \multirow[b]{2}{*}{ Model Errors Compared to Empirical Data } \\
\hline & & Ullage Gas to Wall & Propellant to Wall & Ullage Gas to Propellant & External Tank Wall & & \\
\hline 1962 & 12 & $\begin{array}{l}\text { NLC, Correlation for Conv. H.T. } \\
\text { Coeff. not provided }\end{array}$ & $\begin{array}{l}\text { Based on H.T. from wall } \\
\text { boiling liquid propellant }\end{array}$ & Not Discussed & $\begin{array}{l}\text { NLC, Correlation for Conv. } \\
\text { H.T. Coeff. not shown }\end{array}$ & Not Discussed & $\begin{array}{l}\text { Range: }-9.6 \text { to } 7.8 \% \text {; Mean: } 1.11 \% \text {; Std. Dev. } 5.0 \% ; 10 \\
\text { Tests Compared }\end{array}$ \\
\hline 1965 & 14 & NLC, NC, Note 7 & Assumed Negligible & Assumed Negligible & Not Discussed & Assumed No Mass Transfer & $\begin{array}{l}\text { Range: }-10.4 \text { to } 18.5 \% \text {; Mean: } 0.65 \% \text {; Std. Dev. } 7.74 \% \text {; } \\
18 \text { Tests Compared }\end{array}$ \\
\hline 1962 & 33 & NLC, NC, Note 9 & Assumed Negligible & Not Modeled & Modeled as Adiabatic & Determined from Empirical Data & $\begin{array}{l}\text { Range: }-9.0 \text { to } 8.4 \% \text {; Mean: } 0.34 \% \text {; Std. Dev. } 4.57 \% ; 12 \\
\text { Tests Compared }\end{array}$ \\
\hline 1992 & 79 & $\begin{array}{l}\text { NLC, NC, VP \& HP [Ref. } 87 \\
\text { Correlations] }\end{array}$ & $\begin{array}{l}\text { NLC, NC, VP \& HP [Ref. } 87 \\
\text { Correlations] }\end{array}$ & $\begin{array}{l}\text { NLC, NC, HPCSU [Ref. } 87 \\
\text { Correlations] }\end{array}$ & Modeled as Adiabatic & Assumed Negligible & $\begin{array}{l}\text { Pressurant gas supply bottle press. And temp. show }< \\
1 \mathrm{~K} \text { and }<0.5 \mathrm{MPa} \text { error for part of Test } 74 \text { on E-8 Test } \\
\text { Stand }\end{array}$ \\
\hline 1989 & 80 & $\begin{array}{l}\text { NLC, NC \& FC, Notes } 3 \text { and } 5 \\
\text { [Ref. } 34 \text { Corrrelations] }\end{array}$ & Assumed Negligible & $\begin{array}{l}\text { NLC, NC \& FC, Notes } 3 \text { and } 6 \\
\text { [Ref. } 34 \text { Correlations] }\end{array}$ & $\begin{array}{l}\text { Modeled as Adiabatic, Note } \\
5\end{array}$ & $\begin{array}{l}\text { None, equivalent mass transfer } \\
\text { modeled by added H.T., Note } 6\end{array}$ & $\begin{array}{l}\text { No comparisons presented; model predicts Collapse } \\
\text { Factor of } 1.20 \text { to } 1.24\end{array}$ \\
\hline 1961 & 88 & Notes 1 and 3 & Note 2 & Note 4 & Note 1 & Note 1 & $\begin{array}{l}\text { Range: }-9.3 \text { to } 13.1 \% \text {; Mean: } 2.75 \% \text {; Std. Dev. } 5.74 \% ; \\
11 \text { Tests Compared }\end{array}$ \\
\hline 1967 & 89 & NLC, NC & NLC, NC & Not Discussed & Not Discussed & Not Discussed & $\sim 10$ to $12 \%$ estimated from UG Press. \& Temp. data \\
\hline 1998 & 90 & NLC, NC, HPCSD & $E C$ & NLC, NC, HPCSU & Not Discussed & Not Discussed & $\begin{array}{l}\sim 18 \text { to } 30 \% \text { based on comparison with model data in } \\
\text { Epstein and Anderson (1968) }\end{array}$ \\
\hline 1964 & 91 & NLC, NC, Note 7 & Assumed Negligible & NLC, NC, HPCSU [from Ref. 92] & Not Discussed & (1) and (2) & $\begin{array}{l}-14.1,4.7,-1.8,0 \% \text { for } G H \text { over } L H ;-2.5,-8.7,6.7,- \\
2.5 \% \text { for GHe over } L H\end{array}$ \\
\hline 1964 & 92 & $\mathrm{NLC}, \mathrm{NC}, \mathrm{VP} \& \mathrm{FC}$ & $\mathrm{NLC}, \mathrm{NC}, \mathrm{VP} \& \mathrm{HP}, \mathrm{FC}$ & NLC,NC, HPCSU & NLC, FC \& Radiation & (1), (6), and Note 8 & No Comparisons Presented \\
\hline
\end{tabular}

Key: $\quad$ NLC $=$ Newton's Law of Cooling

$\mathrm{NC}=$ Natural (Free) Convection

$\mathrm{FC}=$ Forced Convection

$\mathrm{HP}=$ Horizontal Plate (Natural Convection Correlations)

HPCSD = Horizontal Plate (Natural Convection Correlations), Cold Side Down

HPCSU = Horizontal Plate (Natural Convection Correlations), Cold Side Up

$\mathrm{VP}=$ Vertical Plate (Natural Convection Correlations)

$\mathrm{EC}=$ Equivalent Conduction; thermal conductivity and slope of temperature gradient across finite segment/element at boundary

(1) = First Mass Transfer Computation Technique, from "Mass Transfer Correlations" section of Chapter II of Ref. 3

(2) = Second Mass Transfer Computation Technique, from "Mass Transfer Correlations" section of Chapter II of Ref. 3

(6) = Sixth Mass Transfer Computation Technique, from "Mass Transfer Correlations" section of Chapter II of Ref. 3

Notes: 1. An energy balance equation using propellant, mean ullage gas, entering pressurant gas, and tank wall temperatures; temp erature differentials; and empirically determined coefficients is used to calculate rate of change of ullage gas temperature at discrete time steps.

2. A condensation or evaporation energy balance equation, whichever has highest magnitude, using propellant, mean ullage gas, and tank wall temperatures; temperature differentials; and empirically determined coefficients is used to calculate rate of change of liquid propellant temperature at discrete time ste ps.

3. Ullage gas is divided into two regions; the lower region contains only the initial mass of ullage gas prior to entry of pressurant gas and the upper region contains only pressurant gas supplied from external source.

4. External tank heating is assumed to heat and evaporate liquid propellant only. Evaporation rate of propel lant is calculated from heat transfer equation using tank wall and liquid propellant temperatures, heat transfer areas, latent heat of vaporization, and empirically determined coefficients.

5. To simulate effects of transient and non-uniform temperatures through thick tank walls, the wall is modeled as having uniform temperature through $70 \%$ of the actual wall thickness where heat is transferred from the ullage gas; $30 \%$ of the wall thickness is modeled as thermally isolated from remianing wall.

6. $740 \mathrm{BTU} / \mathrm{hr}$-ft2-R for GH over LH and $520 \mathrm{BTU} / \mathrm{hr}$-ft2-R for GN over LOX added to calculated convective heat transfer coefficient from Ref. 34 correlations to simulate effects of mixing between ullage gas and cryogenic propellant; these resulted in approximate $10 \%$ increase in required pressurant gas.

7. Ullage gas modeled as having linear vertical temperature profile with temperature at top of region equal to entering pre ssurant gas temperature and temperature at bottom of region equal to saturation temperature of propellant; Mean ullage gas temperature used to calculate heat transfer at ullage gas boundaries with tank wall is av erage of temperatures at top and bottom of ullage gas region.

8. During rapid change in tank pressure, mass transfer across ullage-gas-to-cryogenic-propellant interface is product of ullage volume and ullage gas density change based on net difference between new tank pressure and propellant saturation pressure.

9. Natural convection correlation used with time of pressurant gas entry, thermal properties of ullage gas and tank wall, tank wall thickness and inside diameter to compute ratio of actual to maximum total heat in tank wall; Maximum total heat in tank wall is when all of tank wall is at temperature of the incoming pressurant gas; Coefficients and exponents in the correlation to compute

ratio of actual to maximum total heat in tank wall are derived from curvefits of empirical data. 


\section{Modeling the Cryogenic Propellant Tank System; the Higher Fidelity Multiple Discrete Fluid Segment (MDFS) Models}

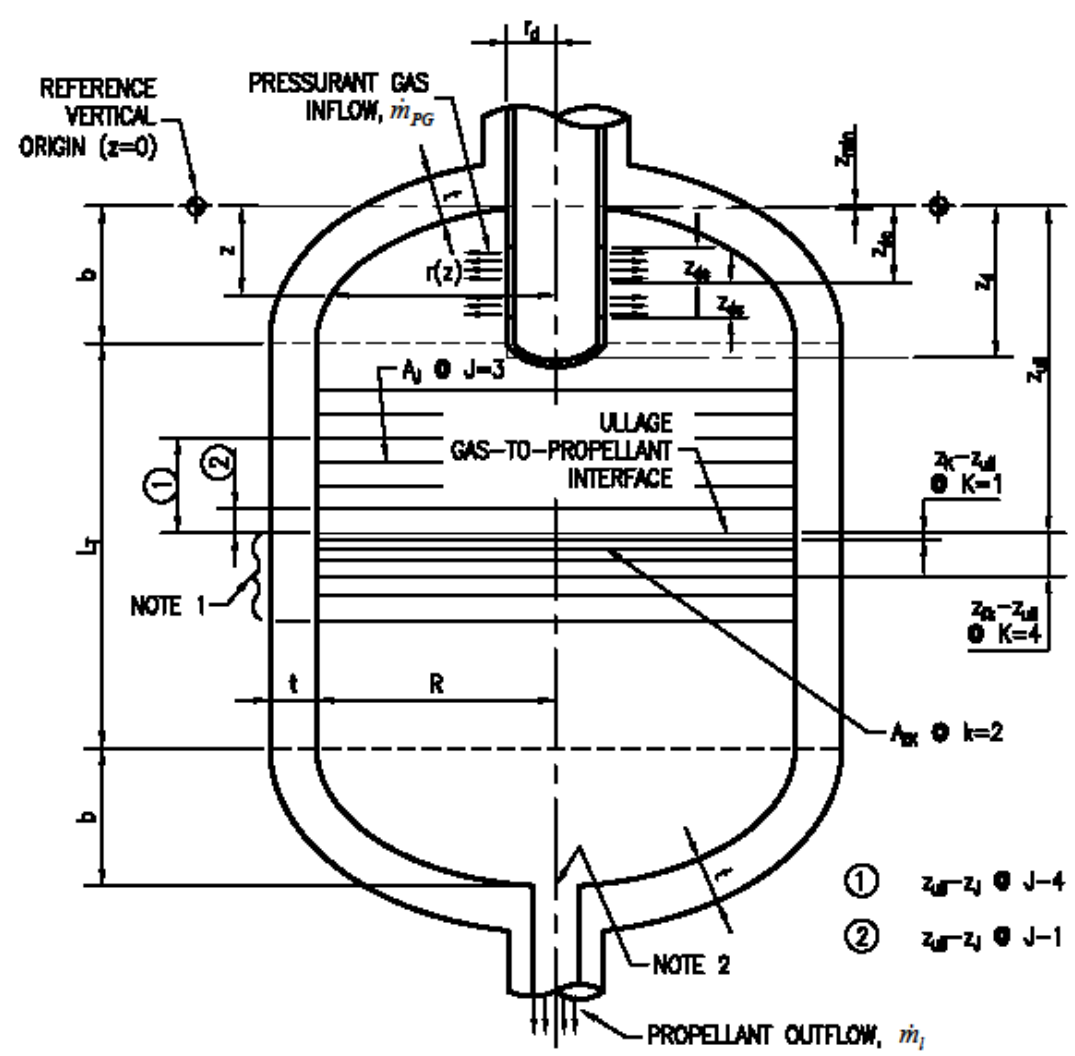

NOTES:

1. SU=STRATIFED UOUD LAYTE REMNNING BUIK LOUID AT UNIFORU TEUP.

2. VORTEX BREAKER LOCATON, ASSUMME NEGUGGBLE

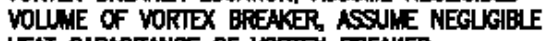
HEAT CAPACIANCE OF WORIDX EREAKER

CEATE SPHEROD TAK IS SPECWN CASE WIT $L \rightarrow \rightarrow$ AND R>b

SPHEACA TANK IS SPECAL CASE WTH $R=b$ AND L $\rightarrow$
Subdivide ullage gas into discrete vertically stacked segments to model vertical temperature distribution

Subdivide upper portion of cryogenic propellant region where most of vertical temperature gradient is expected

Variation of temperature in horizontal or radial direction limited to small boundary layer near the tank wall 
Table 7 Summary Data for Multiple Discrete Fluid Segment (MDFS) Models

\begin{tabular}{|c|c|c|c|c|c|c|c|c|c|c|}
\hline \multirow[b]{2}{*}{ Year } & \multirow[b]{2}{*}{$\begin{array}{l}\text { Reference } \\
\text { Citation } \\
\end{array}$} & \multicolumn{6}{|c|}{ Heat Transfer } & \multicolumn{2}{|c|}{ Mass Transfer } & \multirow[b]{2}{*}{$\begin{array}{l}\text { Model Errors Compared to } \\
\text { Empirical Data }\end{array}$} \\
\hline & & $\begin{array}{l}\text { Ullage Gas to } \\
\text { Wall }\end{array}$ & $\begin{array}{c}\text { Propellant to } \\
\text { Wall }\end{array}$ & $\begin{array}{l}\text { Ullage Gas to } \\
\text { Propellant }\end{array}$ & $\begin{array}{l}\text { Intra-Ullage- } \\
\text { Gas Segment- } \\
\text { to-Segment }\end{array}$ & $\begin{array}{l}\text { Intra-Propellant } \\
\text { Segment-to- } \\
\text { Segment } \\
\end{array}$ & $\begin{array}{l}\text { External Tank } \\
\text { Wall }\end{array}$ & $\begin{array}{l}\text { Ullage Gas to } \\
\text { Propellant }\end{array}$ & $\begin{array}{c}\text { Intra-Ullage-Gas } \\
\text { Segment-to- } \\
\text { Segment }\end{array}$ & \\
\hline 2009 & 3 & NLC, NC \& FC & $\mathrm{NLC}, \mathrm{NC}$ & $\mathrm{NLC}, \mathrm{NC}, \mathrm{FC}$ & $\mathrm{EC} \& \mathrm{EFC}$ & $\mathrm{EC}$ & $\begin{array}{c}\text { Adiabatic Outer } \\
\text { Wall } \\
\text { Modeled } \\
\end{array}$ & $\begin{array}{l}\mathrm{N} / \mathrm{A}, \text { Assumed } \\
\text { to be Zero }\end{array}$ & $\begin{array}{l}\text { No Mass Transfer } \\
\text { other than } \\
\text { Pressurant Gas Entry }\end{array}$ & \begin{tabular}{|l|}
-13.0 to $+1.0 \%$ for Test $004 \mathrm{~A}$ \\
+2.9 to $+14.0 \%$ for Test $0027 \mathrm{~A}$ \\
-2.7 to $+9.1 \%$ for Test $0029 \mathrm{~B}$ \\
\end{tabular} \\
\hline 1970 & 17 and 18 & NLC, NC & $\begin{array}{l}\text { N/A, No Heat } \\
\text { Transfer } \\
\text { Assumed }\end{array}$ & $\begin{array}{l}\text { NLC, NC (Same } \\
\text { correlation as } \\
\text { Ref. 91) }\end{array}$ & EC & $\begin{array}{l}\text { N/A, Uniform } \\
\text { Propellant Region } \\
\text { Modeled }\end{array}$ & $\begin{array}{l}\text { Adiabatic Outer } \\
\text { Wall Modeled }\end{array}$ & (1) & $\begin{array}{l}\text { No Mass Transfer } \\
\text { other than } \\
\text { Pressurant Gas Entry }\end{array}$ & $\begin{array}{l}\text { Range: }-2.73 \text { to } 19.48 \% \text {; Mean: } \\
\text { 5.29\%; Std. Dev.: } 5.56 \% ; 19 \text { Tests } \\
\text { Compared }\end{array}$ \\
\hline 1988 & 23 & NLC, NC & $\mathrm{NLC}, \mathrm{NC}$ & $\mathrm{EC}$ & EC & $\mathrm{EC}$ & NLC, NC, Note 2 & (1) & (6) & $<5 \%$ \\
\hline 1965 & 30 & $\mathrm{NLC}, \mathrm{NC}$ & $\begin{array}{l}\text { N/A, No Heat } \\
\text { Transfer } \\
\text { Assumed }\end{array}$ & NLC, NC & $\begin{array}{l}\text { N/A, No Heat } \\
\text { Transfer } \\
\text { Assumed }\end{array}$ & $\begin{array}{l}\text { N/A, Uniform } \\
\text { Propellant Region } \\
\text { Modeled }\end{array}$ & Input Heat Flux & $\begin{array}{l}\mathrm{N} / \mathrm{A} \text {, Assumed } \\
\text { to be Zero }\end{array}$ & $\begin{array}{l}\text { No Mass Transfer } \\
\text { other than } \\
\text { Pressurant Gas Entry }\end{array}$ & $\begin{array}{l}\text { Range: }-8.23 \text { to } 12.04 \% ; \text { Mean: } \\
\text { 2.22\%; Std. Dev.: } 6.05 \% ; 10 \text { Tests } \\
\text { Compared }\end{array}$ \\
\hline 1966 & 34 & NLC, NC \& FC & $\mathrm{NLC}, \mathrm{NC}$ & NLC, NC \& FC & EC & EC & $\begin{array}{c}\text { NLC, NC \& } \\
\text { Radiation, Note } \\
1 \\
\end{array}$ & (6) & (6) & $\begin{array}{l}\text { Range: Approx. }-30 \text { to } 12 \% \text {; Mean: } \\
\text { 0.1 to } 2.3 \% \text {; Std. Dev.: } 10.9 \text { to } 8.5 \% \text {; } \\
11 \text { Tests Compared }\end{array}$ \\
\hline 1992 & 93 & $\begin{array}{l}\text { No Heat } \\
\text { Transfer } \\
\text { Assumed }\end{array}$ & EC & $\begin{array}{l}\text { EC (liquid side } \\
\text { only) }\end{array}$ & N/A & EC & Input Heat Flux & (1) & $\begin{array}{l}\text { N/A; Ullage Gas at } \\
\text { Uniform Temp. }\end{array}$ & NoComparisons Presented \\
\hline 1963 & 94 & NLC, NC \& FC & NLC, NC & NLC, NC \& FC & EC & EC & $\begin{array}{c}\text { NLC, NC \& } \\
\text { Radiation, Note } \\
1\end{array}$ & (1) and (6) & (6) & $\begin{array}{l}\text { Comparisons not presented; 10\% } \\
\text { Max. Cumulative Error; } \sim 20 \% \text { Max. } \\
\text { Instantaneous Error from Nein and } \\
\text { Thompson (1966) } \\
\end{array}$ \\
\hline 1965 & 95 & NLC, NC \& FC & $\mathrm{NLC}, \mathrm{NC}$ & $\mathrm{NLC}, \mathrm{NC} \& \mathrm{FC}$ & EC & EC & Unknown & (1) & Unknown & $\begin{array}{l}\sim 10 \% \text { for Test } 130-9 ; \sim 10 \text { to } 12 \% \text { for } \\
\text { Test } 130-6 ; \sim 5 \% \text { for Test } 6 \mathrm{E}\end{array}$ \\
\hline 1974 & 96 & NLC, NC \& FC & $\begin{array}{l}\text { No Heat } \\
\text { Transfer } \\
\text { Assumed }\end{array}$ & $\begin{array}{l}\text { NLC, NC (Same } \\
\text { correlation as } \\
\text { Ref. 91) }\end{array}$ & EC & $\begin{array}{l}\text { N/A, Uniform } \\
\text { Propellant Region } \\
\text { Modeled }\end{array}$ & Input Heat Flux & Not Discussed & $\begin{array}{c}\text { No Mass Transfer } \\
\text { other than } \\
\text { Pressurant Gas Entry }\end{array}$ & $\begin{array}{l}0.5 \text { to } 16.0 \% \text { Error for Tank } \\
\text { Pressurization; } 7.0 \text { to } 12.4 \% \text { Error } \\
\text { for Propellant Expulsion }\end{array}$ \\
\hline
\end{tabular}

Key:
NLC $=$ Newton's Law of Cooling
$\mathrm{NC}=$ Natural (Free) Convection; Ref. 34 correlations unless noted otherwise
$\mathrm{FC}=$ Forced Convection; correlation presented in "Combined Natural and Forced Convection Correlations" section
$\mathrm{EC}=$ Equivalent Conduction; thermal conductivity and slope of temperature gradient across finite segment/element at boundary
EFC = Equivalent Forced Convection (and Mixing); similar to correlation presetned in "Combined Natural and Forced Convection Correlations" section
(1) = First Mass Transfer Computation Technique, from "Mass Transfer Correlations" Section of Chapter II in Ref. 3
(6) = Sixth Mass Transfer Computation Technique, from "Mass Transfer Correlations" Section of Chapter II in Ref. 3

The MDFS Models had Errors Comparable to LMFR Models, but the MDFS Models Covered

Wider Range of Tank Sizes, Pressures, and Expulsion Flow Rates 


\section{Summary}

-Wide Range of Empirical Collapse Factors; 0.87 to 10.34 (Cannot directly apply empirical data to all cases without understanding parameters that cause the wide variations)

- For Majority of Cases, Empirical Collapse Factor Data at Low Subcritical Operating Pressures

- For Some Cases, Empirical Collapse Factor Data at Supercritical \& High Subcritical Operating Pressures

- Significant Effects on Collapse Factors; Pressurant Gas Entry Velocity Vectors into Ullage which Drive Heat Transfer Rates at Ullage Gas Region Boundaries, Ullage Gas Vertical Temperature Gradients, Mass Transfer between Ullage Gas and Propellant Regions

- Many Types of Analytical Models for Collapse Factor Prediction

- MDFS (Multiple Discrete Fluid Segment) Models Provide best Predictions over Full Range of Operating Conditions 